FERNANDA DE JESUS TORRES

CICLO VIGÍLIA/SONO EM ADOLESCENTES DE UMA

POPULAÇÃO INDÍGENA

\author{
Dissertação apresentada \\ ao Instituto de Psicologia \\ da Universidade de São \\ Paulo como parte dos \\ requisitos para obtenção \\ do título de Mestre em \\ Psicologia
}

São Paulo

2005 
FERNANDA DE JESUS TORRES

\section{CICLO VIGÍLIA/SONO EM ADOLESCENTES DE UMA POPULAÇÃO INDÍGENA}

Dissertação apresentada ao Instituto de Psicologia da Universidade de São Paulo como parte dos requisitos para obtenção do título de Mestre em Psicologia

Área de Concentração:

Neurociências e Comportamento

Orientador:

Prof. Dr. Luiz Silveira Menna Barreto

São Paulo

2005 
AUTORIZO A REPRODUÇÃO E DIVULGAÇÃO TOTAL OU PARCIAL DESTE TRABALHO, POR QUALQUER MEIO CONVENCIONAL OU ELETRÔNICO, PARA FINS DE ESTUDO E PESQUISA, DESDE QUE CITADA A FONTE.

Catalogação na publicação Serviço de Biblioteca e Documentação Instituto de Psicologia da Universidade de São Paulo

Torres, Fernanda de Jesus.

Ciclo vigília/sono em adolescentes de uma população indígena / Fernanda de Jesus Torres; orientador Luiz Silveira Menna Barreto. -São Paulo, 2005.

$139 \mathrm{p}$.

Dissertação (Mestrado - Programa de Pós-Graduação em Psicologia. Área de Concentração: Neurociências e Comportamento) Instituto de Psicologia da Universidade de São Paulo.

1. Ritmos biológicos 2. Ciclo vigília-sono 3. Adolescentes 4. Índios 5. Fatores socioculturais I. Título.

QP84.6.B56 


\section{CICLO VIGÍLIA/SONO EM ADOLESCENTES DE UMA POPULAÇÃO INDÍGENA}

FERNANDA DE JESUS TORRES

\section{BANCA EXAMINADORA}

(Nome e assinatura)

(Nome e assinatura)

(Nome e assinatura)

Dissertação defendida e aprovada em:

I I 


\section{DEDICATÓRIA}

Aos meus pais,

Antonio e Ocelia

Ao meu namorado,

Felipe

...com muito amor, sou

muito grata pelo apoio

afetivo e o espírito

aventureiro que os

permitiu estar ao meu

lado nos momentos

mais difíceis. 


\section{AGRADECIMENTOS}

Aos membros da comunidade Guarani da Aldeia Boa Vista, pelas colaborações e lições de vida.

Ao Professor Doutor Luiz Menna-Barreto pela orientação de longa data.

Às Professoras Doutoras Emma Otta e Frida Fischer pelas sugestões apresentadas por ocasião do exame de qualificação.

A todos os participantes, pela amizade e colaboração que permitiram a produção deste trabalho.

Ao senhor Altino, respeitável cacique, que me ensinou que a opinião da comunidade é sempre a mais importante entre os Guarani.

A Leila Affini, José Ricardo Lopes, Maria Raquel Carvalho, Juliana Tonsmann, Roberta Arêas e Felipe Apollonio pelo auxílio técnico durante a composição desta dissertação.

À família Carvalho, que possibilitou o contato com a população estudada, oferecendo também sua hospitalidade.

À família Tambelli, que forneceu hospedagem em Ubatuba durante as coletas.

A Océlia, Felipe, Márcia, Ana Amélia, Mark, Leila, Roberta, Flávio e Daniela, que me fizeram companhia durante as coletas na aldeia, sempre com muita simpatia pela comunidade Guarani.

A Antonio, meu pai, por ter me acompanhado em algumas viagens de reuniões com os membros da comunidade Boa Vista e por ter 0 desprendimento de ficar sem seu automóvel para que eu pudesse usá-lo em todas as coletas.

A dona Íris, dona Nádia, dona Cida, senhor Fernando, senhor Sebastião e doutora Gianna pelo auxílio no dia-a-dia na aldeia, histórico familiar e esclarecimentos sobre as condições físicas dos participantes.

E, finalmente, aos estimados amigos do GMDRB pelos momentos de alegria e de aprendizagem que pude ter com cada um de seus (ex) integrantes. 


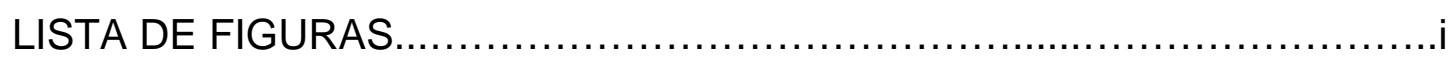

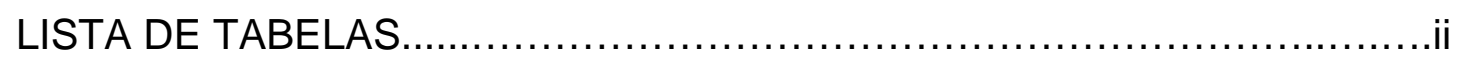

LISTA DE ABREVIATURAS E SIGLAS .....................................

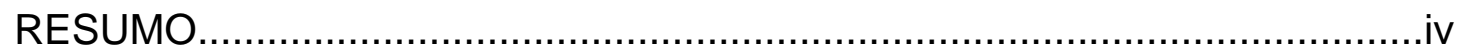

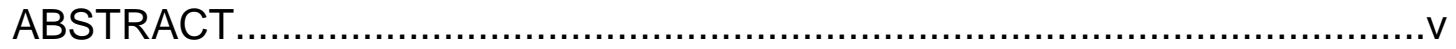

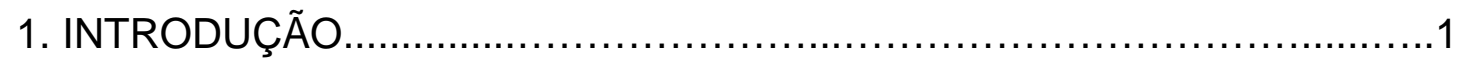

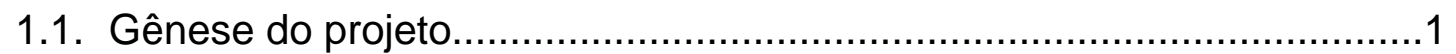

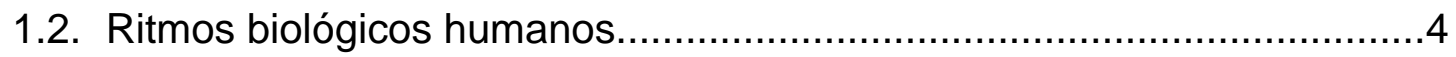

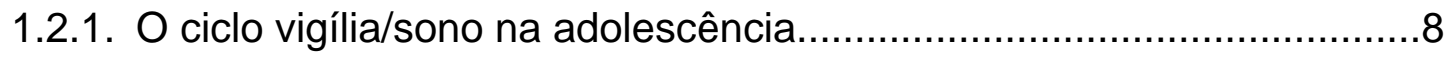

1.2.2. O ciclo vigília/sono de adolescentes de diversas nações.....................15

1.2.3. O ciclo vigília/sono de adolescentes de regiões rurais.......................20

1.3. Aspectos históricos e culturais dos Guarani do litoral brasileiro.............22

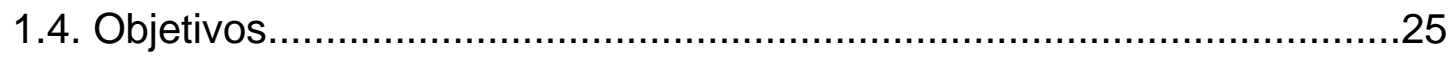

2. METODOLOGIA

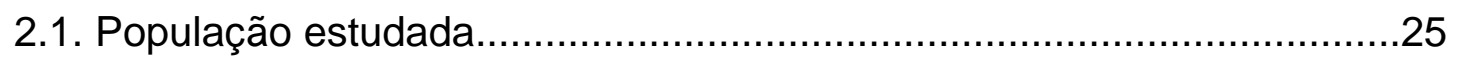

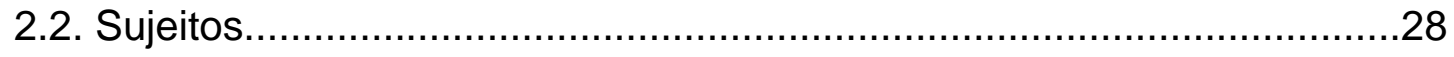

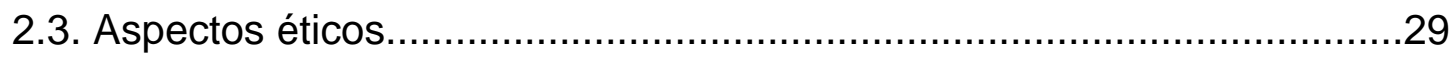

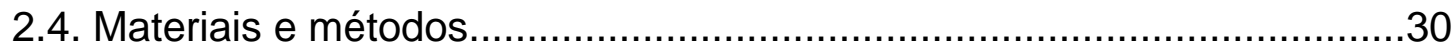

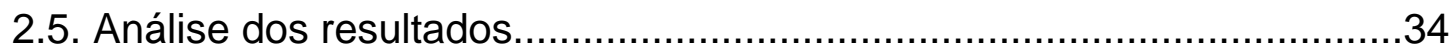




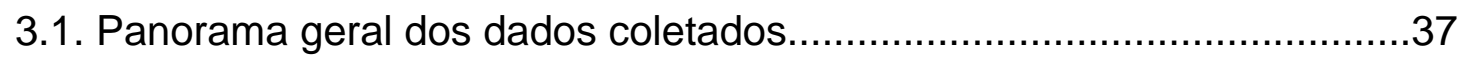

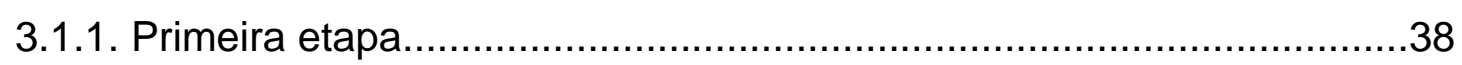

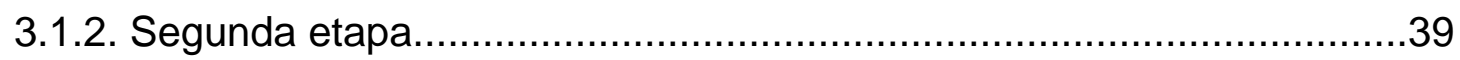

3.1.3. Terceira etapa

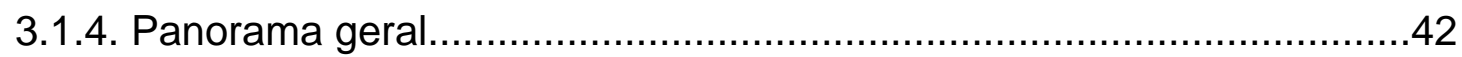

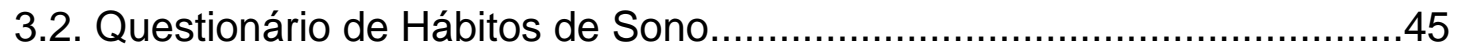

3.3. Questionário de Matutinidade e Vespertinidade (Cronotipo)...................49

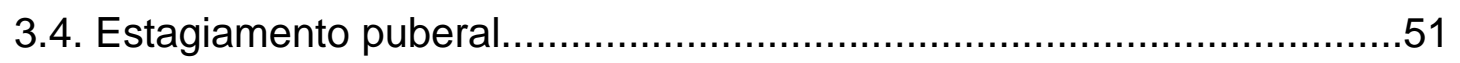

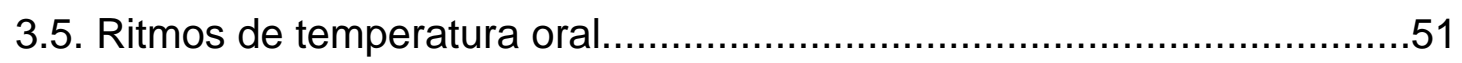

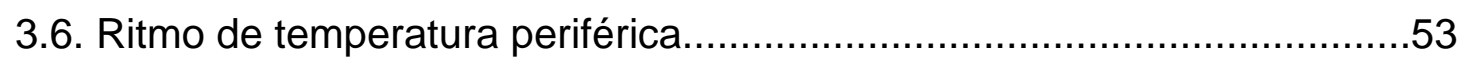

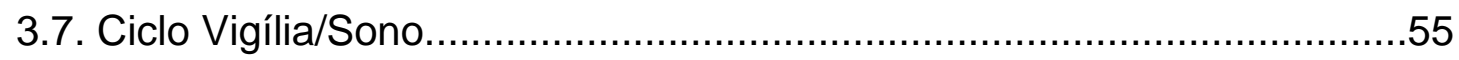

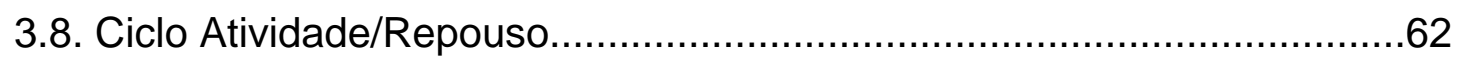

3.9. Relações entre Ciclo Vigília/Sono e Atividade e Repouso........................70

4. DISCUSSÃO

4.1. Condições de moradia, saúde e hábitos de sono..................................71

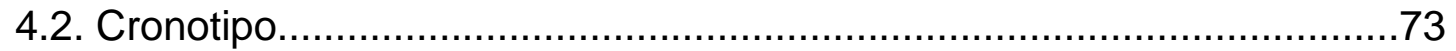

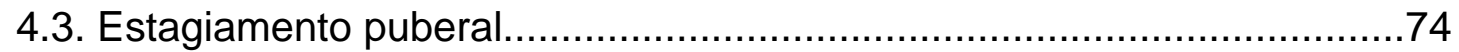

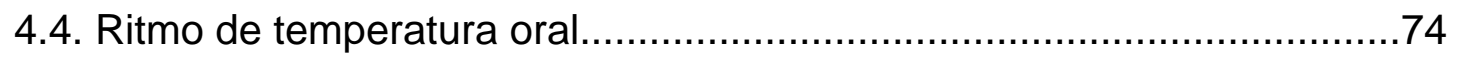

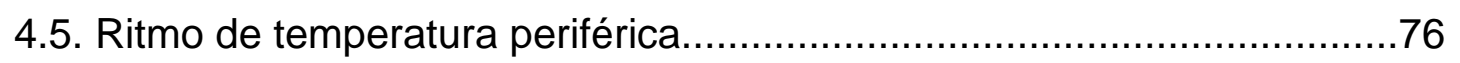

4.6. Ciclo vigília/sono e ciclo atividade/repouso............................................77

5. CONCLUSÕES E CONSIDERAÇÕES FINAIS......................................... 
A. Parecer do Conselho Nacional de Ética em Pesquisa.............................84

B. Parecer da Fundação Nacional do Índio............................................86

C. Termo de Consentimento Livre e Esclarecido do Instituto de Ciências Biomédicas. 88

D. Questionário de matutinidade e vespertinidade adaptado. 91

E. Questionário de Hábitos de Sono. .97

F. Diário de sono. .103

G. Fotografias de actímetro, termômetro digital e Thermocron ${ }^{\circledR}$ 107

H. Actogramas de diários de sono e actímetro. 108 


\section{LISTA DE FIGURAS}

Figura $\mathbf{n}$.

Página

1. esquema geral da distribuição das casas na Aldeia Boa Vista...........27

2. cronograma das coletas de dados na Aldeia Boa Vista.....................31

3. código de identificação dos participantes por iniciais, ano de nascimento, sexo, etapa da pesquisa, freqüencia escolar e tipo de escola.

4. constituição familiar segundo Questionários de Hábitos de Sono, considerando a primeira aplicação para cada sujeito $(n=19)$.....

5. condições de moradia e de saúde segundo Questionários de Hábitos de Sono, considerando a primeira aplicação para cada sujeito $(n=19)$. 48

6. consumo de bebidas estimulantes segundo Questionários de Hábitos de Sono, considerando a primeira aplicação para cada sujeito $(n=19)$.

7. queixas de problemas de sono segundo Questionários de Hábitos de Sono, considerando a primeira aplicação para cada sujeito $(n=19) \ldots . .50$

8. estimativa de início do sono durante a semana e nos finais de semana segundo Questionários de Hábitos de Sono, considerando a primeira aplicação para cada sujeito $(n=19)$ .50

9. estimativa de fim do sono durante a semana e nos finais de semana segundo Questionários de Hábitos de Sono, considerando a primeira aplicação para cada sujeito $(n=19)$

10. pontuações obtidas no questinário Cronotipo nas duas aplicações de cada sujeito. Sujeitos em ordem etária crescente $(n=11)$. .52

11. diferenças entre as pontuações obtidas no questinário Cronotipo nas duas aplicações de cada sujeito $(n=11)$

12. médias e erros padrão dos horários de acrofase da temperatura oral para todos os sujeitos, por idade cronológica e etapa, cujos ritmos de temperatura foram detectados pelo "Método Cosinor" $(n=6)$. 
13. médias e erros padrão dos horários de acrofase da temperatura periférica para todos os sujeitos, por idade cronológica e etapa, cujos ritmos de temperatura foram detectados pelo "Método Cosinor" $(n=17)$. .56

14. médias dos horários de início de sono para todos os sujeitos, por etapa $(n=20)$. .55

15. médias e desvios padrão dos horários de início de sono para todos os

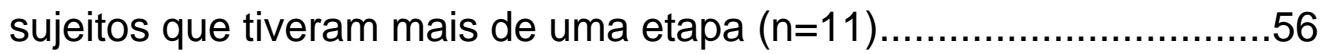

16. horários médios de fim de sono, individuais, por etapa $(n=20)$.... .57

17. médias e desvios padrão dos horários de fim de sono para todos os sujeitos que tiveram mais de uma etapa $(n=11)$.

18. durações médias do sono, individuais, por etapa $(n=20)$. .58

19. médias e desvios padrão da duração de sono para todos os sujeitos que tiveram mais de uma etapa $(n=11)$. 58

20. horários médios de início de repouso, individuais, por etapa $(n=19) . .63$

21. médias e desvios padrão do início do repouso para todos os sujeitos que tiveram mais de uma etapa $(n=11)$.

22. horários médios de fim de repouso, individuais, por etapa $(n=19) \ldots .64$

23. médias e desvios padrão do fim do repouso para todos os sujeitos que

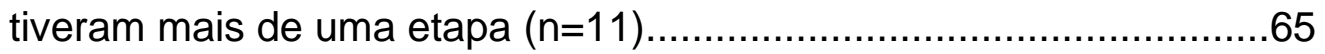

24. durações médias do repouso, individuais, por etapa $(n=19) \ldots \ldots \ldots \ldots . . .66$

25. médias e desvios padrão da duração do repouso para todos os que

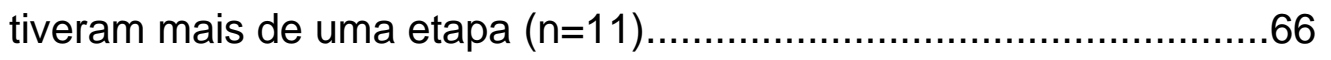

26. médias e desvios padrão dos horários de início e fim de sono e de repouso de todos os participantes em todas as etapas $(n=20$ para sono e $n=19$ para repouso) 


\section{LISTA DE TABELAS}

Tabela $\mathbf{n}$.

Página

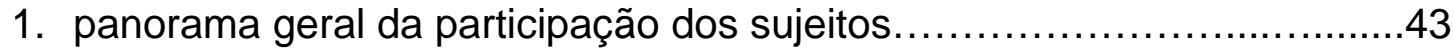

2. correlações entre horário de início, fim e duração de sono em cada etapa. 59

3. horários médios de início e fim de sono e duração de sono dos participantes que estudam e que não estudam, nas etapas 2 e 3. 60

4. horários médios de início e fim de sono e duração de sono, nos dias da semana e nos finais de semana, nas três etapas.

5. horários médios de início e fim de sono e duração de sono, nos dias da semana e nos finais de semana, dos estudantes, nas etapas 2 e 3 . 62

6. correlações entre horário de início, fim e duração de repouso em cada etapa.

7. horários médios de início e fim de repouso e duração de repouso dos participantes que estudam e que não estudam, nas etapas 2 e 3...........68

8. horários médios de início e fim de repouso e duração de repouso, nos dias da semana e nos finais de semana, nas três etapas. 69 


\section{LISTA DE ABREVIATURAS E SIGLAS}

CVS Ciclo Vigília/Sono

GMDRB Grupo Multidisciplinar de Desenvolvimento e Ritmos Bilógicos

DP

Desvio Padrão

EP Erro Padrão

n.s. não significativo 


\section{RESUMO}

TORRES, Fernanda de Jesus. Ciclo Vigília/Sono em adolescentes de uma população indígena. São Paulo, 2005. 153p. Dissertação (Mestrado). Instituto de Psicologia, Universidade de São Paulo.

O ciclo vigília/sono (CVS) muda durante a adolescência. Nos dias letivos, há maior sonolência diurna e menor duração de sono do que nos finais de semana. Além disso, os adolescentes apresentam atraso da fase de sono. Acredita-se que essas mudanças resultam da interação entre fatores biológicos e ambientais. Neste trabalho, observamos o CVS de 21 jovens Guarani da Aldeia Boa Vista - SP, que vivem numa floresta, sem energia elétrica. Pretendíamos verificar se eles apresentam um padrão semelhante ao descrito em adolescentes urbanos ou se tal característica é menos evidente, como tem sido relatado na população rural. Aplicamos 0 Questionário de Hábitos de Sono e o Questionário de Matutinidade e Vespertinidade. Os participantes preencheram diários de sono, usaram actímetros e coletaram temperatura a cada 3 horas, na vigília, por 10 ou mais dias consecutivos em 3 ocasiões com intervalos de 6 meses. Fizemos inspecção visual dos actogramas de diários e actímetros, comparando-os entre si por meio de teste $t$ de Student; avaliamos a significância das oscilações da temperatura pelo Método Cosinor; utilizamos as correlações de Pearson e Spearman para identificar relações entre variáveis, adotando como nível de significância $\alpha=0,05$. Comparamos as etapas e discutimos os resultados no cenário de outras pesquisas realizadas com adolescentes. Observamos atraso da fase do sono e da temperatura oral nos Guarani, conforme descrito entre adolescentes de regiões urbanas, e menor duração do sono nos finais de semana do que nos demais dias. Os resultados apontam para a importância de fatores biológicos no atraso da fase dos ciclos vigília/sono e de temperatura na adolescência. 


\begin{abstract}
TORRES, Fernanda de Jesus. Sleep/Wake Cycle in adolescents of a native population. São Paulo, 2005. 153p. Master Thesis. Instituto de Psicologia, Universidade de São Paulo.
\end{abstract}

The sleep/wake cycle (SWC) changes along adolescence. During weekdays there is higher diurnal sleepiness and shorter sleep duration than on weekends; moreover, they display sleep phase delay. Some authors believe these changes result from the interaction between biological and environmental factors. In this work, we observed the SWC in 21 adolescents from the ethnic group Guarani living in Boa Vista village (São Paulo) who live in a rural area, without electric light. We intended to verify whether they show a SWC pattern similar to that found in urban adolescents or if these characteristics are less evident under their condition as has been reported for rural area adolescents. We applied Sleep Habits and MorningnessEveningness questionnaires. The participants kept Sleep Diaries and wore wrist actimeters for at least 10 consecutives days, and collected oral temperature every 3 hours when awake. This protocol was applied on 3 occasions with 6 months intervals between them. We examined the actograms from Diaries and Actimetries, comparing them with $t$ Student test; we evaluated the temperature oscillations by Cosinor Method, we used Pearson's and Spearman's correlations in order to identify relationships between the measures, adopting the significance level at $\alpha=0.05$. We compared the occasions and considered our results in the context of adolescent sleep researches. We observed sleep and temperature phase delays in Guarani adolescents similar to the delays found in other groups, as well as shorter sleep duration on weekends than on weekdays. Our results point to the importance of biological factors on sleep/wake and temperature phase delays along adolescence. 
1. Introdução

1.1. Gênese do projeto

O Grupo Multidisciplinar de Desenvolvimento e Ritmos Biológicos (GMDRB) foi criado em 1981 no Departamento de Fisiologia e Biofísica do Instituto de Ciências Biomédicas da Universidade de São Paulo. A meta do GMDRB é, desde o princípio, estudar os aspectos dinâmicos e temporais da matéria viva, área de conhecimento científico conhecida como Cronobiologia (www.crono.icb.usp.br).

O presente trabalho insere-se numa das linhas de pesquisa do GMDRB - a ontogênese do ciclo vigília/sono (CVS) humano. Dentro desta linha, os estudos sobre o ciclo vigília/sono em adolescentes foram inicialmente conduzidos por Miriam Andrade. Em seu mestrado, Andrade (1991) estudou o CVS, o ritmo de temperatura oral e acompanhou o desenvolvimento puberal de 66 estudantes com idades entre 12 e 13 anos, durante três etapas com seis meses de intervalo entre elas. Nesse estudo, ela observou que os adolescentes que mostraram mudanças de fase no desenvolvimento puberal deslocaram seus horários de dormir e acordar para horários mais tardios nos finais de semana, enquanto aqueles que permaneceram nos mesmos estágios puberais não apresentaram tais mudanças, sugerindo que o avanço puberal poderia ser indutor de um atraso de fase do sono na adolescência.

Luciana Mello (1999) observou, também longitudinalmente, os padrões do CVS, a sonolência diurna e o ritmo de temperatura oral de adolescentes antes e depois da transição dos horários escolares - do turno 
vespertino, na quarta série, ao matutino, na quinta série do ensino fundamental. Seus resultados indicaram privação parcial do sono após a transição, tendo em vista que os avanços dos horários de dormir não foram suficientes para compensar o deslocamento para mais cedo dos horários de acordar durante a semana, o que demonstra a importância dos horários escolares sobre a expressão dos ritmos estudados.

O trabalho de iniciação científica de Ingrid Rodrigues foi semelhante ao realizado por Luciana Mello e seu objeto foi verificar o que acontece com o CVS quando os adolescente são transferidos do turno vespertino ao turno matutino um ano mais tarde, da quinta para a sexta série do ensino fundamental. Ela observou que a troca de turnos num momento de desenvolvimento puberal mais avançado teve impacto maior sobre o CVS do grupo estudado (Menna-Barreto \& Rodrigues, 2003).

Em 2000, Fernando Louzada, em seu trabalho de doutorado, aplicou Questionários de Hábitos de Sono para 423 adolescentes de regiões rurais e urbanas que estudavam no turno matutino. Ele observou que os horários de início e fim de sono entre os adolescentes de meio urbano estavam atrasados em relação aos dos demais, sugerindo que fatores sociais estariam na base do atraso de fase do sono na adolescência.

Em meu trabalho de iniciação científica (Torres \& Menna-Barreto, 2002), observei o CVS de adolescentes com síndrome de Turner, antes e após a reposição hormonal com estrógenos, e crianças com puberdade precoce antes e após a supressão farmacológica do desenvolvimento puberal. O objetivo desta pesquisa foi descrever o padrão do CVS destes dois grupos no cenário das discussões sobre a influência da puberdade sobre 
tal ritmo. Como o número de participantes foi restrito, Andrea Ferrari, também durante sua iniciação científica, continuou o estudo. Os resultados mostram que, mesmo entre adolescentes com síndrome de Turner, há um padrão de restrição da duração do sono durante os dias letivos entre aquelas participantes que estudavam em turno matutino (Torres et al., 2003).

Como os resultados obtidos por Miriam Andrade, em um estudo longitudinal, e Fernando Louzada, num estudo transversal, divergiam nas explicações sobre as características do CVS na adolescência, surgiu o interesse em estudar longitudinalmente os ritmos de adolescentes que estivessem sob um contexto sociocultural diferenciado, como acontece em populações relativamente isoladas das pistas sociais urbanas (energia elétrica, televisão, internet, etc). Especialmente relevante nesse cenário é o papel da exposição dos indivíduos a iluminação artificial, muito provavelmente fator presente, senão determinante, no atraso da fase do sono em adolescentes que vivem em meio urbano que vem sendo descrito em diversos países (Carkadon, 2002).

A oportunidade de estudar os ritmos biológicos de adolescentes indígenas surgiu após um contato com o senhor José Nélio de Carvalho, que tem uma relação de amizade com a comunidade Guarani da Aldeia Boa Vista e soube de nosso interesse em estudar os ritmos biológicos de populações indígenas por meio de sua filha, Maria Raquel de Carvalho, também pesquisadora do GMDRB.

Além do meu interesse de estudar o CVS de adolescentes daquela comunidade indígena, tendo em vista que o projeto se enquadrava na linha de pesquisa na qual eu estava inserida, também surgiu a idéia de realizar um 
estudo descritivo dos hábitos de sono da população adulta daquela comunidade, que está sendo conduzido por Daniela Wey em seu trabalho de doutorado.

Os primeiros contatos com a população foram feitos por telefonemas e visitas à comunidade, nas quais fizemos entrevistas informais com adultos e jovens da aldeia, explicando os objetivos da pesquisa e demonstrando os instrumentos que utilizaríamos. Após informá-los a respeito da pesquisa, indagamos sobre a viabilidade do trabalho, afirmando o caráter voluntário da participação deles.

Obtivemos uma posição favorável dos representantes da comunidade para o desenvolvimento da pesquisa na aldeia em 2003, quando efetuamos os procedimentos necessários para obter pareceres favoráveis do CONEP e da FUNAI (anexos A e B, respectivamente) para, então, iniciarmos a pesquisa descrita nesta dissertação.

\subsection{Ritmos biológicos humanos}

Muitos fenômenos biológicos apresentam ritmos. Como exemplos, temos a alternância entre dormir e acordar, secreção de diversos hormônios, batimento cardíaco e temperatura central, entre outros, que se expressam segundo padrões circadianos, ultradianos e infradianos.

O ciclo vigília/sono (CVS) de adultos é um ritmo circadiano, ou seja, é um ciclo que se completa num período de 24 horas na presença de sinais 
ambientais que o sincronizem e que na ausência de tais sinais, numa situação conhecida como livre-curso, passa a expressar a ritmicidade endógena que, no caso, é de aproximadamente 25 horas.

O CSV humano, além de ser ajustado diariamente aos ciclos ambientais, pelo processo conhecido como arrastamento, também é passível de mudanças mais rápidas e menos duradouras resultantes de demandas imediatas do ambiente, processo conhecido como mascaramento. Quando, por exemplo, mudamos para uma cidade com três horas de diferença de fuso horário em relação à cidade de origem, nosso CVS demora alguns dias até se ajustar aos novos horários. Por outro lado, se precisarmos passar uma noite em claro para terminar um trabalho, conseguiremos fazer isto sem que tal troca vire rotina para os dias seguintes. O primeiro exemplo ilustra 0 processo de arrastamento, enquanto o segundo retrata o mascaramento.

O sistema de regulação do ciclo vigília/sono, que permite a ocorrência de um padrão de sono estável e flexível, foi modelado por Daan e colaboradores (1984) com base em dois processos. O primeiro é o processo homeostático fundamental (processo S) e o segundo é o sistema de temporização circadiana (processo C). Os dois processos interagem e influenciam os horários em que acontecem o sono e a vigília no cotidiano e também podem ocasionar mudanças no CVS durante o desenvolvimento humano.

O bebê nasce com um padrão de vigília/sono polifásico (ultradiano) e, no decorrer dos primeiros anos de vida, os episódios de sono vão sendo alocados na fase noturna, com cochilos vespertinos ainda presentes. De acordo com Andrade (1997), a criança pré-pubere apresenta, geralmente, um 
ciclo vigília/sono circadiano já consolidado, composto por um episódio de sono noturno com duração média entre nove e dez horas.

Existe uma grande variedade de padrões de ciclo vigília/sono em humanos, sendo que as diferenças devem-se tanto a características ontogenéticas quanto individuais. Assim, é possível dizer que, em geral, a duração do sono é maior na infância do que na vida adulta, mas diferenças individuais que acontecem em todas as faixas etárias não nos permitem afirmar que qualquer criança sadia sempre dormirá mais horas que um adulto sadio.

As pistas temporais são essenciais para manter o CVS sincronizado em relação à organização social e ambiental (Monk, 1992), já que o período endógeno do ritmo não é de exatamente 24 horas e está sempre sendo ajustado a ciclos externos de periodicidade regular. Essa consideração é importante na medida em nos impede de conceber a ritmicidade circadiana de uma variável qualquer (CVS incluído) como fenômeno "solidificado" uma vez estabelecido nas primeiras semanas de vida - na verdade o processo de ajuste (arrastamento + mascaramento) é cotidiano ao longo de toda a existência dos organismos.

Uma importante pista temporal que sincroniza o ciclo vigília/sono é o ciclo claro/escuro ambiental. Os ciclos de interação social, por outro lado, são sincronizadores não-fóticos importantes para diversas espécies. Para os seres humanos, o ciclo claro/escuro ambiental também é bastante influenciado por fatores sociais - basta lembrar que somos capazes de atuar sobre o ciclo claro/escuro ambiental, utilizando recursos como a luz elétrica, o que nos possibilita controlar a luminosidade segundo nossas necessidades, 
sejam estas de cunho econômico, como por exemplo, para prolongar a produtividade no trabalho ao longo das 24 horas do dia; de caráter cultural, como em situações religiosas em que grupos fazem vigílias e rezas noturnas, ou aquelas voltadas ao lazer, que tem como exemplo os encontros de jovens durante a madrugada em bares e boates das grandes cidades.

Monk e colaboradores (2003) avaliaram a relação entre regularidade do estilo de vida e a qualidade subjetiva de sono em 100 indivíduos adultos, com idades entre 19 e 49 anos. Eles observaram que, quanto maior a regularidade do estilo de vida, menos freqüentes eram os relatos de problemas de sono, mesmo quando os gêneros foram considerados separadamente, havendo maior número de "maus dormidores" entre aqueles que tinham um estilo de vida "irregular".

Assim, as características sociais, econômicas e culturais têm importância fundamental para o nosso ciclo vigília/sono e muitos problemas deste ritmo e seus respectivos tratamentos podem também receber influências de tais fatores, pois a exposição inadequada de um indivíduo a pistas temporais significativas para a sincronização dos seus ritmos biológicos pode provocar modificações na expressão dos mesmos. Exemplo da relação entre estimulação inadequada e distúrbios dos ritmos biológicos encontra-se na pesquisa de Rotenberg e colaboradores (2001) que evidencia o comprometimento dos ritmos biológicos de trabalhadores em turnos.

Existem algumas categorias de distúrbios relacionados ao ciclo vigília/sono humano características de determinadas fases do desenvolvimento de nossa espécie. Como exemplos, há bebês com grande dificuldade em consolidar o padrão circadiano, adolescentes que não 
conseguem manter-se suficientemente despertos nas primeiras horas de aula, adultos com ciclo vigília/sono diferente de 24 e idosos que freqüentemente apresentam fragmentação de sono. Todos estes distúrbios geralmente têm sua ocorrência facilitada por complicadores ambientais e/ou patologias diversas, também bastante característicos de cada faixa etária.

\subsubsection{O ciclo vigília/sono na adolescência}

A puberdade humana é um fenômeno com dimensões físicas e psicológicas determinadas. O desenvolvimento físico acelerado, as mudanças hormonais e a definição das características sexuais secundárias estão muito bem descritas. Contudo, as características psicológicas relacionadas à puberdade, que definem a adolescência, são bastante distintas entre os indivíduos e dependem dos aspectos culturais em que se inserem - a adolescência não é um fenômeno natural, mas sim social e historicamente contextualizado, reconhecido por sociedades ocidentais pósmodernas. Concebê-la como um fenômeno natural implicaria em assumir a universalidade deste fenômeno, contudo não podemos afirmar que a adolescência é inerente a todas as culturas, a não ser que levemos em conta apenas a faixa etária, sem fazer alusões a respeito de fatores psicossociais.

Neste trabalho, estudamos os aspectos do ciclo vigília/sono e do ritmo de temperatura corporal dos adolescentes, considerando o termo adolescência segundo uma definição exclusivamente etária. Os ritmos circadianos dos adolescentes têm sido bastante estudados desde o fim da 
década de 70, quando pesquisadores começaram a observar alguns aspectos de tais ritmos inerentes a esta parcela da população que apresenta problemas freqüentes de comportamento e de desempenho acadêmico.

$\mathrm{Na}$ adolescência, ocorre o fenômeno conhecido como "atraso da fase de sono", caracterizado por tendência a dormir mais tardiamente que quando criança, sem que haja dificuldade em permanecer dormindo no início da manhã (Levy et al., 1986 e Thorpy et al., 1988). Além disso, são mais freqüentes as queixas de necessidade de dormir mais, mesmo que os horários escolares não tenham sido alterados desde a infância (Strauch \& Meier, 1988). Ocorre também uma diminuição da duração do sono noturno em até duas horas dos nove aos 19 anos (Montagner et al., 1994). Após os 11 anos, a duração do sono torna-se cada vez maior nos finais de semana do que nos dias letivos, fenômeno conhecido como padrão de restrição-extensão do sono, que resulta em privação de sono e é geralmente acompanhado por aumento da sonolência diurna de acordo com o avanço da puberdade (Carskadon et al., 1980).

Diferenças entre os sexos na duração de sono e nos horários de dormir e acordar foram observadas por Carskadon e colaboradores (1993 e 1998). Contudo, o mesmo grupo, em vários estudos em situação laboratorial, não observou diferenças entre sexos nos padrões de sono ou na organização interna do sono (Carskadon et al., 1980, 1998 e 1999).

Em um estudo longitudinal realizado por Andrade e colaboradores (1993), foi constatada uma relação direta entre avanço nos estágios de maturação puberal (Tanner, 1962) e a intensificação de características tais como: atraso de fase do sono, diminuição da duração do sono e padrão 
semanal de restrição-extensão do sono. Os autores concluem que os jovens que avançaram nos estágios puberais durante a pesquisa apresentaram horários mais tardios de dormir do que os demais.

A sonolência diurna de adolescentes pode estar relacionada à privação de sono segundo a pressão ambiental no sentido de horários mais matutinos de acordar. Mello e colaboradores (2001) estudaram o ciclo vigília/sono de um grupo de adolescentes antes e depois da transição de horários escolares do turno vespertino ao matutino e puderam observar avanços de fase dos ritmos de temperatura e vigília/sono, porém tais avanços foram insuficientes para compensar a antecipação do horário de acordar, o que resultou na diminuição da duração total do sono após a transição e em duração maior do sono nos finais de semana que nos dias letivos, possivelmente relacionadas à privação parcial do sono.

Fallone e colaboradores (2002) discutem as implicações clínicas de sonolência diurna excessiva entre adolescentes, demonstrando a existência de correlações entre sonolência excessiva e comportamentos desajustados em meninos, entre eles, o abuso de drogas em maior escala. Além disso, os adolescentes mais sonolentos dormem menos e apresentam sintomas de depressão mais freqüentemente.

Eliasson e colaboradores (2002) conduziram um estudo sobre a associação entre desempenho acadêmico e duração total de sono entre alunos americanos do ensino médio e não encontraram correlações significativas. Por outro lado, Carskadon \& Wolfson (2003), em uma revisão a respeito dos hábitos de sono e desempenho escolar durante a adolescência, citam trabalhos em que a redução do tempo total de sono; os esquemas de 
sono irregulares; os horários tardios de dormir e acordar e a baixa qualidade de sono são sempre negativamente associados com desempenho acadêmico nessa faixa etária.

Com o objetivo de comparar o padrão de sono de adolescentes nos meses letivos e nas férias, e verificar o efeito da exposição matinal à luz, Hansen e colaboradores (2005) observaram os padrões de sono de 60 estudantes do turno matutino, expondo-os à luz intensa pela manhã nos dias letivos (1800 lux das 8:10 às 9:43 horas). Os autores verificaram perda de 120 minutos de sono por noite nos dias letivos; duração do sono 30 minutos maior nos finais de semana do período letivo e ausência de efeitos da luz intensa sobre a duração do sono e sobre o desempenho em testes neuropsicológicos.

Para verificar os efeitos da discrepância entre a necessidade subjetiva de sono e o sono obtido Mercer e colaboradores (1998) observaram o ciclo vigília/sono de jovens de 14 anos que julgavam necessitar de duas ou mais horas a mais de sono por noite e de outros que julgavam necessitar de uma ou menos horas a mais de sono por noite. Ambos grupos apresentavam duração de sono e atividades diárias semelhantes, contudo o primeiro grupo preferia horários mais tardios de dormir e acordar do que o segundo, ou seja, eram mais vespertinos.

A tendência ao atraso de fase do sono e a redução na duração de sono na adolescência têm sido relatadas como fatores de risco para aumento de incidência de acidentes; dificuldade em relação ao humor; sonolência ou ausências em aula; comprometimento da função imune, entre outros (Carskadon, 2004). Outro estudo mostra ainda que a redução no tempo de 
sono está associada ao comportamento sedentário entre os jovens, sendo fator mais importante para tal característica comportamental do que as mudanças de imagem corporal ou índice de massa corporal durante a adolescência, (Murdey et al., 2004). Numa revisão recente sobre a sonolência excessiva entre adolescentes e jovens adultos, Millman (2005) discute a importância da entrevista clínica no diagnóstico de distúrbios do sono nesta faixa etária, para melhor compreensão e aconselhamento aos pacientes sobre as causas de sonolência diurna excessiva.

Kim e colaboradores (2002), ao padronizarem uma versão americana infantil do questionário de matutinidade-vespertinidade desenvolvido por Horne \& Ostberg (1976), aplicaram o questionário original e a versão adaptada em 989 estudantes de oito a 16 anos. Além de validarem seu questionário, os autores encontraram uma diferença etária na distribuição dos escores de ambos os questionários. A média dos escores obtidos teve correlação negativa significativa, a partir dos 13 anos, com a ascensão etária, o que reflete tendências mais vespertinas a partir dessa idade, independentemente da origem étnica dos adolescentes, exceto no grupo hispânico, que não teve alterações na média de escores, segundo a idade, quando as correlações foram feitas separadamente por grupos de origem.

Natale e colaboradores (2005) aplicaram dois diferentes questionários para avaliar o cronotipo em adolescentes de 13 anos de idade, dividindo os grupos entre aqueles que nasceram a termo e pré-termo e observaram que, nos dois questionários, houve maior matutinidade no grupo nascido pré-termo. Os resultados são discutidos no âmbito da modulação de 
tipologia circadiana pelo nascimento precoce per se ou pelo processo de hospitalização diferenciado em nascimentos deste tipo.

Uma interessante discussão foi levantada por Roenneberg e colaboradores (2004) num estudo em que observaram uma mudança abrupta nos horários de sono por volta dos 20 anos de idade, quando começa a haver um avanço de fase. Os autores propõem que esta alteração nos hábitos de sono pode ser o marcador do final da adolescência, assim como a soldadura das epífises é o marcador do final da puberdade.

Em um estudo laboratorial de dessincronização forçada e rotina constante realizado com dez adolescentes, Carskadon e colaboradores (1999) observaram o período do ritmo circadiano intrínseco de cada sujeito através de três parâmetros - fase de valor mínimo da temperatura central, início e fim da fase secretória de melatonina. Os autores relataram alta coerência entre as três medidas, sendo que o período circadiano intrínseco dos adolescentes foi maior do que aquele encontrado entre adultos submetidos a protocolos experimentais semelhantes.

Numa revisão sobre as características dos processos homeostáticos do sono durante a adolescência, Dahl e Lewin (2002) citam a diminuição na duração e na profundidade dos estágios III, IV e paradoxal do sono, sem que haja evidências de que adolescentes necessitam de menos sono que crianças, ocorrendo também diminuição da latência para o primeiro episódio de sono paradoxal e maior tendência à vespertinidade. Numa outra revisão, Carskadon e colaboradores (2004) concluem que alguns aspectos do processo homeostático não se alteram da infância avançada até a idade adulta, enquanto outros fatores mudam de modo a facilitar o atraso de fase 
do horário de ir para a cama durante a adolescência, fenômeno que é impulsionado por alterações no sistema de temporização circadiana.

Jenni \& Carskadon (2004) compararam a distribuição dos estágios do sono de crianças pré-púberes (estágio puberal de Tanner 1) e de adolescentes (estágio puberal de Tanner 5) por meio de análises espectrais de eletroencefalogramas realizados durante 0 sono. Os adolescentes apresentaram redução do estágio IV, aumento do estágio II e menor potência espectral em algumas freqüências do sono de ondas lentas e paradoxal quando comparados ao grupo pré-púbere. A atividade de ondas lentas, marcadora da pressão homeostática do sono, apresentou dinâmicas idênticas dentro de cada episódio e ao longo da noite em crianças pré-púberes e adolescentes. Os autores concluem que o mecanismo de recuperação homeostática do sono permanece inalterado durante a puberdade e que mudanças na composição do sono podem ser reflexo de mudanças do cérebro como um todo.

Uma explicação para as alterações no ciclo vigília/sono do sono dos adolescentes centra-se na aquisição de novos hábitos, por envolvimento maior com grupos de pares e menor controle parental sobre seus horários. Outra hipótese é que as mudanças hormonais na puberdade influenciariam o ciclo vigília/sono nesta fase da vida humana, modificando diretamente a atividade dos osciladores endógenos que atuam sobre a expressão deste ritmo biológico. Tais hipóteses são possivelmente complementares, ou seja, a interação entre fatores biológicos e socioculturais predisporia o ciclo vigília/sono a mudanças durante a adolescência. 


\subsubsection{O ciclo vigília/sono de adolescentes de diversas nações}

Muitos pesquisadores estudam o ciclo vigília/sono em adolescentes de diferentes nações, com objetivos freqüentemente voltados para a caracterização dos padrões deste ritmo biológico segundo características étnicas, especificidades climáticas, rotinas escolares ou condições socioeconômicas. Os aspectos mais ressaltados situam-se no âmbito do desempenho escolar, das dificuldades comportamentais e dos riscos à saúde gerados pelo sono inadequado nesta faixa etária. Em tais estudos, os resultados são geralmente semelhantes aos observados inicialmente por Carskadon e seus colaboradores (Carskadon, 1990) entre adolescentes americanos desde o fim da década de 70 .

Laberge e colaboradores (2001) conduziram um estudo longitudinal, baseado nos relatos dos pais de 1.146 adolescentes canadenses, com idades entre dez aos 13 anos, sobre os padrões de sono segundo gênero, hábitos de sono e distúrbios de sono. Houve diminuição na duração média de sono noturno, atraso dos horários de dormir e aumento nas diferenças dos padrões de sono entre dias letivos e finais de semana. Problemas de sono foram mais intensos em indivíduos com horários mais tardios de acordar nos finais de semana. As meninas permaneciam mais tempo na cama e tinham horários mais tardios de acordar nos finais de semana. Os autores alegam que as diferenças entre gêneros podem estar associadas ao avanço puberal mais precoce em meninas e o atraso do início do sono pode decorrer de atraso na fase circadiana. 
Fukuda \& Ishihara (2001) estudaram os padrões de sono de jovens do ensino fundamental e médio (um grupo de 12 a 15 anos e outro de 15 a 18 anos) e de universitários no Japão. Eles observaram atraso dos horários de dormir nos grupos mais velhos, sendo que os horários de acordar foram semelhantes entre os indivíduos até o fim do ensino básico, havendo atraso dos mesmos após o ingresso na universidade. Houve diminuição considerável na duração de sono e aumento da sonolência diurna entre os estudantes mais velhos do ensino básico, enquanto os estudantes universitários apresentaram menor sonolência diurna.

Uma pesquisa realizada em 15 escolas de Okinawa, com estudantes do ensino médio, sobre os hábitos de sono e estilo de vida dos adolescentes japoneses daquela região demonstrou que os horários de dormir tornam-se progressivamente mais tardios com o avanço etário, havendo também aumento do débito de sono (Arakawa et al., 2001). Os autores afirmam que os adolescentes mais velhos apresentam sono insuficiente, maior dificuldade em permanecer acordados e levantam-se mais tarde, diminuindo o intervalo entre o despertar e a chegada à escola, o que prejudica a alimentação dos mesmos por falta de tempo para o café da manhã.

A estimativa de necessidade de sono; horário habitual de sono; latência de sono e adequação do sono de estudantes noruegueses foram avaliados por Sorensen e Ursin (2001) por meio de questionários respondidos por estudantes de 17 anos e por pais de crianças de sete anos. Eles observaram que a média de duração de sono nos dias letivos foi menor do que nos finais de semana entre os jovens de 17 anos (7,3 e 10,1 horas respectivamente). Além disso, os adolescentes deitavam-se mais tarde e 
acordavam mais cedo do que as crianças. Os jovens entrevistados queixaram-se por não terem suas necessidades de sono atendidas e o grau de insatisfação foi mais elevado entre os indivíduos com maior diferença na duração de sono entre dias letivos e finais de semana.

Na Islândia, Thorleifsdottir e colaboradores (2002) conduziram um estudo em três etapas, com intervalos de cinco anos entre elas, nas quais enviavam questionário sobre os hábitos de sono, via correio, a 668 sujeitos com idades entre um e vinte anos. Os autores discutem os resultados não apenas ontogeneticamente, mas também como conseqüência do tipo de residência, estações do ano e ano de levantamento de dados. Fenômenos já observados entre outras populações foram confirmados, tais como diminuição da duração total de sono nos primeiros anos de vida e tendências para maior duração de sono nos finais de semana entre os jovens, assim como maior sonolência e diminuição do sono noturno na adolescência. Os autores afirmam que os adolescentes islandeses têm horários de dormir atrasados e menor duração de sono noturno do que os adolescentes europeus.

Park e colaboradores (2002) conduziram um estudo com 2.252 sujeitos japoneses, com idades entre 6 e 89 anos, visando analisar a influência do sexo e da idade nos hábitos de sono e na tendência à matutinidade e à vespertinidade. Eles observaram que, dos seis anos até o fim da puberdade, os horários de dormir nos dias de semana e finais de semana, assim como os horários de acordar nos finais de semana, estavam atrasados após o início da puberdade em relação aos horários observados entre crianças e havia uma mudança gradual para tipo vespertino, acompanhada de diminuição na duração de sono durante dias letivos. Nos 
indivíduos mais velhos, os autores observaram uma tendência inversa, com nova troca para tendências mais matutinas e número maior de despertares noturnos acima dos 40 anos.

Giannotti e colaboradores (2002) estudaram as relações entre a preferência circadiana, a regularidade dos padrões de sono, problemas de sono e comportamentais em adolescentes italianos. Indivíduos vespertinos apresentaram horários mais tardios de dormir e acordar nos finais de semana, menor duração de sono em dias letivos, menor regularidade do sono, pior avaliação subjetiva da qualidade do sono, mais queixas de sonolência diurna, índices maiores de dificuldades emocionais e de atenção, além de pior desempenho escolar do que os indivíduos matutinos. Não houve diferenças entre os sexos na distribuição entre cronotipos, mas os meninos vespertinos apresentam pior desempenho escolar, maior tendência a cochilar em aula e menor capacidade de manter atenção do que as meninas vespertinas.

Em um estudo realizado com 3.871 adolescentes coreanos foram constatadas duração de sono insuficiente para ambos os sexos e diferença na duração de sono entre moças e rapazes (respectivamente, média de 6,5 e 6,3 horas de sono por noite), além de relação significativa entre prevalência de sonolência excessiva diurna e declínio no desempenho escolar (Shin et al., 2003).

A relação entre série escolar e fase de preferência de sono na adolescência foi estudada por Gau e Soong (2003) por meio de questionários de hábitos de sono aplicados a 1.572 estudantes de Taipei, em Taiwan do ensino fundamental até o médio. Os autores observaram que a proporção de 
jovens do tipo vespertino aumentava entre os alunos de níveis escolares mais avançados, o que foi associado com diminuição na duração do sono noturno, horários mais tardios de dormir e acordar, aumento da sonolência diurna e maior duração do sono nos finais de semana.

Iglowstein e colaboradores (2003), em um estudo longitudinal realizado com bebês que foram acompanhados até os 16 anos de idade em Zurique, observaram que a média de duração de sono decresceu de 14,2 horas aos seis meses de vida para 8,1 horas aos 16 anos. Os autores relacionam a diminuição da duração do sono noturno com a prevalência de horários cada vez mais tardios de dormir e manutenção dos horários de acordar ao longo dos últimos anos de estudo.

Em um estudo com 1.362 adolescentes chineses, Liu (2004) observou uma preocupante incidência elevada de pesadelos (40\% da amostra relatou que teve pesadelos no mês anterior à pesquisa), baixa duração de sono e alta freqüência de idéias suicidas (19\% já tiveram pensamentos suicidas) entre os jovens.

Ainda na temática sobre qualidade de sono entre os adolescentes, LeBourgeois e colaboradores (2004) encontraram diferenças nos hábitos de sono entre adolescentes italianos e norte-americanos, sendo que a qualidade do sono e as práticas de higiene do sono foram melhores entre os italianos.

Há crescente interesse nos ritmos biológicos dos adolescentes, em muitos casos associado à preocupação com as conseqüências da má qualidade do sono, decorrente da irregularidade do ciclo vigília/sono e privação de sono, sobre o comportamento e o desempenho acadêmico nesta faixa etária. Só no último ano, foram publicados aproximadamente 150 
estudos científicos sobre adolescentes que levam em conta os ritmos circadianos (http://www.ncbi.nlm.nih.gov/entrez, palavras-chave: circadian e adolescence - busca realizada em 03 de agosto de 2005). Existem até mesmo movimentos organizados na sociedade para mudar os horários escolares de adolescentes, privilegiando a boa qualidade de sono (www.educationworld.com/a admin/admin/admin314.shtml ).

\subsubsection{O ciclo vigília/sono de adolescentes de regiões rurais}

Grande parte dos trabalhos relacionados com a ontogênese do ciclo vigília/sono foi realizada com populações urbanas. Não encontramos estudos que caracterizassem o padrão de sono em adolescentes indígenas e existem poucas pesquisas que se remetem ao estudo de adolescentes de população rural, com ou sem energia elétrica nas residências.

Apesar da escassez de trabalhos sobre o ciclo vigília/sono de populações sem energia elétrica, é importante lembrar que muitos estímulos sociais relacionam-se a um aumento da intensidade luminosa à qual o indivíduo está submetido, o que pode atuar sobre o sistema de temporização circadiana e provocar um atraso de fase, como acontece com os adolescentes, dependendo do momento do dia em que tais estímulos ocorram (Louzada, 2000).

Existem relatos recentes, baseados em questionários respondidos por indígenas Terena, indicativos de diferenças culturais, em relação às populações urbanas, na cultura de sesta (Reimão et al., 2000a) e na duração 
do sono noturno (Reimão et al., 2000b) de adultos com mais de 18 anos. Entre as crianças indígenas Bororo e Terena há uma prevalência cultural do hábito de dormir na mesma cama com familiares, além de ser muito comum ter cerca de cinco pessoas dormindo no mesmo quarto (Reimão et al., 1998 e 1999).

Com o intuito de investigar a influência da diversidade de estímulos ambientais sobre os hábitos de sono de adolescentes, Louzada e MennaBarreto (2003) realizaram um estudo comparativo do ciclo vigília/sono de adolescentes que viviam em ambiente urbano e ambiente rural, considerando estímulos como televisor, telefone e acesso à Internet na residência. Os sujeitos residentes em ambiente urbano apresentaram as fases do ciclo vigília/sono atrasadas em relação aos adolescentes de área rural. Com base neste resultado, os autores sugerem que o contexto social influenciou a expressão deste ciclo nos adolescentes estudados.

Louzada e colaboradores (2004), ao examinarem os hábitos de uma adolescente antes e após a instalação de energia elétrica em sua residência, observaram um atraso do início do sono nos finais de semana em relação aos dias letivos após a presença de eletricidade em sua casa.

Worthman e Melby (2002), em sua revisão sobre a ecologia do sono em humanos, agruparam os relatos de etnógrafos e antropólogos sobre os hábitos gerais de sono de povos primitivos, principalmente da América do Sul, África e Austrália. Os autores enfatizam a importância da história natural do sono para a compreensão dos padrões de sono em observados em contextos específicos, além de criticarem a escassez de contatos entre cronobiólogos e antropólogos ou etnógrafos, que impedem a realização de 
estudos sistemáticos sobre os ritmos biológicos de populações com hábitos tão diversos daquelas comumente estudadas.

\subsection{Aspectos históricos e culturais dos Guarani do litoral brasileiro}

No presente estudo, descrevermos as características de alguns ritmos biológicos de adolescentes da Aldeia Boa Vista, composta por índios Guarani, no litoral de São Paulo. Para melhor compreensão daquilo que observamos, é fundamental a contextualização cultural do grupo estudado, tanto no que tange os hábitos gerais da etnia estudada como na consideração do que é a adolescência ou quais são os ritos de passagem que marcam este momento na vida dessa população.

Os índios Guarani são classificados em três grupos pela literatura etnográfica, de acordo com seus dialetos, costumes e rituais: Kaiova, Nhandéva e Mbya. A população Guarani no litoral brasileiro é composta basicamente pelos Mbya e Nhandéva (Ladeira \& Matta, 2004).

A população Guarani da Aldeia Boa Vista do Sertão do Promirim (Jaexa Porã) é, predominantemente, da etnia Mbya. Este grupo é originário do Paraguai, num território que abrange a região do Paraguai Oriental e o alto do Paraná. Sua migração para o litoral de São Paulo, Rio de Janeiro e Espírito Santo foi retomada entre os anos 50 e 60, seguindo uma tradição que possivelmente é anterior à colonização européia (Ladeira \& Azanha, 1988). 
Os Guarani Mbya do litoral têm uma relação mítica com a Mata Atlântica - as aldeias no litoral atlântico estariam mais perto do mundo celestial, pois é neste local que teriam acesso à "terra sem mal" (Ladeira, 2001). Para eles, o conceito de território supera os limites físicos da aldeia e é daí que decorrem as migrações de famílias inteiras ou indivíduos isolados de uma aldeia para outra de acordo com uma rede ampla de parentescos.

O local em que os Guarani Mbya vivem é chamado de tekoa, que é entendido como espaço político e social formado a partir de uma família extensa, entre 20 e 300 pessoas, composta tradicionalmente por um casal, filhas, genros e netos, com uma liderança espiritual e política própria. Atualmente, as famílias extensas são unidades de produção agrícola (Ladeira, 2000).

O casamento entre os Mbya é geralmente precoce - a mulher com cerca de 14 anos e o homem um pouco mais velho (Schaden, 1974). O discurso Guarani, ao contrário daqueles de muitos outros povos indígenas, enfatiza a necessidade de harmonia entre diferentes povos, contudo é orientado contra o casamento com os brancos (Ladeira, 1997).

A agricultura Guarani está voltada para cultivos seculares, como milho, batata-doce e mandioca, e as roças são dispostas próximas às casas. A caça é realizada de acordo com as estações do ano mais propícias, contudo tal atividade está cada vez menos presente em suas vidas por causa da redução da fauna. A coleta de sementes, frutos, ervas e caules ainda existe e está voltada para a alimentação, produção de medicamentos, construção de casas, fabricação de ornamentos e até mesmo para 
comercialização, tanto do palmito in natura quanto de alguns artesanatos produzidos (Veloso et al., 1991 apud Ladeira \& Matta, 2004).

Em relação à educação das crianças, é costume Guarani não intervir no desenvolvimento da personalidade das mesmas, o que inclui a nãovalorização de métodos educativos diretivos, principalmente no que tange à repressão (Schaden, 1974). A correção do comportamento sempre acontece de forma ritualística, como as cerimônias de puberdade, que servem para controlar o discurso do jovem e o seu apetite. Os meninos passam por uma cerimônia coletiva na casa de reza, onde seus lábios inferiores são furados com pedaços de madeira. As meninas passam por um processo individual que começa com a menarca, momento em que seus cabelos são cortados, e segue por um período de isolamento em casa (Guimarães, 2001).

As aldeias Guarani no Estado de São Paulo preservam a organização social descrita acima, com pequenos grupos estruturados a partir de uma família extensa. São formadas a partir de casas dispersas, ligadas entre si por trilhas. Geralmente, o domínio político é exercido pela família que iniciou o agrupamento que originou a aldeia (Ladeira \& Azanha, 1988). Grande parte do tempo dos membros de aldeias paulistas é voltada para a produção e venda de artesanatos, o que tem gerado mudanças na organização social do trabalho, nos hábitos alimentares e nas relações dos grupos (Cherobim, 1986). As comunidades do litoral brasileiro vivem um momento de contato mais íntimo com artefatos não-indígenas, o que tem gerado conseqüências sobre os hábitos e saúde de seus membros, que se encontram sob risco intermediário para doenças crônico-degenerativas (Cardoso e colaboradores, 2001). 


\subsection{Objetivos}

No presente trabalho observamos o ciclo vigília/sono e o rtimo de temperatura de adolescentes Guarani da Aldeia Boa Vista (Ubatuba, São Paulo), que vivem num ambiente florestal, afastado de centros urbanos, sem energia elétrica e que freqüentam, em sua maioria, escola indígena na própria região onde vivem.

Pretendíamos verificar se estes apresentam padrões de ciclo vigília/sono e o ritmo de temperatura semelhantes àqueles encontrados em adolescentes de mesma idade que vivem em ambientes urbanos e apresentam o atraso da fase do sono ou se nos indivíduos da aldeia esta característica é menos evidente, como na população rural (Louzada, 2000), ou ainda se não é detectável por se tratar de indivíduos que não dispõem de energia elétrica.

2. Metodologia

2.1. População estudada

Ao início da pesquisa em fevereiro de 2004, moravam na aldeia Boa Vista 36 famílias Guarani, num total de 148 pessoas (dados do posto médico local). Os adolescentes da comunidade, nascidos entre 1986 e 1993, eram nove garotas, que não eram mães ou gestantes, e 18 rapazes. 
A aldeia ocupa 801 alqueires e localiza-se a um quilômetro e meio de distância do quilômetro 15 da rodovia Rio-Santos $(\mathrm{Br} 101)$ no Parque Florestal da Serra do Mar (figura 1), local afastado de centros urbanos e que não recebe energia elétrica.

Existem, a 800 metros da casa de reza, uma escola bilíngüe, um posto médico, ambos abastecidos com energia solar no início da pesquisa, e a residência da auxiliar de enfermagem que atende diariamente à comunidade, senhora Íris Araújo Barbosa, que nos forneceu todos os dados demográficos da aldeia e o histórico sobre a saúde dos participantes. A comunidade é atendida pela FUNASA, que conta com dois carros e dois funcionários para transporte de seus membros; posto de saúde; a auxiliar de enfermagem fixa no local; médica clínica geral e enfermeira que atendem a população quatro vezes por semana.

A escola local é freqüentada por crianças e adultos que estão cursando o ensino fundamental 1. Estes alunos recebem aulas em Guarani, ministradas por professor indígena, e aulas em português, ministradas por professora não-indígena. Após a quarta série, os alunos que pretendem continuar os estudos devem freqüentar a escola municipal de Poruba, que também recebe alunos não-indígenas. 


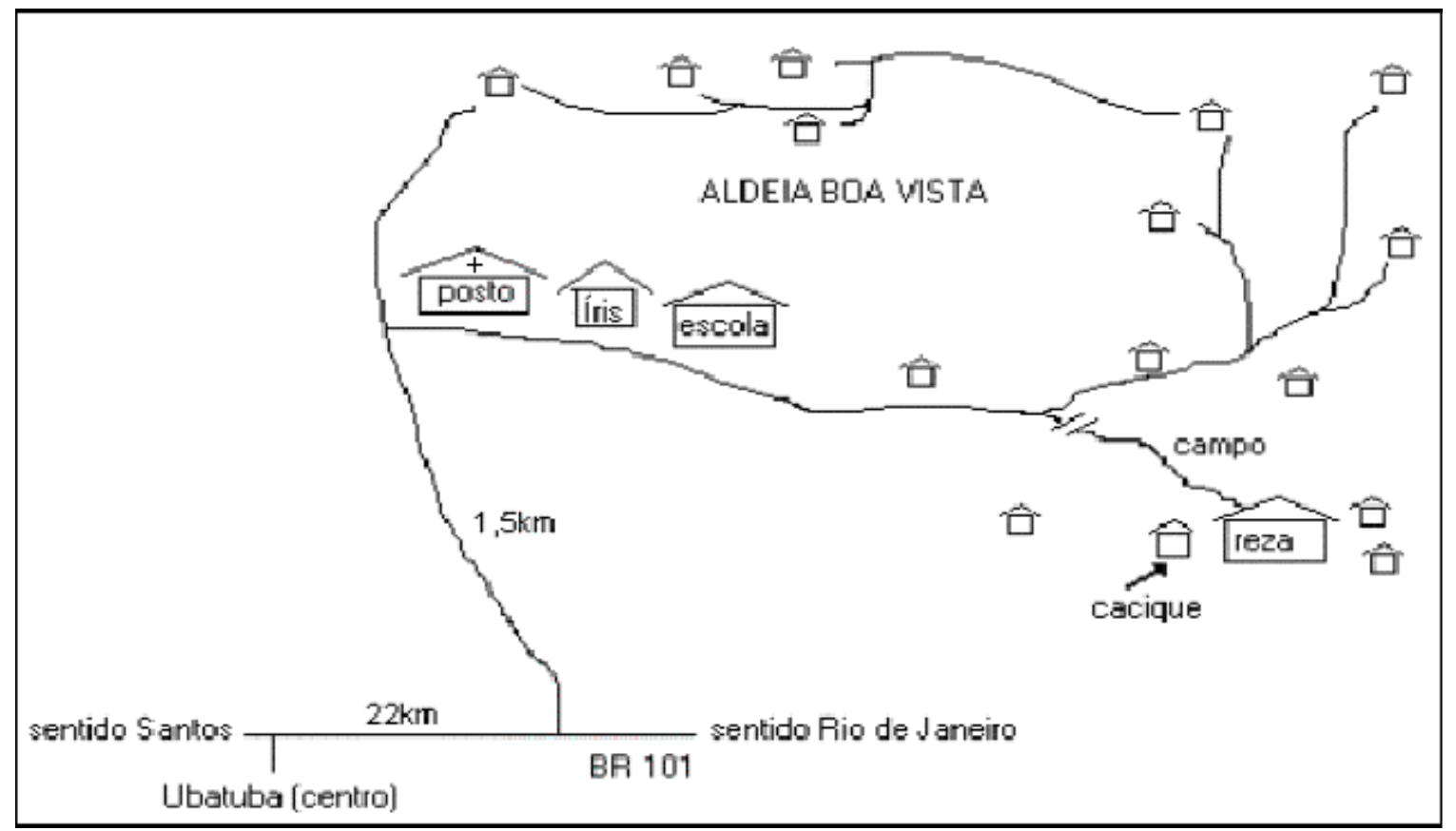

Figura 1: esquema geral da distribuição das casas na Aldeia Boa Vista.

As casas são geralmente pequenas, com um ou dois cômodos, construídas de pau-a-pique, com uma entrada e uma ou duas janelas. Nos quantos, há várias camas e colchões, há alguns beliches e é comum os parentes compartilharem as camas. Nem todos residem em torno da região central da aldeia, onde está localizada a casa de reza. A residência mais distante desse ponto fica, aproximadamente, a dois quilômetros de distância da casa de reza, para dentro da mata.

Conforme soubemos em nossas conversas com o cacique da aldeia, senhor Altino dos Santos, grande parte dos adultos e adolescentes complementa suas despesas com a venda do palmito extraído na mata, enquanto outra parcela da população produz e comercializa artesanatos nos dois casos os consumidores são, em grande parte, turistas. Os adultos mais velhos reúnem-se todas as noites na casa de reza para discutirem 
temas da comunidade e fazem rituais religiosos que podem avançar pela madrugada. As crianças e os adolescentes participam esporadicamente de tais reuniões e não costumam ficar até o final das cerimônias.

\subsection{Sujeitos}

Participaram da pesquisa 21 adolescentes de ambos os sexos, com idades entre 10 e 18 anos. Não foram incluídos na amostra adolescentes que apresentavam problemas de saúde durante as coletas ou que estavam grávidas, amamentando ou cuidando de filhos pequenos.

A primeira etapa de pesquisa, em fevereiro de 2004 , foi realizada com 11 adolescentes (nove meninos e duas meninas). Na segunda etapa, em julho e agosto de 2004, um dos participantes estava em outra aldeia, os demais continuaram na pesquisa e mais 6 adolescentes foram incluídos, totalizando 16 participantes na segunda etapa. Houve uma migração de várias famílias para outras aldeias entre a segunda e terceira etapas, o que ocasionou a exclusão de quatro participantes (um menino e três meninas). Além disso, um rapaz não quis continuar na pesquisa. Por outro lado, contamos com a participação de mais quatro jovens (dois meninos e duas meninas), totalizando 15 participantes nesta última etapa, realizada em fevereiro de 2005, e 21 na pesquisa como um todo. 


\subsection{Aspectos éticos}

Após reuniões com o cacique e deste com a sua comunidade, por meio das quais recebemos a notícia de que eram favoráveis ao desenvolvimento da pesquisa com membros da aldeia, solicitamos análise da Comissão Nacional de Ética em Pesquisa com Seres Humanos e obtivemos parecer favorável em 08 de setembro de 2003 pelo Conselho Nacional de Ética em Pesquisa - CONEP, sob o parecer n 1434/2003, em sua trigésima sexta reunião, de acordo com as atribuições definidas na Resolução CNS 196/96 (anexos A).

A Fundação Nacional do Índio - FUNAI concedeu-nos Autorização para Ingresso em Terra Indígena em 13 de fevereiro de 2004, através do processo no 2252/03 e autorização no 10/CGEP/04, de acordo com as atribuições definidas na Instrução Normativa no 001/PRESI de 29 de novembro de 1995, aprovadas pelo decreto $n^{\circ} 564$ de 08 de julho de 1992 (anexos B).

Pedimos o consentimento individualmente aos adolescentes e seus responsáveis, segundo o termo de consentimento livre e esclarecido do Comitê de Ética em Pesquisa com Seres Humanos do Instituto de Ciências Biomédicas da Universidade de São Paulo (anexo C). 


\subsection{Materiais e métodos}

A primeira etapa foi inicialmente planejada para ser uma etapa piloto a ser conduzida com cinco participantes durante sete dias de coleta para testarmos a viabilidade do protocolo. Com a expectativa de que a energia elétrica fosse implantada na aldeia ainda no início de 2004, remanejamos as etapas da pesquisa, na tentativa de viabilizar a realização de coletas anteriores a tal mudança no ambiente daquela comunidade. É importante frisar que, até a última etapa da pesquisa, as instalações elétricas chegaram apenas até o posto médico, casa da senhora Íris e a escola, ou seja, nenhuma casa indígena foi contemplada com luz elétrica até o encerramento das coletas.

A primeira etapa foi, então, conduzida com a participação de 11 adolescentes e realizada ao longo de dez dias. Como os dados obtidos foram passíveis de análises, consideramos tal etapa em nossas discussões sobre os resultados da pesquisa e, após seis meses e um ano desta etapa inicial, realizamos as etapas 2 e 3 com duração de, respectivamente, 20 e 18 dias cada. Tal divisão em etapas fez-se necessária para que possíveis relações entre mudanças nos ritmos estudados e desenvolvimento puberal fossem observadas (figura 2). 


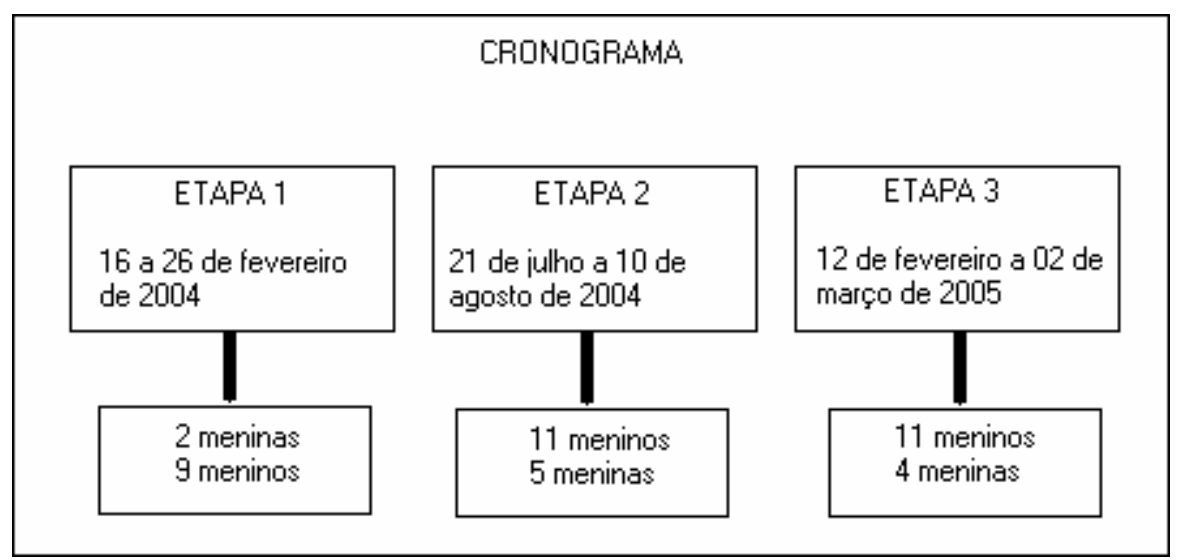

Figura 2: cronograma das coletas de dados na Aldeia Boa Vista.

Dois questionários foram utilizados nesta pesquisa (anexos D e E). Para a análise das diferenças individuais na preferência entre horários matutinos e vespertinos, utilizamos o questionário desenvolvido por Horne e Östberg (1976) - denominado Cronotipo por nosso grupo de pesquisa (GMDRB), já aplicado em adolescentes brasileiros por Andrade e colaboradores (1993) e Louzada (2000) com intuito de verificar a tendência para a matutinidade ou vespertinidade de cada indivíduo. Na primeira aplicação do questionário Cronotipo com um rapaz, na primeira coleta, percebemos a necessidade de adaptação deste instrumento para o grupo indígena. A versão adaptada foi aplicada com os demais participantes nas outras etapas. É importante frisar que a padronização do questionário Cronotipo para a população brasileira não pode ser diretamente transferida para os índios Guarani devido à adaptação que fizemos das questões e da forma de apresentação para que, em modo de entrevistas, fossem melhor compreendidas pelos participantes (anexo D).

O segundo questionário (anexo E) foi aplicado também em forma de entrevistas individuais com os participantes. Trata-se do Questionário de 
Hábitos de Sono (Andrade et al., 1993), que inclui questões sobre a rotina, hábitos de sono e fatores que poderiam interferir no ciclo vigília/sono ou no ritmo de temperatura dos adolescentes, independentemente da idade ou desencadeamento puberal. Este questionário foi respondido, em alguns casos, com o auxílio de familiares.

Tanto o Cronotipo adaptado quanto o Questionário de Hábitos de Sono foram aplicados duas vezes com aqueles participantes que fizeram coleta de dados na pesquisa por, pelo menos, duas etapas. O intuito foi verificar a compreensão dos questionários por meio das variações das respostas dadas nas duas aplicações, considerando a possibilidade de variações acontecerem de acordo com o contexto (por exemplo, mudanças no número de pessoas que vivem na mesma casa).

Utilizamos diários de sono, que são cadernos que incluem campos para registros de horários de acordar e dormir, como acontece o despertar (espontâneo ou induzido), possíveis cochilos e despertares noturnos (anexo F). Também há, nos diários de sono, campos para registros da temperatura oral, realizados com termômetro digital (anexo G), que foram preenchidos cinco vezes ao dia (nunca na fase de sono), durante o mesmo período do preenchimento do diário. Esses registros, realizados pelos próprios participantes, foram importantes para compreendermos como se dá a relação entre os dois diferentes ritmos, temperatura e ciclo vigília/sono, nos indivíduos estudados. Existe também em cada caderno uma página-treino, que demonstra o uso adequado do diário e do termômetro em cada etapa da pesquisa. Os cadernos, canetas para o preenchimento dos mesmos e os termômetros digitais foram fornecidos pela pesquisadora, a qual foi também 
responsável pela condução das entrevistas e orientação diária sobre a maneira correta de fazer os registros.

Ao mesmo tempo em que os diários foram preenchidos, os adolescentes utilizaram actímetros (Mini Motionlogger Actigraph ${ }^{\circledR}$ Ambulatory Monitoring, Inc.), instrumentos semelhantes a relógios de punho que registram a atividade motora (anexo $G$ ) e permitem-nos inferir o estado de repouso ou atividade, complementando os registros sobre sono e vigília dos diários. O actímetro era colocado no punho, com uma pulseira de velcro, durante todo o tempo de coleta de dados, sendo retirado apenas para o banho.

A médica que atende aos indígenas no posto médico local, doutora Gianna Guiotti Testa, realizou a avaliação puberal nos participantes que concordaram em ser examinados fisicamente por ela. O intuito deste exame foi verificar, a cada etapa da pesquisa, o estágio puberal dos participantes por meio de avaliação visual das características sexuais secundárias, segundo os estágios puberais de Tanner (1962).

Devido à dificuldade que encontramos em obter registros satisfatórios de temperatura oral durante a primeira etapa, incluímos medidas de temperatura periférica registradas por um termistor (Thermocron ${ }^{\circledR}$ ) no protocolo de pesquisa durante as etapas seguintes. Trata-se de um aparelho de metal, com cerca de um centímetro e meio de diâmetro e meio centímetro de altura (anexo G), que é fixado no punho dos participantes com esparadrapo cirúrgico fino e envolvido com uma munhequeira de tecido elástico. Com tal aparelho, pudemos obter registros contínuos de temperatura cutânea durante 3 a 4 dias seguidos e armazená-los a cada 30 minutos, de 
acordo com a programação prévia do aparelho para tal intervalo de armazenamento por meio de software específico.

A ritmicidade circadiana da temperatura de algumas regiões periféricas do corpo tem sido recentemente estudada, inclusive no que tange as relações de fase entre medidas de temperatura em diferentes pontos do corpo e CVS (Gradisar \& Lack, 2004 e Van Someren, 2004). Ainda não há trabalhos publicados sobre a relação de fase entre os ritmos de temperatura no punho e central. Em nosso grupo de pesquisa (GMDRB) há um trabalho que está sendo desenvolvido com o intuito de estabelecer tal relação, sendo os resultados preliminares satisfatórios no que diz respeito ao uso da temperatura do punho como indicadora da ritmicidade da temperatura corporal (Arêas et al., 2005).

Com o intuito de esclarecer as funções do actímetro para o grupo estudado, transferimos os dados de actimetria para um computador portátil na presença dos participantes e outros membros da comunidade durante as coletas, aos quais explicamos o que estava sendo representado. Além disso, foram exibidas e explicadas aos participantes, no início das etapas 2 e 3, as representações gráficas referentes aos dados de temperatura oral, temperatura periférica e actogramas de diários de sono.

2.5. Análises dos resultados

Os dados sobre o ciclo vigília/sono (diário de sono) e sobre o ciclo atividade/repouso (actimetria) foram representados graficamente em 
actogramas que ilustram início, fim e duração sono e de repouso nas diferentes etapas de cada sujeito (anexo $\mathrm{H}$ ).

Apesar de alguns autores utilizarem os registros actimétricos como correlatos de sono e vigília, optamos por considerar os registros em diário, sobre sono/vigília, e os registros dos actímetros, sobre atividade/repouso, como informações complementares, tendo em vista que nem sempre há superposição dos resultados obtidos pelos dois instrumentos. Um exemplo disso reside no fato de que uma pessoa pode estar acordada, porém em repouso enquanto está pensando em algo, e dormindo, porém em atividade motora enquanto muda sua posição na cama.

Cada variável relacionada ao sono e ao repouso foi analisada em três diferentes níveis. Primeiro, abordamos as diferenças entre as etapas, considerando apenas os dados daqueles indivíduos que participaram das etapas comparadas. Em seguida, consideramos dois grupos diferentes estudantes e não-estudantes nas etapas 2 e 3, tendo em vista que tal divisão não foi possível na primeira etapa pelo número reduzido de participantes que não estudavam. Por fim, separamos dois dias na semana que não estavam na rotina de saídas para a mata ou para a cidade - segundas e terças-feiras, e os finais de semana - sábados e domingos, e fizemos comparações entre os dois grupos de dias da semana e os dias da semana equivalentes entre as etapas.

Os valores médios individuais dos registros de actimetria e de diário de sono, em cada etapa, tiveram a correlação testada pela correlação linear de Pearson, adotando como nível descritivo do teste $\alpha=0,05$ e índice de correlação significativo para $r>0,7$ ou $r<-0,7$. As características dos dados de 
início, fim e duração de sono e de repouso do grupo foram analisadas por meio de Teste $t$ de Student para amostras dependentes, tendo em vista que as amostras foram relativamente pequenas, adotando como nível descritivo $\alpha=0,05$. Para tais análises, foram averiguadas as condições de normalidade, por análise descritiva da regressão linear entre pontos obtidos e esperados na Normal (0;1), e homocedasticidade, por meio de análise de variâncias dos conjuntos de dados.

Quando as condições de normalidade e a homocedaticidade do conjunto de dados não foram observadas, como aconteceu com a pontuação no $\mathrm{HO}$, o estagiamento puberal e diário de sono na primeira etapa, utilizamos o teste de Wilcoxon pareado, a ANOVA de Friedman e o teste de correlação por postos de Spearman, sempre adotando como nível descritivo $\alpha=0,05$.

Os dados de temperatura central e periférica foram processados pelo programa COSANA (Benedito-Silva, 1997), que permite avaliar a significância das oscilações regulares (periodicidade), bem como a amplitude, a acrofase e o valor médio de curva ajustada aos dados, em procedimento conhecido como "Método do Cosinor" (Nelson et al., 1979).

Correlações por postos foram testadas com os horários de ocorrência das acrofases de temperatura central e periférica entre si e destes com as médias de horários de início, fim e duração de sono; com as médias de horários de início, fim e duração de repouso; pontuações no Cronotipo, idade cronológica e estágio puberal (Spearman, considerando $\alpha=0,05$ e índice de correlação significativo para $r>0,7$ ou $r<-0,7)$.

Gráficos de dispersão foram construídos a partir dos dados sobre horários de início e fim de sono e repouso; duração de sono e repouso; 
horários de ocorrência das acrofases de temperatura oral e horários de ocorrência das acrofases de temperatura periférica (médias e respectivos desvios padrão, no caso das variáveis de sono e repouso, e médias e erros padrão, no caso dos horários de acrofase). Os gráficos tiveram seus pontos organizados por idade e por etapa para que uma inspeção visual das tendências fosse realizada, assim como um teste de correlação entre as variáveis (Spearman, considerando $\alpha=0,05$ e e índice de correlação significativo para $r>0,7$ ou $r<-0,7)$.

Para todas as análises (Teste $t$ de Student, ANOVA de Friedman, Wilcoxon pareado, correlação linear de Pearson e correlação de postos de Spearman), consideramos como tendências, os valores de p entre 0,051 e 0,069. Para todos os testes de correlação (linear de Pearson e postos de Spearman) consideramos tendências, os valores de $r$ entre 0,60 e 0,69 e entre $-0,60$ e $-0,69$.

3. Resultados

3.1. Panorama geral das coletas de dados 


\subsubsection{Primeira etapa}

A primeira etapa da pesquisa foi realizada do dia 16 ao dia 26 de fevereiro de 2004. Esta etapa estava prevista para ser uma etapa piloto, mas o número de participantes e o tempo de coleta foram ampliados em função da notícia que recebemos pelo agente da FUNAI, por telefone, de que a energia elétrica seria implantada na aldeia no mês de março, o que poderia acarretar em mudanças muito importantes no padrão de sono dos adolescentes. O mesmo motivo levou-nos a iniciar a coleta numa data que englobaria o feriado de carnaval, o que coincidiu com a obtenção da aprovação de ingresso em terras indígenas pela FUNAI em 13 de fevereiro de 2004.

Assim, contamos com a participação de 11 adolescentes nessa primeira etapa, dos quais nove eram meninos e duas meninas, todos entre 10 e 15 anos. Entre os participantes, quatro estavam na quinta série do ensino fundamental na escola municipal de Poruba. Estes jovens precisavam acordar muito cedo para pegar o primeiro ônibus para a vila de Poruba, às 06:00 horas da manhã. Outros quatro estudavam na escola da aldeia e tinham aulas das 09:00 às 12:00 horas. Dois meninos terminaram a quarta série do ensino fundamental na aldeia e não estavam estudando nesse ano.

Todos responderam o Questionário de Hábitos de Sono. O questionário de Cronotipo (matutinidade-vespertinidade) foi respondido por um adolescente apenas para que a compreensão deste questionário em sua versão original fosse averiguada, tendo em vista que se trata de um instrumento cuja padronização brasileira não engloba grupos indígenas. Dos 11 participantes, seis preencheram os seus diários de sono com informações 
a respeito dos horários de dormir e acordar por mais de cinco dias. Entre eles, cinco fizeram medidas de temperatura suficientes para a análise do ritmo de temperatura oral e dois tiveram resultados significativos. Entre os 11 actímetros utilizados foram analizados os dados de sete, pois dois não funcionaram e outros dois não foram usados corretamente por pelo menos cinco dias. Seis participantes aceitaram passar por avaliação puberal com a médica que atende à comunidade da aldeia.

\subsubsection{Segunda etapa}

A segunda etapa foi conduzida entre os dias 21 de julho e 10 de agosto de 2004. Contamos com a participação de 16 pessoas, 11 meninos e cinco meninas. Entre os 11 indivíduos que participaram da primeira etapa, dez participaram da segunda e mais seis pessoas foram incluídas.

Entre os participantes desta etapa, uma estudava na escola municipal de Poruba, seis estudavam na escola indígena local e os demais não freqüentavam a escola. Dois rapazes eram casados e tinham filhos. Uma menina teve um filho que morreu um ano antes de sua participação na pesquisa.

Ao início da coleta, mostramos, num computador portátil, os resultados de temperatura, actimetria e diário de sono obtidos na primeira etapa para todos os participantes e, ao longo da segunda etapa, transferimos os dados de actimetria para o computador na presença deles a cada três ou quatro dias. 
O Questionário de Hábitos de Sono foi aplicado apenas para aqueles que não participaram da etapa anterior, entre os novos participantes, dois não responderam. Entrevistamos individualmente os participantes, usando como base o questionário Cronotipo adaptado. Três indivíduos não quiseram responder às perguntas. Nesta etapa, 11 participantes preencheram os seus diários de sono com informações a respeito dos horários de dormir e acordar por mais de cinco dias. Entre eles, nove fizeram medidas de temperatura oral suficientes para a análise do ritmo e quatro tiveram resultados ritmicos significativos. Todos actímetros utilizados funcionaram bem, porém três participantes não usaram o aparelho por, pelo menos, cinco dias. Um dos participantes esteve fora da aldeia durante quase toda a coleta e seus dados de actimetria, de temperatura oral e de diário de sono foram excluídos por conter apenas os três dias iniciais da pesquisa.

O termistor cutâneo foi, pela primeira vez, usado por 14 participantes. Uma menina não quis usar o aparelho durante os três dias necessários e outra não usou o aparelho por ter passado grande parte do período de coleta em casa, num local afastado do centro da aldeia em direção à mata, o que dificultaria um monitoramento eficaz durante os três dias necessários. Um garoto perdeu o termistor com seus dados. No total, 11 coletas foram passíveis de análise pelo "Método Cosinor". Cinco avaliações puberais foram realizadas pela médica ao fim da segunda etapa da pesquisa. 


\subsubsection{Terceira etapa}

A terceira etapa foi realizada entre os dias 12 de fevereiro e 02 de março de 2005. Contamos com a participação de 15 pessoas, 11 meninos e quatro meninas. Entre aqueles que participaram da etapa anterior, quatro não estavam morando na aldeia nesta etapa e um rapaz não quis continuar na pesquisa, porém contamos com quatro novos participantes.

Entre os participantes dessa etapa, uma continuou estudando na escola municipal de Poruba, sete estudavam na escola indígena e os demais não freqüentavam a escola. Três meninos eram casados, dois tinham filhos.

O Questionário de Hábitos de Sono e a versão modificada do questionário de Cronotipo foram aplicados com todos os participantes individualmente. Nesta etapa, todos preencheram os seus diários de sono com informações a respeito dos horários de dormir e acordar por mais de cinco dias e 12 fizeram medidas de temperatura oral suficientes para a análise do ritmo, sendo que cinco tiveram resultados ritmicos significativos. Os actímetros utilizados funcionaram bem e apenas um participante não usou o aparelho por tempo suficiente para análises de seus dados. Os termistores cutâneos foram usados corretamente por 14 participantes por tempo suficiente para que os dados foram passíveis de análise pelo "Método Cosinor". Dez avaliações puberais foram realizadas pela médica ao fim da terceira etapa da pesquisa. 


\subsubsection{Panorama geral}

Nas tabelas e nos gráficos que representam os resultados individuais, cada participante é identificado pelo código abaixo exemplificado na figura 3 abaixo:

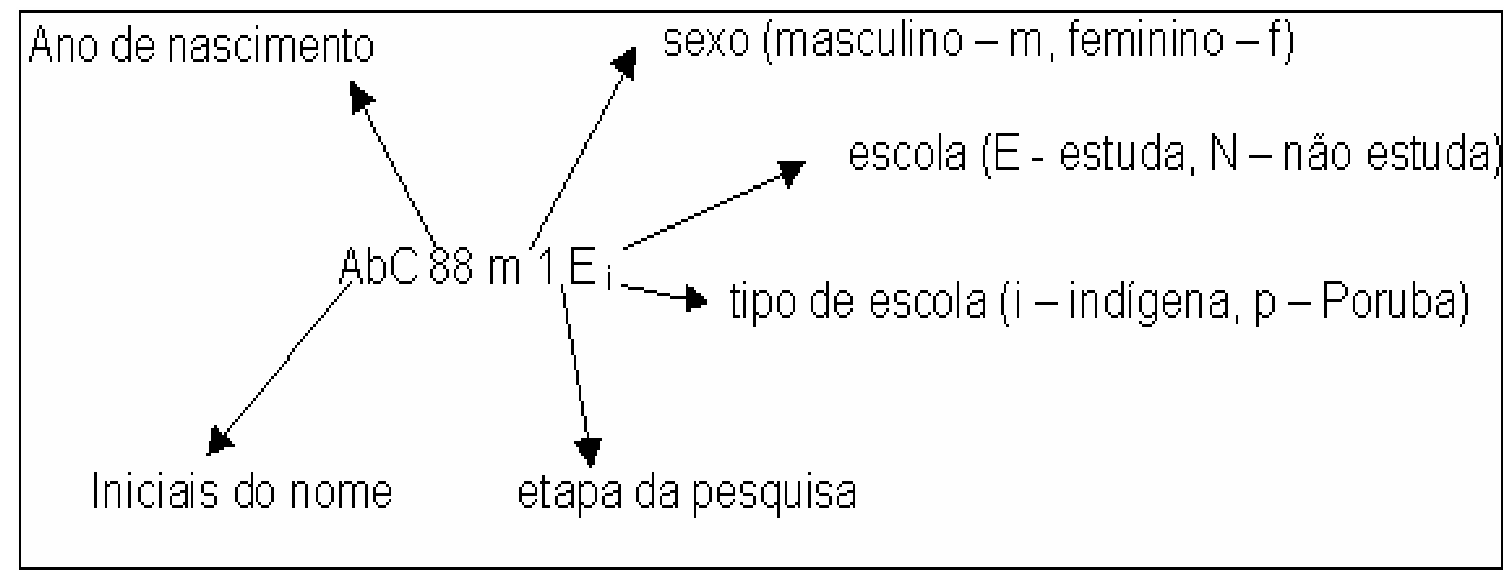

Figura 3: código de identificação dos participantes por iniciais, ano de nascimento, sexo, etapa da pesquisa, freqüencia escolar e tipo de escola.

A tabela 1 ilustra o panorama geral da participação dos 21 sujetos ao longo das três etapas da pesquisa, além de identificá-los segundo sexo, idade, ano de nascimento e situação escolar, como no quadro acima. Como podemos observar nesta tabela, houve grande rotatividade de participantes, além de empenho muito variado dos mesmos no que tange à execução do protocolo de pesquisa (uso de actimetria e termistor de punho, coleta de temperatura, preenchimento do diário de sono e disponibilidade para responder aos questionários). 


\begin{tabular}{|c|c|c|c|c|c|c|c|}
\hline \multirow[t]{2}{*}{$\begin{array}{l}\text { participante } \\
\text { por etapa: }\end{array}$} & \multicolumn{7}{|c|}{$\begin{array}{l}\text { A, B, C e D: número de dias com dados passíveis de análise; E e F: se respondeu aos questionários; G: } \\
\text { se aceitou passar por avaliação. *Contabilizados apenas dados com } 5 \text { dias ou mais; "-“ participou da } \\
\text { etapa mas não teve dados passíveis de análise ou não quis ou não pode participar de determinado } \\
\text { protocolo. }\end{array}$} \\
\hline & $\begin{array}{l}\text { A- diário } \\
\text { de sono* }\end{array}$ & B- actímetro* & $\begin{array}{l}\text { C - temperatura } \\
\text { central }\end{array}$ & $\begin{array}{l}\text { D - temperatura } \\
\text { periférica }\end{array}$ & $\mathrm{E}-\mathrm{QHS}$ & $\begin{array}{l}\mathrm{F} \text { - cronotipo } \\
\text { segundo } \mathrm{HO}\end{array}$ & $\begin{array}{l}\text { G - aval. } \\
\text { puberal }\end{array}$ \\
\hline LP94f2Ei & 14 & 6 & - & - & - & - & - \\
\hline AS94m1Ei & - & - & - & não incluída & sim & não incluído & sim \\
\hline AS94m2Ei & - & 20 & - & 3 & & $\operatorname{sim}$ & $\operatorname{sim}$ \\
\hline AS94m3Ei & 17 & 16 & 17 & 4 & $\operatorname{sim}$ & $\operatorname{sim}$ & $\operatorname{sim}$ \\
\hline MS94f2Ei & 15 & 20 & 13 & - & sim & sim & sim \\
\hline MS94f3Ei & 18 & 16 & 18 & 1 & sim & $\operatorname{sim}$ & sim \\
\hline MaS93f3Ei & 9 & 13 & - & 4 & $\operatorname{sim}$ & - & $\operatorname{sim}$ \\
\hline AB93f3Ei & 15 & 14 & - & 4 & sim & sim & sim \\
\hline AL92m1Ei & - & 9 & - & não incluída & $\operatorname{sim}$ & & - \\
\hline AL92m2Ei & 17 & 21 & 15 & 3 & não incluso & $\operatorname{sim}$ & - \\
\hline AL92m3Ei & 17 & 16 & 17 & 4 & sim & sim & sim \\
\hline Esa92m2iE & 6 & - & 6 & 3 & sim & $\operatorname{sim}$ & $\operatorname{sim}$ \\
\hline Esa92m3Ei & 13 & 9 & 14 & 3 & $\operatorname{sim}$ & $\operatorname{sim}$ & sim \\
\hline MvS92f1Ep & 10 & 7 & 10 & não incluída & $\operatorname{sim}$ & não incluído & $\operatorname{sim}$ \\
\hline MvS92f2Ep & 14 & 12 & 14 & 3 & não incluso & $\operatorname{sim}$ & $\operatorname{sim}$ \\
\hline MvS92f3Ep & 16 & 13 & 16 & 3 & $\operatorname{sim}$ & $\operatorname{sim}$ & sim \\
\hline MA91m1Ep & 6 & 6 & - & não incluída & sim & não incluído & - \\
\hline MA91m2N & - & - & - & 2 & não incluso & $\operatorname{sim}$ & - \\
\hline AS91m1N & 6 & - & 4 & não incluída & $\operatorname{sim}$ & não incluído & $\operatorname{sim}$ \\
\hline AS91m2N & 14 & - & 14 & - & não incluso & $\operatorname{sim}$ & - \\
\hline GE91m1N & - & 5 & - & não incluída & sim & não incluído & $\operatorname{sim}$ \\
\hline GE91m2N & 5 & 9 & 5 & 3 & não incluso & $\operatorname{sim}$ & - \\
\hline GE91m3N & 17 & 16 & 17 & 3 & $\operatorname{sim}$ & sim & sim \\
\hline
\end{tabular}




\begin{tabular}{|c|c|c|c|c|c|c|c|}
\hline \multirow[t]{2}{*}{$\begin{array}{l}\text { participante } \\
\text { por etapa: }\end{array}$} & \multicolumn{7}{|c|}{$\begin{array}{l}\text { A, B, C e D: número de dias com dados passíveis de análise; E e F: se respondeu aos questionários; G: } \\
\text { se aceitou passar por avaliação. *Contabilizados apenas dados com } 5 \text { dias ou mais; "-“ participou da } \\
\text { etapa mas não teve dados passíveis de análise ou não quis ou não pode participar de determinado } \\
\text { protocolo. }\end{array}$} \\
\hline & $\begin{array}{l}\text { A- diário } \\
\text { de } \text { sono* }\end{array}$ & B- actímetro* & $\begin{array}{l}\text { C - temperatura } \\
\text { central }\end{array}$ & $\begin{array}{l}\text { D - temperatura } \\
\text { periférica }\end{array}$ & E - QHS & $\begin{array}{l}\mathrm{F}-\text { cronotipo } \\
\text { segundo } \mathrm{HO}\end{array}$ & $\begin{array}{l}\text { G - aval. } \\
\text { puberal }\end{array}$ \\
\hline FS90f1Ep & 10 & 5 & 7 & não incluída & sim & não incluído & $\operatorname{sim}$ \\
\hline FS90f2N & - & 8 & - & - & não incluso & - & - \\
\hline Esi90m1Ep & - & - & - & não incluída & $\operatorname{sim}$ & não incluído & - \\
\hline Esi90m2N & 16 & 14 & 14 & 4 & não incluso & $\operatorname{sim}$ & $\operatorname{sim}$ \\
\hline Esi90m3N & 13 & 14 & 10 & 4 & $\operatorname{sim}$ & $\operatorname{sim}$ & $\operatorname{sim}$ \\
\hline AdS90m1Ei & - & 8 & - & não incluída & sim & não incluído & sim \\
\hline AdS90m2Ei & - & 18 & - & - & não incluso & $\operatorname{sim}$ & $\operatorname{sim}$ \\
\hline AdS90m3Ei & 10 & 16 & 8 & 4 & $\operatorname{sim}$ & $\operatorname{sim}$ & $\operatorname{sim}$ \\
\hline EL90m1N & 10 & 8 & 9 & não incluída & sim & $\operatorname{sim}$ & - \\
\hline EL90m2N & - & 12 & - & 3 & não incluso & - & - \\
\hline EL90m3N & 14 & 15 & 14 & 3 & $\operatorname{sim}$ & $\operatorname{sim}$ & - \\
\hline VB89m1Ei & 10 & - & 6 & não incluída & sim & não incluído & - \\
\hline CS88m3N & 5 & 13 & 5 & 4 & sim & $\operatorname{sim}$ & - \\
\hline JS87m2N & 8 & 5 & 6 & 3 & $\operatorname{sim}$ & $\operatorname{sim}$ & - \\
\hline JS87m3N & 11 & - & 3 & - & $\operatorname{sim}$ & $\operatorname{sim}$ & - \\
\hline AT86m2N & 15 & 15 & 14 & 3 & sim & $\operatorname{sim}$ & - \\
\hline AT86m3N & 16 & 15 & 16 & 3 & sim & $\operatorname{sim}$ & - \\
\hline FaS86m3N & 16 & 13 & - & 2 & $\operatorname{sim}$ & $\operatorname{sim}$ & - \\
\hline SB86f2N & - & 10 & - & 2 & - & $\operatorname{sim}$ & - \\
\hline
\end{tabular}




\subsection{Questionários de Hábitos de Sono}

Consideramos os resultados da primeira aplicação do Questionário de Hábitos de Sono, tendo em vista que nem todos os participantes tiveram uma segunda aplicação e houve coerência nas respostas entre as duas aplicações, com flutuações maiores apenas no que tange ao número de pessoas em cada casa.

Podemos observar na figura 4 que grande parte dos participantes mora com muitas pessoas na mesma casa, em média 5,53 pessoas por residência, e compartilha o ambiente de dormir com toda a família, em média quatro pessoas por cômodo.

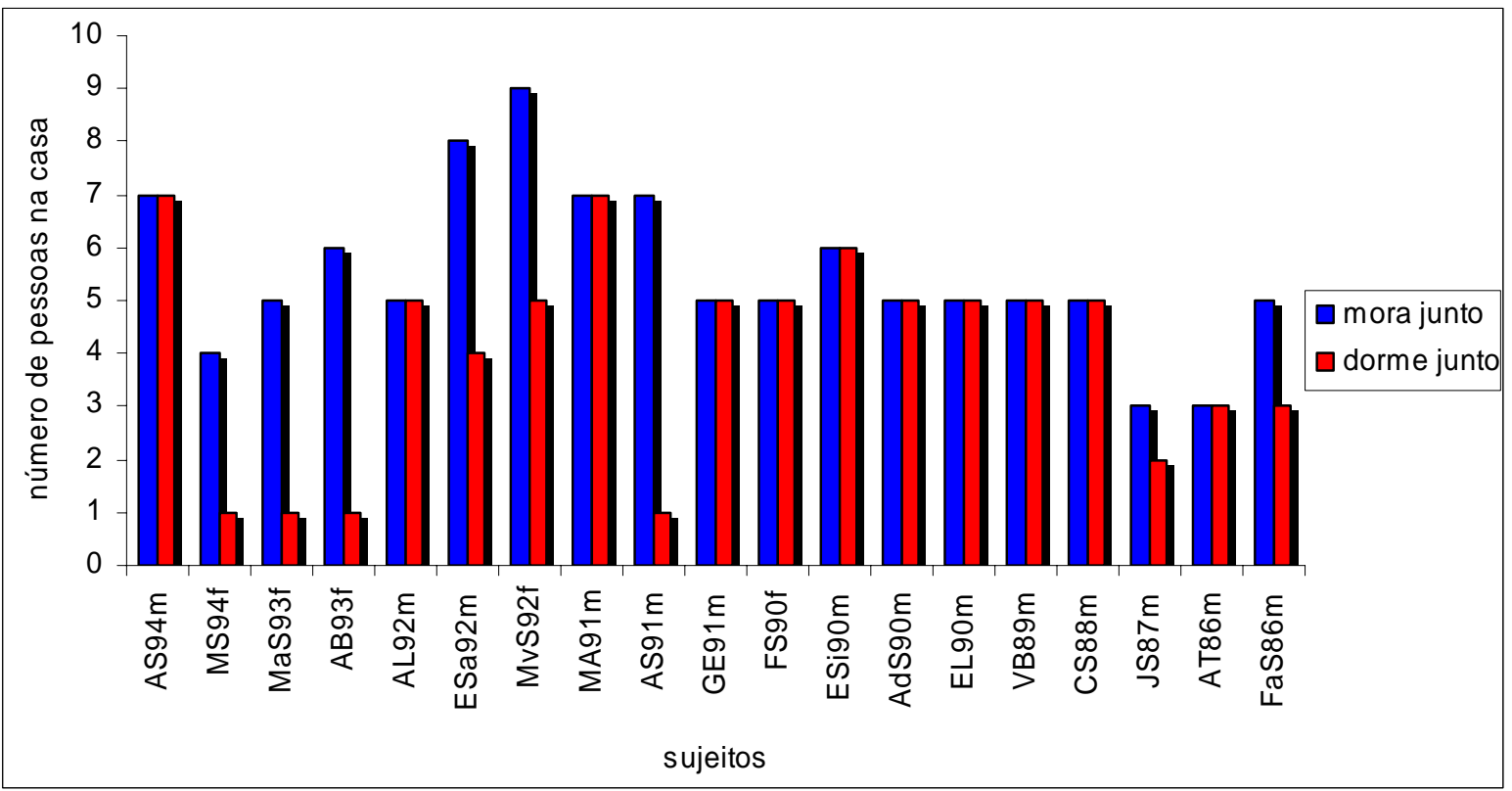

Figura 4: constituição familiar segundo Questionários de Hábitos de Sono, considerando a primeira aplicação para cada sujeito $(n=19)$.

A figura 5 exemplifica um fato muito comum do cotidiano dos Guarani-Mbya que já foi constatado por antropólogos, como citamos 
anteriormente: existe uma grande rotatividade de pessoas nas aldeias ou nas casas, tanto decorrente de casamentos como migrações. Apesar do número elevado de co-habitantes, apenas três participantes queixaram-se da presença de incômodos no dormitório - um queixou-se do ronco de um familiar e os outros dois reclamaram dos mosquitos.

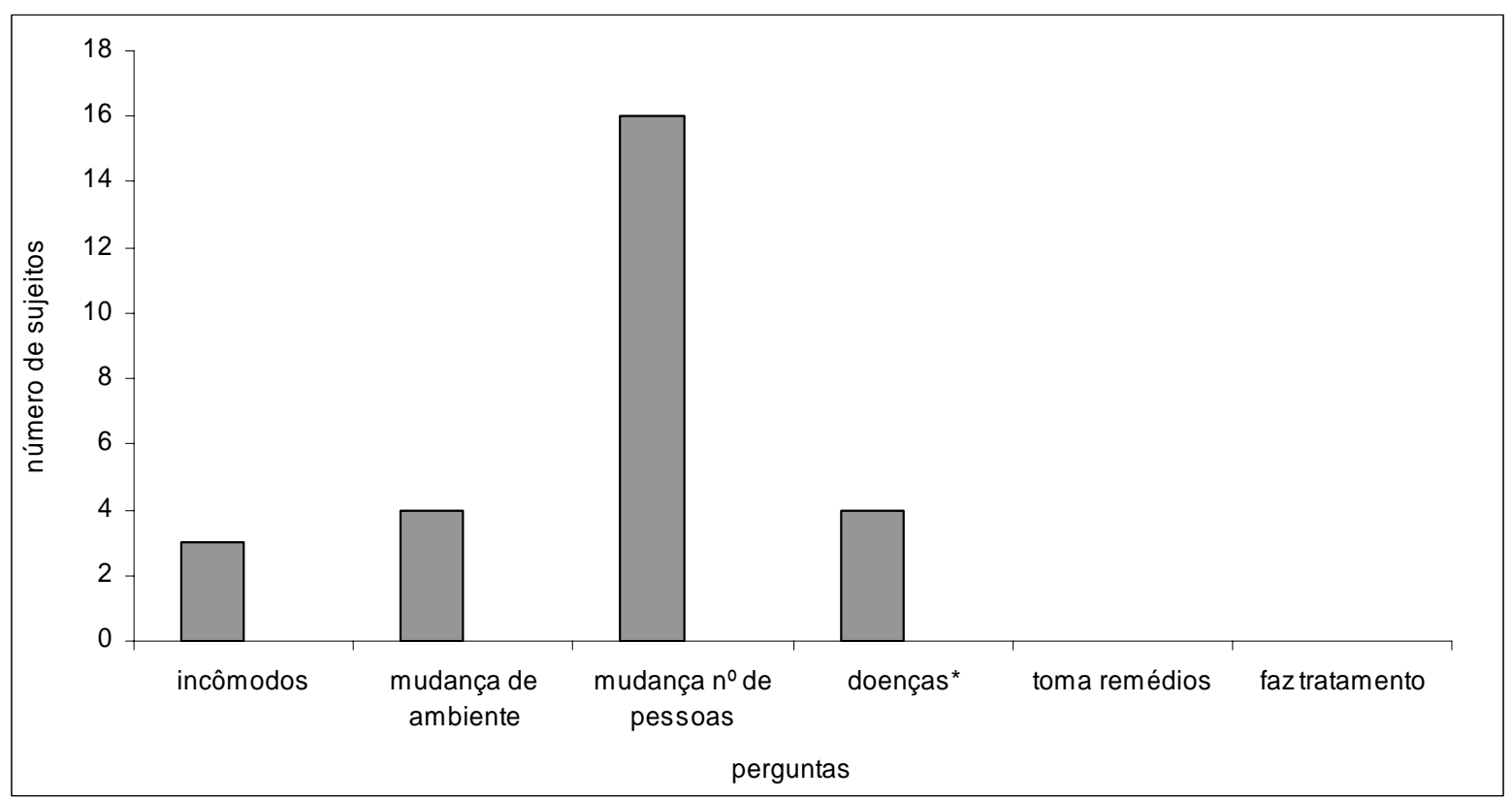

Figura 5: condições de moradia e de saúde segundo Questionários de Hábitos de Sono, considerando a primeira aplicação para cada sujeito $(n=19)$. *doenças presentes na primeira infância já com remissão de sintomas.

Não há relatos de consumo de bebidas estimulantes em grandes quantidades entre os sujeitos, os quais têm como hábito consumir café, principalmente aquele servido para a comunidade na escola pela manhã (figura 6). Conversando com a funcionária da FUNASA, senhora Íris Araújo Barbosa, soube quais adolescentes tinham o hábito de consumir bebidas alcoólicas e estes não foram incluídos na pesquisa. 


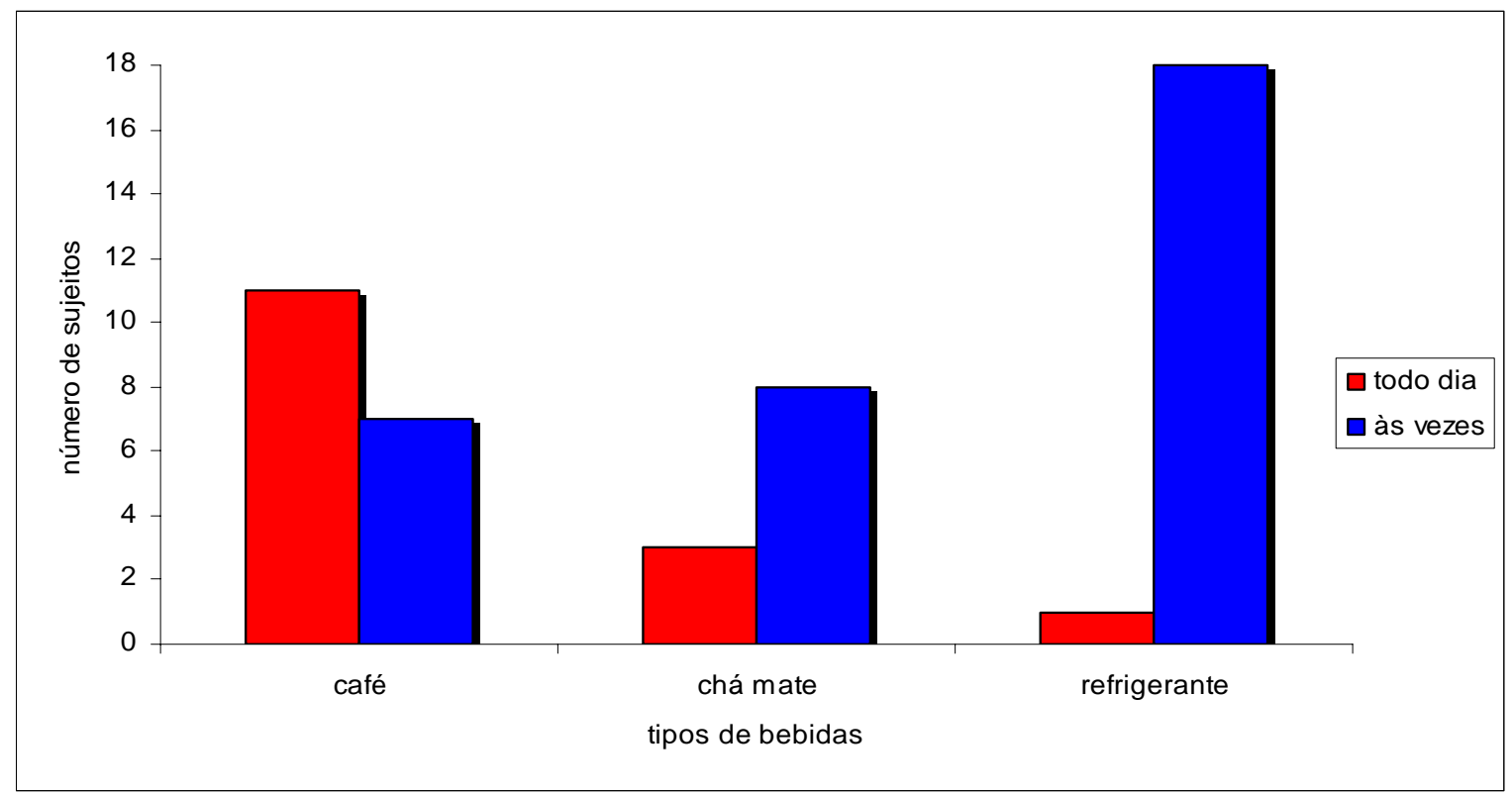

Figura 6: consumo de bebidas estimulantes segundo Questionários de Hábitos de Sono, considerando a primeira aplicação para cada sujeito $(n=19)$.

Em relação aos problemas de sono (figura 7), existe prevalência de queixas por dificuldades para iniciar o sono $(26,3 \%)$ e, quando há despertares noturnos, dificuldades em voltar a dormir $(36,8 \%)$, sem que haja relatos a respeito dos motivos atribuídos a tais dificuldades. Apesar disso, não há queixas de sonolência diurna persistentes. Alguns relataram sensação de sufocamento durante o sono, mas relacionaram o problema a resfriados ou gripes. 


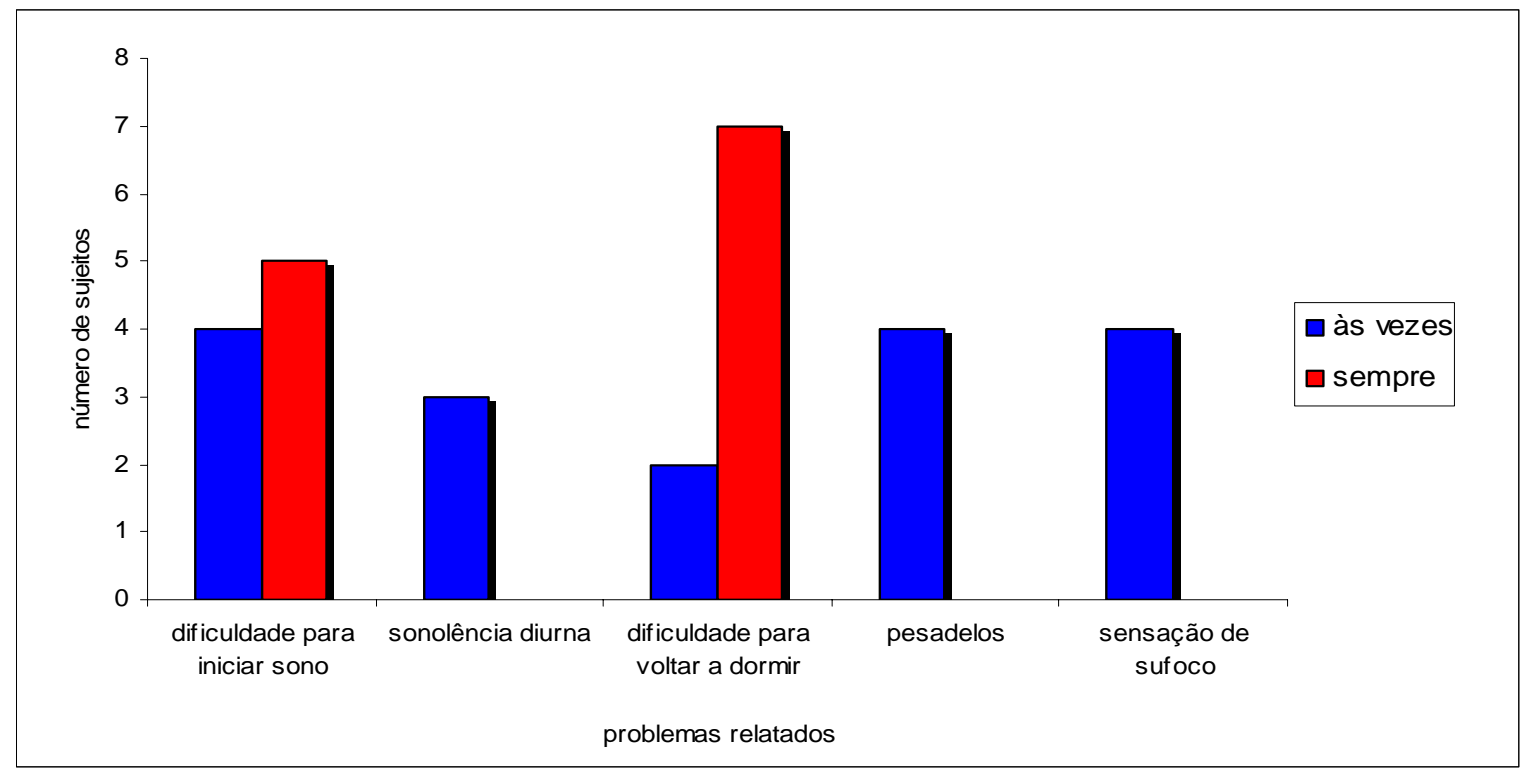

Figura 7: queixas de problemas de sono segundo Questionários de Hábitos de Sono, considerando a primeira aplicação para cada sujeito $(n=19)$.

É interessante notar que, na estimativa de início e fim de sono em questionário, há um deslocamento para horários mais tardios nos finais de semana em relação aos demais dias (figuras 8 e 9).

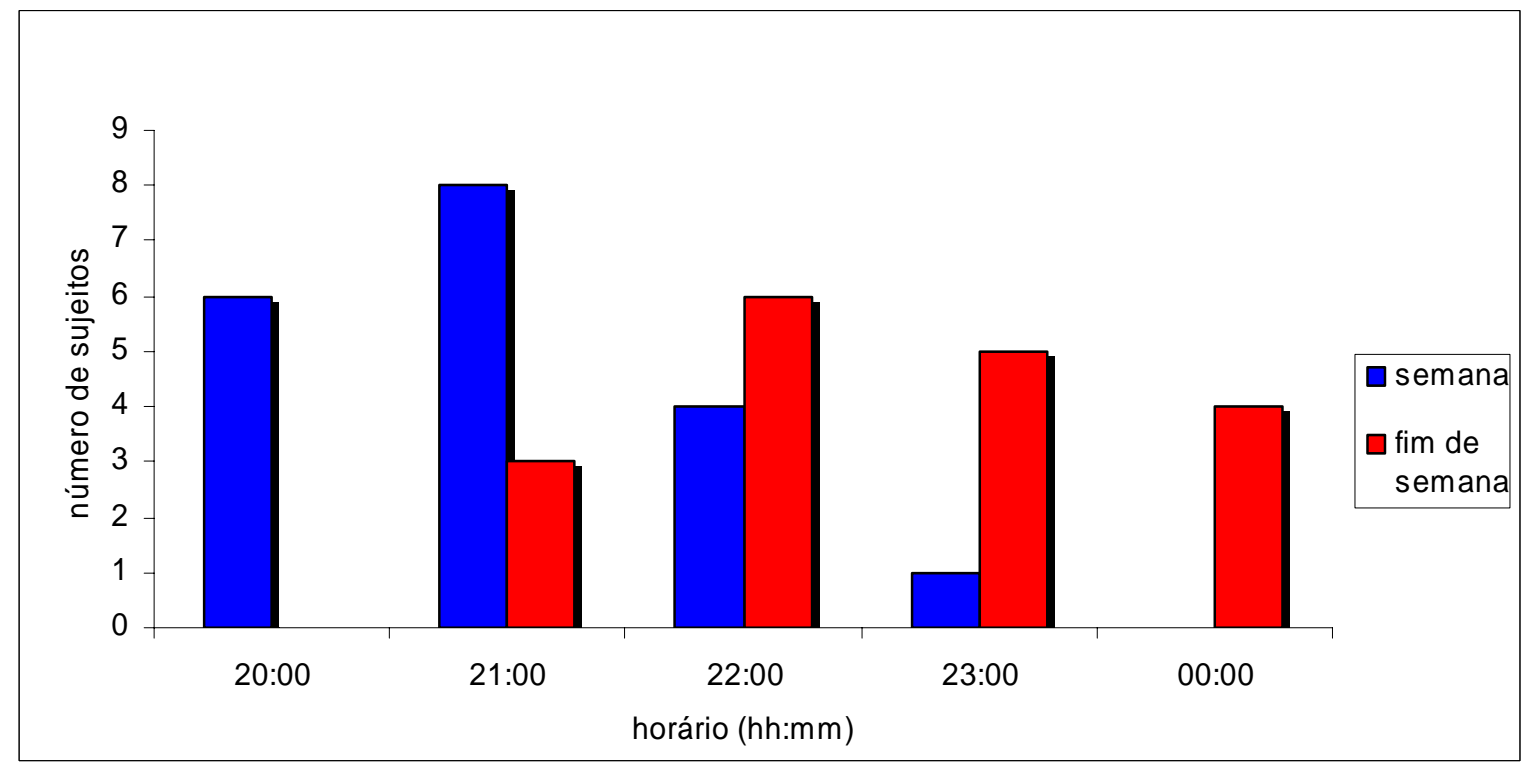

Figura 8: estimativas de início do sono durante a semana e nos finais de semana segundo Questionários de Hábitos de Sono, considerando a primeira aplicação para cada sujeito $(n=19)$. 


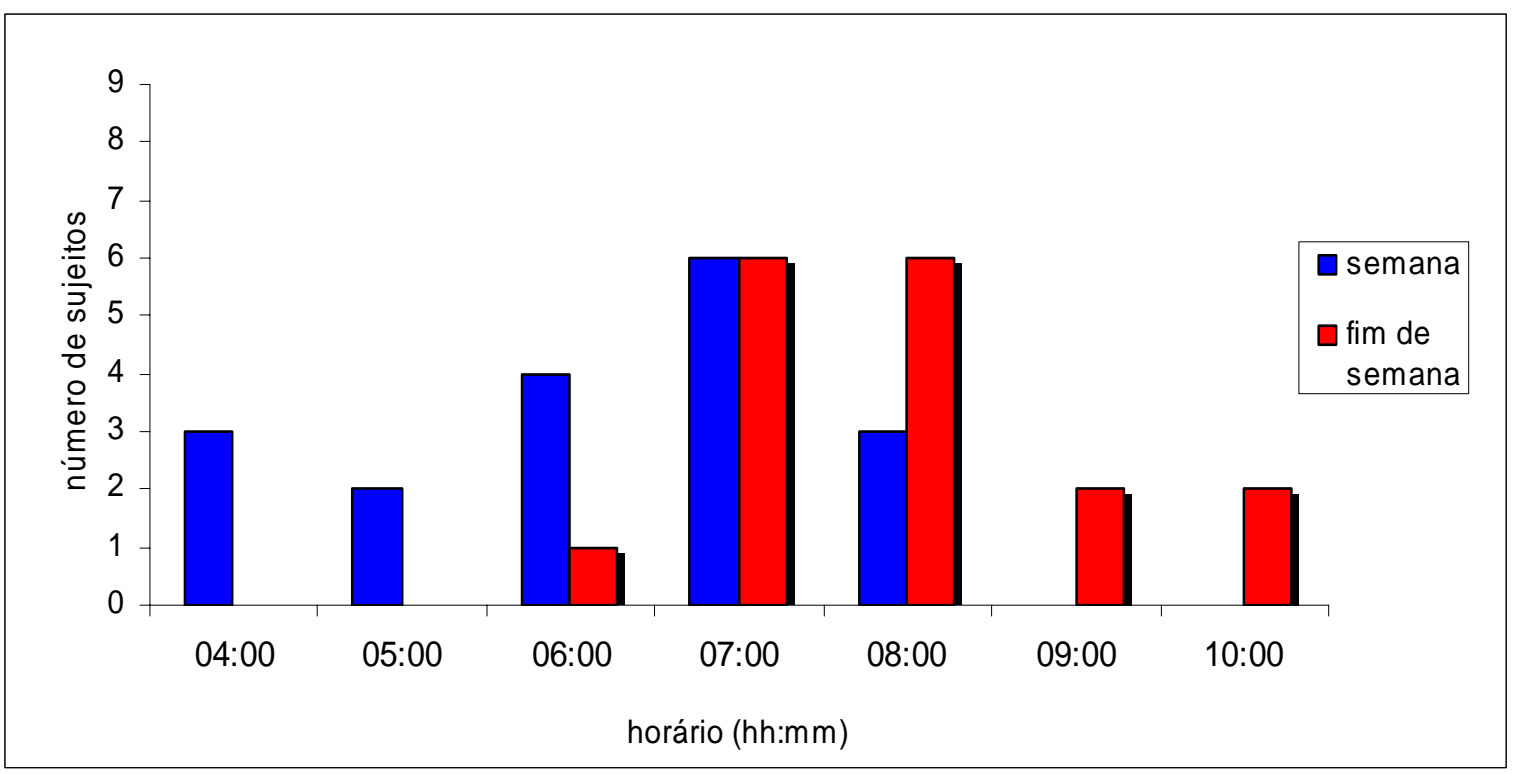

Figura 9: estimativa de fim do sono durante a semana e nos finais de semana segundo Questionários de Hábitos de Sono, considerando a primeira aplicação para cada sujeito $(\mathrm{n}=19)$.

Apenas um dos entrevistados relatou qual era o motivo para dormir e acordar mais tardiamente nos finais de semana. Este rapaz disse que dormia na casa da tia, que mora na cidade, em alguns finais de semana, nos quais sempre dormia muito mais tarde que o costume. Os demais participantes não sabiam ou não quiseram responder.

\subsection{Questionário de Matutinidade e Vespertinidade (Cronotipo)}

A distribuição da pontuação no Cronotipo nas duas aplicações não se correlaciona com a idade, como podemos observar na figura 10. Não houve correlação entre as pontuações obtidas na primeira aplicação, realizada em julho de 2004, com a segunda, realizada em fevereiro de 2005. 


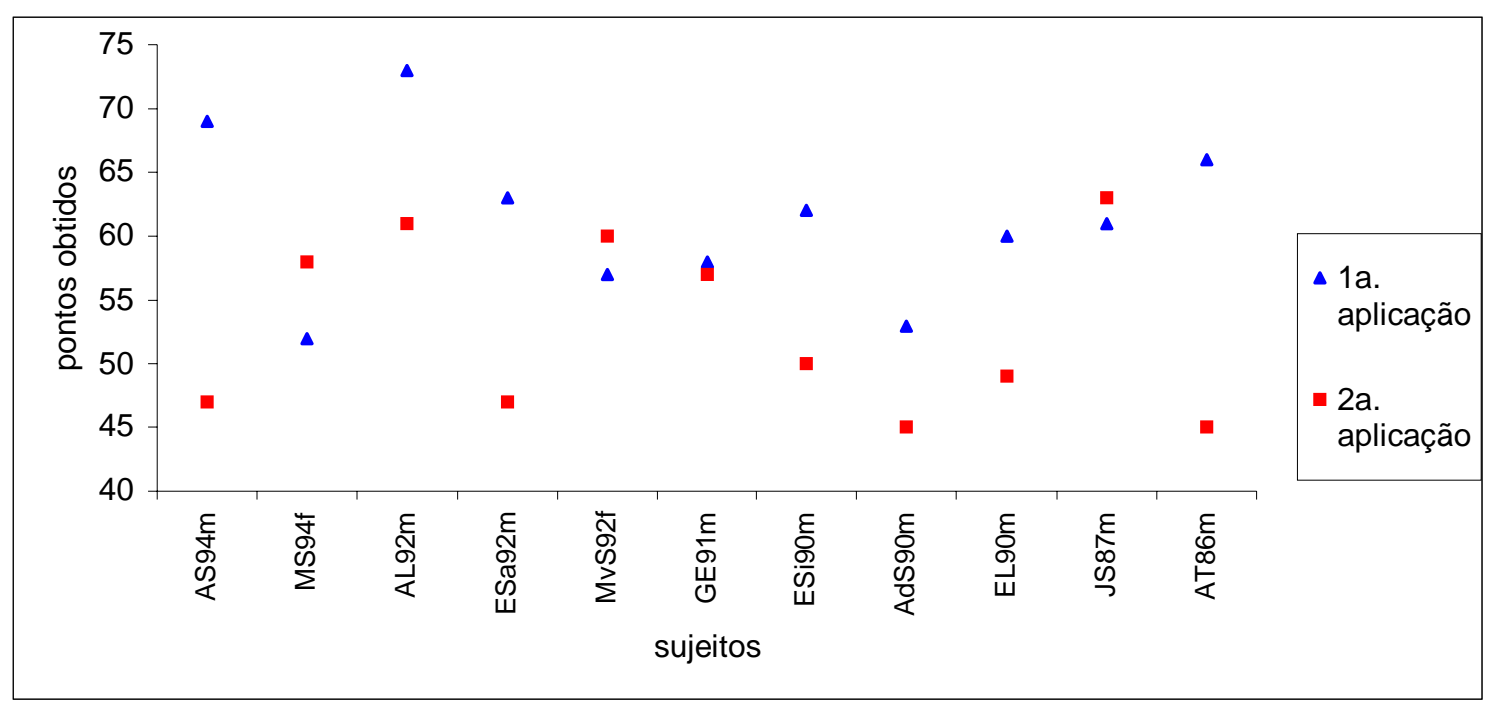

Figura 10: pontuações obtidas no questinário Cronotipo nas duas aplicações de cada sujeito. Sujeitos em ordem etária crescente $(n=11)$.

Houve diferença significativa (Wilcoxon pareado, $p=0,033$ ), entre as duas pontuações, indicando que os participantes obtiveram menores escores na segunda aplicação do que na primeira (figura 11), ou seja, seus resultados indicam maior vespertinidade na segunda aplicação.

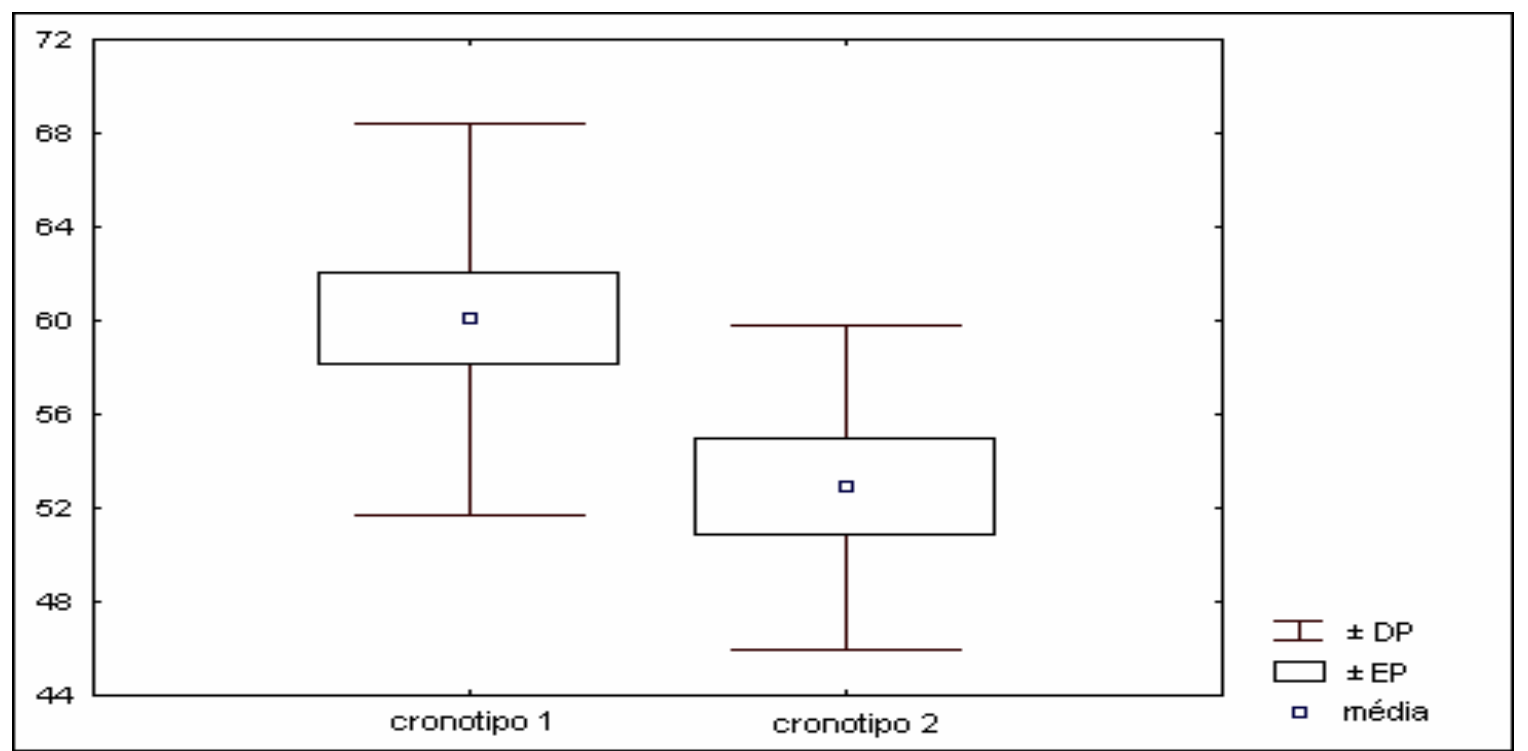

Figura 11: diferenças entre as pontuações obtidas no questinário Cronotipo nas duas aplicações de cada sujeito $(n=11)$. 
A pontuação no Cronotipo na primeira aplicação não foi correlacionada com os demais dados referentes à etapa em que foi feita a primeira aplicação. Houve correlação negativa apenas entre pontuação no Cronotipo na segunda aplicação e início de repouso durante a etapa em que o questionário foi aplicado (Spearman $r=-0,8 ; p=0,005$ ), indicando que, quanto menor a pontuação, mais tardio foi o início do repouso, ou seja, pontuações indicativas de maior vespertinidade correspondem a horários de início de repouso mais tardios.

\subsection{Estagiamento Puberal}

Não identificamos correlação significativa entre estágio puberal e pontuação no Cronotipo, horários de acrofase da temperatura oral, horários de acrofase da temperatura periférica, início, fim e duração de sono e de repouso em quaisquer etapas da pesquisa.

3.5. Ritmo de temperatura oral

Ritmos diários significativos de temperatura oral foram detectados em dados de seis participantes, entre os quais, dois exibiram ritmo em uma etapa, três em duas etapas e um nas três etapas. 


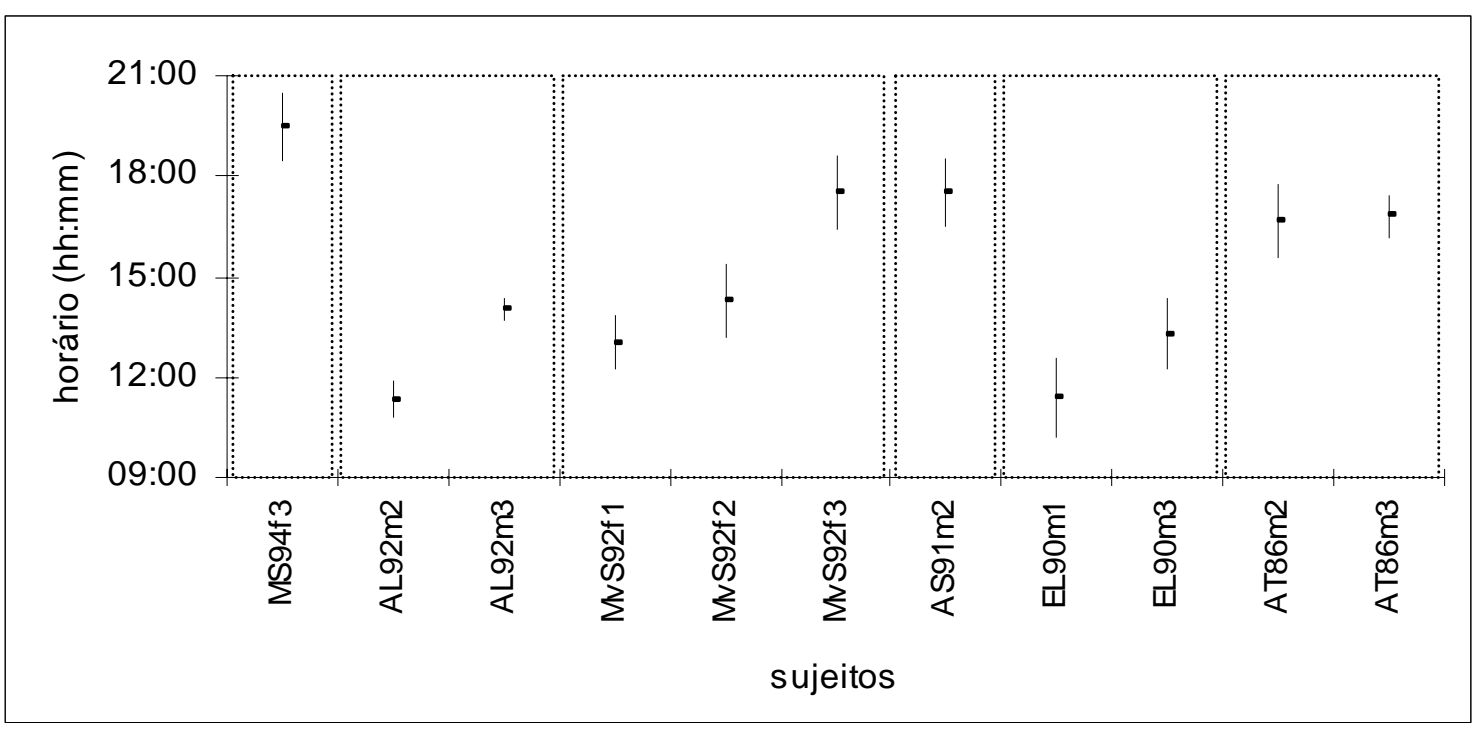

Figura 12: médias e erros padrão dos horários de acrofase da temperatura oral para todos os sujeitos, por idade cronológica e etapa, cujos ritmos de temperatura foram detectados pelo "Método Cosinor" $(n=6)$. Os retângulos pontilhados delimitam os resultados do mesmo sujeito nas diferentes etapas.

Como podemos observar na figura 12, não há correlação entre idade e horários de acrofase da temperatura oral. Há uma tendência para horários mais tardios de ocorrência da acrofase de temperatura oral para três sujeitos que tiveram seus ritmos detectados por mais de uma etapa (Wilcoxon pareado, $p=0,067)$. Apenas AT86m, que iniciou sua participação na pesquisa já com 17 anos e meio, não apresentou mudanças na acrofase de temperatura oral entre as etapas.

A acrofase de temperatura oral não se correlaciona significativamente com a idade, estágio puberal ou cronotipo dos indivíduos na etapa em que os dados de temperatura passíveis de análise foram coletados.

Em relação ao CVS, existe tendência à correlação positiva entre a acrofase de temperatura oral e o momento final do sono (Spearman, $r=0,6$, $p=0,035$ ), indicando que o fim do sono ocorreu mais tardiamente entre 
aqueles cujas acrofases de temperatura oral aconteciam em horários também mais tardios. Quanto ao ciclo atividade/repouso, houve correlação positiva entre acrofase de temperatura oral e início de repouso (Spearman, r=0,7, $p=0,028) ;$ correlação positiva entre tal acrofase e o fim do repouso (Spearman, $r=0,6, p=0,035)$ e tendência à correlação negativa entre a mesma e a duração do repouso (Spearman, $r=-0,6, p=0,059)$. Tais resultados indicam que, quanto mais tardia a ocorrência da acrofase de temperatura oral, mais tardio o início de repouso e o mesmo ocorre com o fim do repouso, sendo que a duração do repouso nesta situação tende a ser menor.

\subsection{Ritmo de temperatura periférica}

Houve detecção do ritmo de temperatura periférica de todos os participantes que usaram o termistor cutâneo por mais de dois dias. Não houve diferença significativa entre as etapas no que se refere aos horários de ocorrência da acrofase da temepratura periférica daqueles participantes que tiveram registros com ritmos observáveis nas etapas 2 e 3. Não há correlação entre os horários de ocorrência da acrofase de temperatura periférica e as idades dos participantes (figura 13). 


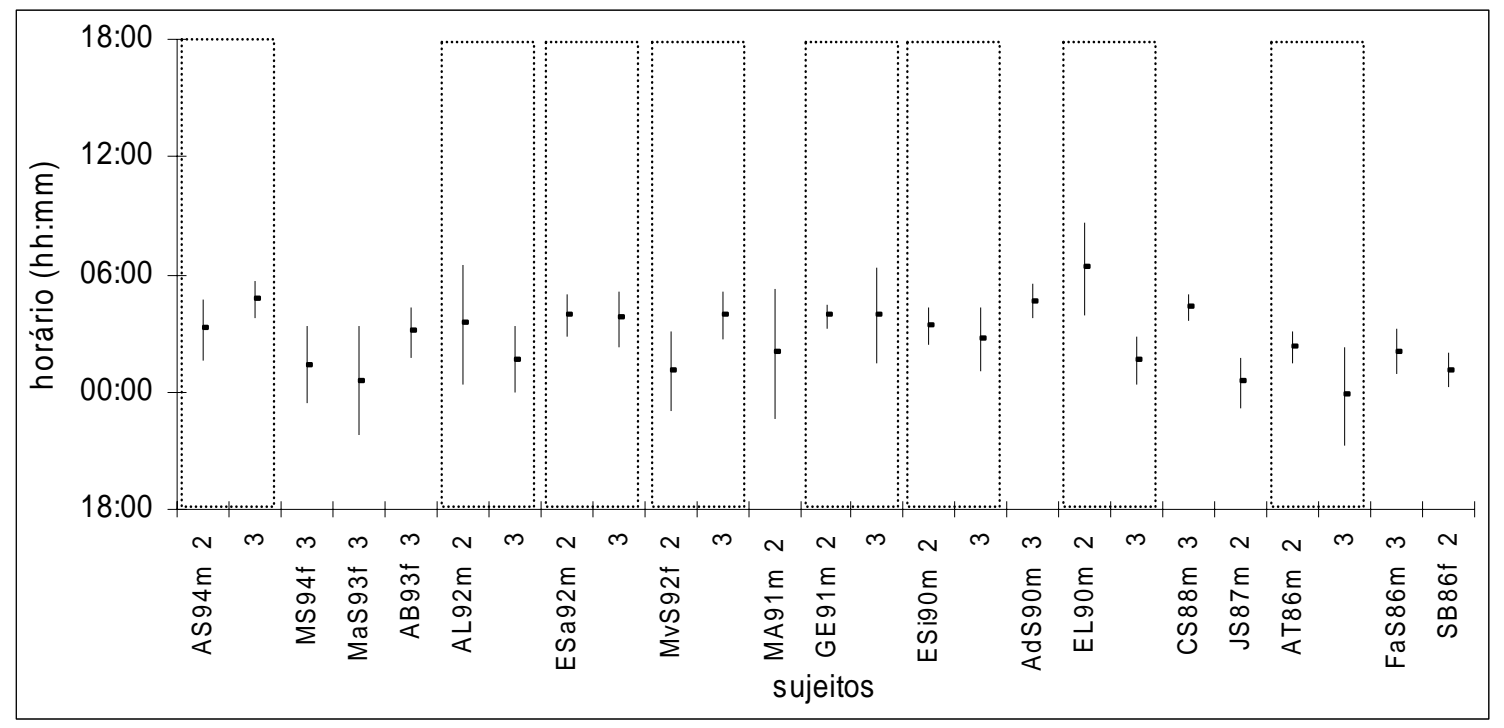

Figura 13: média e erros padrão dos horários de acrofase da temperatura periférica para todos os sujeitos, por idade cronológica e etapa, cujos ritmos de temperatura foram detectados pelo "Método Cosinor" $(n=17)$. Os retângulos pontilhados delimitam os resultados do mesmo sujeito nas diferentes etapas.

A acrofase da temperatura periférica ocorreu durante a madrugada para todos os participantes, nas duas etapas, sendo que o horário médio da acrofase foi às 02:45 horas ( \pm 94 minutos). Os horários de ocorrência da acrofase da temperatura periférica não se correlacionam com início, fim e duração de sono e de repouso, nem mesmo houve correlação da variável em questão com a acrofase da temperatura oral, estágio puberal ou pontuação no questionário Cronotipo dos participantes. 


\subsection{Ciclo Vigília/Sono}

Os actogramas que representam as participações individuais dos sujeitos, no que diz respeito ao preenchimento de diários de sono, estão no anexo $\mathrm{H}$. As representações gráficas dos horários médios de início, fim e duração de sono de cada sujeito, nas três etapas, estão dispostas abaixo (figuras 14, 16 e 18), assim como os valores médios e desvios padrão das mesmas variáveis para aqueles sujeitos que estiveram em, pelo menos, duas etapas (figuras 15, 17 e 19).

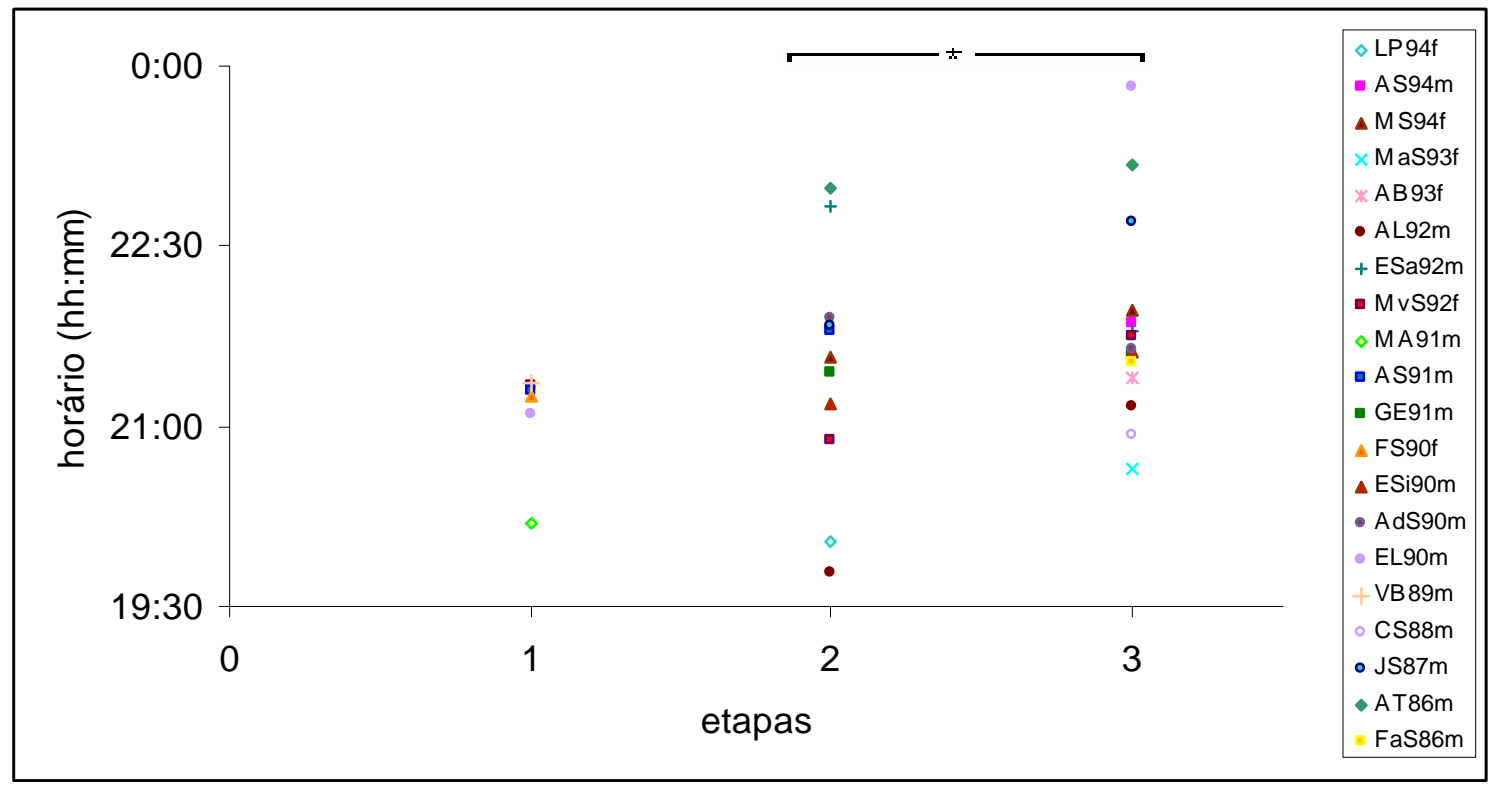

Figura 14: horários médios de início de sono, individuais, por etapa $(n=20)$. 0 asterisco indica diferenças significativas entre etapas. 


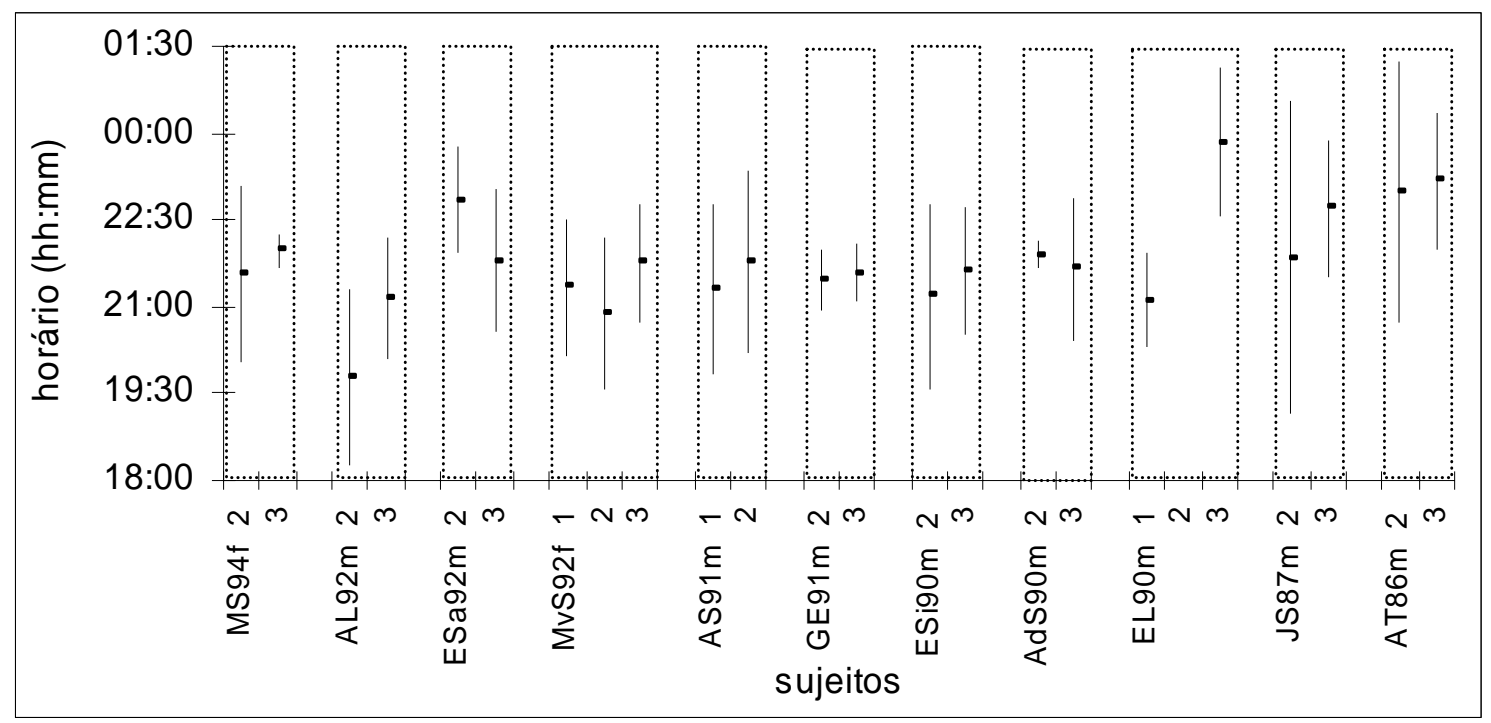

Figura 15: médias e desvios padrão dos horários de início de sono para todos os sujeitos que tiveram mais de uma etapa $(n=11)$. Os retângulos pontilhados delimitam os resultados do mesmo sujeito nas diferentes etapas.

Como podemos observar na figura 15, há variações no horário de dormir de cada sujeito entre as etapas e, quando consideramos os horários individuais, apenas os indivíduos com idade acima de 15 anos e meio tiveram horários de fim de sono mais tardios que os demais. Analisando este conjunto de variações, encontramos diferença significativa entre o início de sono durante a segunda e a terceira etapas, indicativa de horários mais tardios na terceira etapa (Teste $t$ de Student para amostras dependentes, $p=0,002$ ), conforme verificamos na figura 14. 


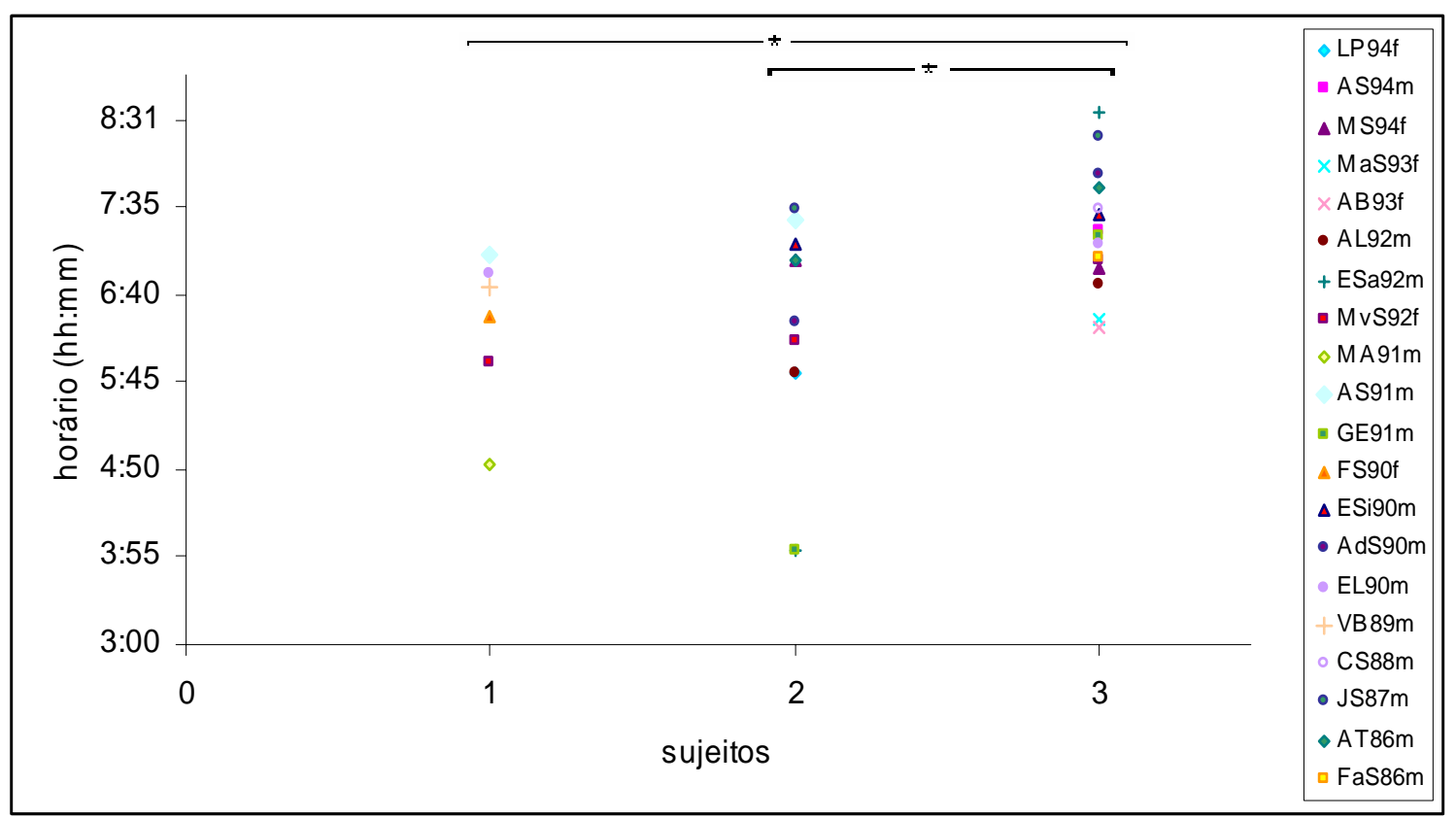

Figura 16: horários médios de fim de sono, individuais, por etapa $(n=20)$. Os asteriscos indicam diferenças significativas.

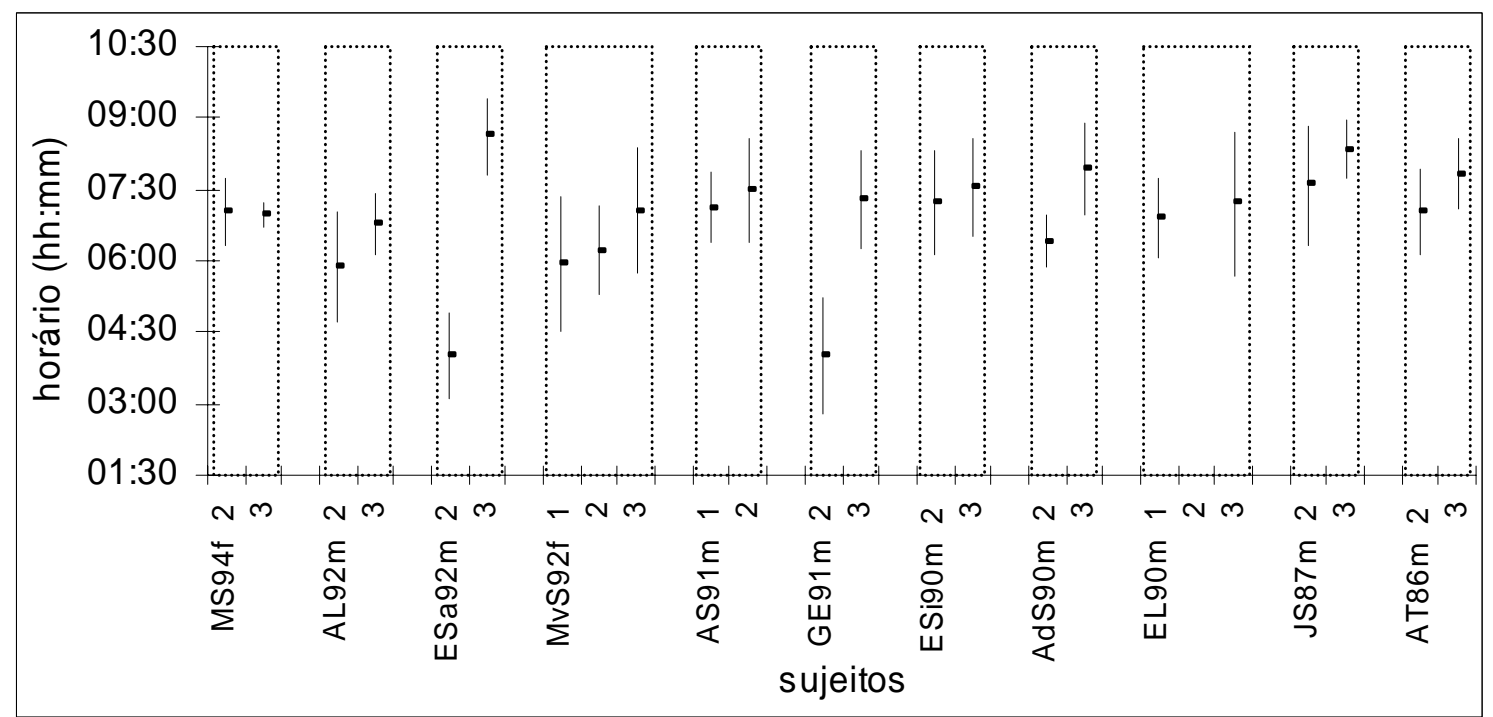

Figura 17: médias e desvios padrão dos horários de fim de sono para todos os sujeitos que tiveram mais de uma etapa $(n=11)$. Os retângulos pontilhados delimitam os resultados do mesmo sujeito nas diferentes etapas.

Na figura 16 observamos que os horários de fim de sono foram mais tardios na etapa 3 do que na etapa 2 (Teste $t$ de Student para amostras dependentes, $p=0,000)$. Os horários de fim de sono também foram mais 
tardios na etapa 3 do que na etapa 1 (Teste ANOVA de Friedman, $p=0,029$ ).

Não há correlação entre idade dos participantes e os horários de fim de sono (figura 17).

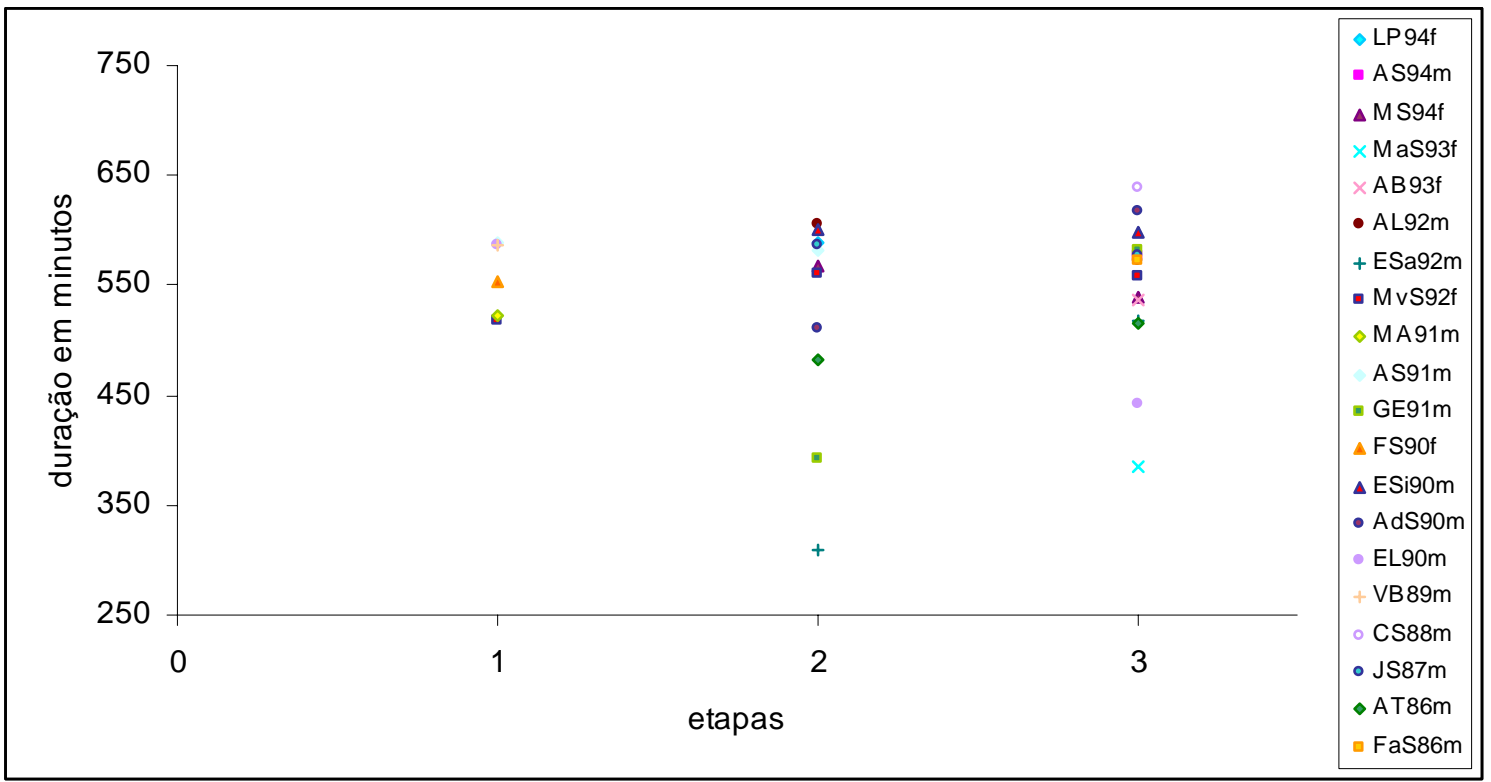

Figura 18: durações médias do sono, individuais, por etapa $(n=20)$.

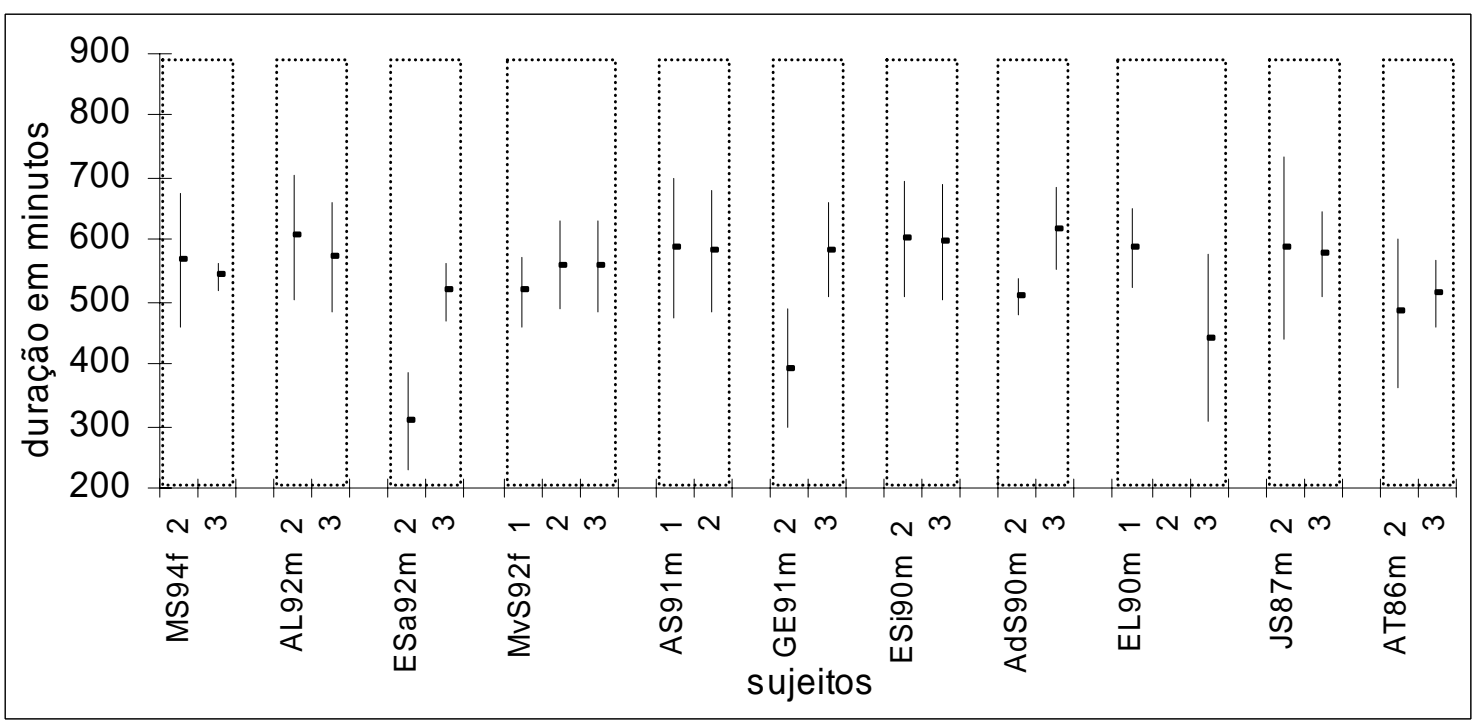

Figura 19: médias e desvios padrão da duração de sono para todos os sujeitos que tiveram mais de uma etapa $(n=11)$. Os retângulos pontilhados delimitam os resultados do mesmo sujeito nas diferentes etapas. 
Não há correlação entre idade cronológica e duração do sono (figura 19), assim como não há diferença significativa entre as durações do sono nas etapas (figura 18).

\begin{tabular}{llll}
\hline $\begin{array}{l}\text { Tabela 2: correlações entre horário de início, fim e duração de sono em cada } \\
\text { etapa. }\end{array}$ & Etapa 1 & Etapa 2 & Etapa 3 \\
& $($ Spearman $r)$ & (Pearson $r)$ & (Pearson r) \\
\hline início e fim de sono & $r=0,7$ & n.s. & $r=0,6$ \\
\hline início e duração de sono & n.s. & $r=-0,8$ & n.s. \\
\hline Fim e duração de sono & n.s. & n.s. & n.s. \\
\hline
\end{tabular}

n.s. não significativo para $p<0,05$

$\mathrm{Na}$ tabela 2 verificamos que existe correlação positiva entre os horários de início e fim de sono na etapa 1 (Spearman, $r=0,7, p=0,000$ ), indicando que, quanto mais tardio o início do sono, mais tardio também é o fim de sono. Na etapa 2, o início e a duração do sono correlacionam-se negativamente (Pearson, $r=-0,8, p<0,5$ ), ou seja, horários de início de sono mais tardios correspondem a menor duração do sono. Uma tendência à correlação positiva entre horários de início e fim de sono foi encontrada na etapa 3 (Pearson, $r=0,6, p<0,5$ ), indicando que, com horários mais tardios de início de sono, havia uma tendência a acordar mais tardiamente.

Dividindo o grupo entre estudantes e não estudantes, nas etapas 2 e 3 (tabela 3) observamos que há diferença significativa entre as etapas no que diz respeito aos horários de início do sono do grupo que estuda (Teste $t$ de Student para amostras dependentes, $p=0,001$ ), indicando que os horários de 
início de sono foram mais tardios na terceira etapa entre os estudantes. Há diferença significativa entre as etapas nos dois grupos nos horários de fim do sono (Teste $t$ de Student para amostras dependentes, $p=0,000$ para os dois grupos), também indicativa de horários mais tardios na última etapa. Não houve diferença na duração do sono entre as etapas nos dois grupos.

\begin{tabular}{lccc}
\hline $\begin{array}{l}\text { Tabela 3: horários médios de início e fim de sono e duração de sono dos } \\
\text { participantes que estudam e que não estudam, nas etapas } 2 \text { e 3. }\end{array}$ \\
\hline & Início do sono & Fim do sono & Duração do sono \\
\hline Etapa 2 - estuda & $20: 53 \mathrm{~h}( \pm 90 \mathrm{~min}) \star$ & $06: 26 \mathrm{~h}( \pm 49 \mathrm{~min})^{\star}$ & $573 \mathrm{~min}( \pm 94 \mathrm{~min})$ \\
\hline Etapa 3 - estuda & $21: 37 \mathrm{~h}( \pm 56 \mathrm{~min})$ & $07: 05 \mathrm{~h}( \pm 56 \mathrm{~min})$ & $566 \mathrm{~min}( \pm 71 \mathrm{~min})$ \\
\hline Etapa 2 - não estuda & $21: 56 \mathrm{~h}( \pm 126 \mathrm{~min})$ & $06: 51 \mathrm{~h}( \pm 89 \mathrm{~min})^{\star}$ & $535 \mathrm{~min}( \pm 132 \mathrm{~min})$ \\
\hline Etapa 3 - não estuda & $22: 15 \mathrm{~h}( \pm 72 \mathrm{~min})$ & $07: 41 \mathrm{~h}( \pm 57 \mathrm{~min})$ & $565 \mathrm{~min}( \pm 78 \mathrm{~min})$ \\
\hline
\end{tabular}

Os asteriscos $\left(^{*}\right)$ indicam diferenças significativas entre as etapas do mesmo grupo (Teste $t$ de Student para amostras dependentes).

Quando comparamos, em cada etapa, os horários de início e fim de sono, assim como a duração de sono entre semana - segundas e terçasfeiras, e final de semana - sábados e domingos (tabela 4), encontramos diferenças significativas nos horários de fim de sono na segunda etapa (Teste $t$ de Student para amostras dependentes, $p=0,005)$, indicando horários mais tardios durante a semana. Na terceira etapa, os horários de início de sono foram mais tardios durante o final de semana (Teste $t$ de Student para amostras dependentes, $p=0,009)$ e houve duração menor de sono, quando comparado com a semana (Teste $t$ de Student para amostras dependentes, $p=0,047)$. 
Tabela 4: horários médios de início e fim de sono e duração de sono, nos dias da semana e nos finais de semana, nas três etapas.

\begin{tabular}{llll}
\hline & Início de sono & Fim de sono & Duração de sono \\
\hline Etapa 1 - semana & $21: 20 \mathrm{~h}( \pm 72 \mathrm{~min})$ & $07: 14 \mathrm{~h}( \pm 72 \mathrm{~min})$ & $575 \mathrm{~min}( \pm 72 \mathrm{~min})$ \\
\hline Etapa 1 - fim de semana & $21: 08 \mathrm{~h}( \pm 51 \mathrm{~min})$ & $06: 44 \mathrm{~h}( \pm 45 \mathrm{~min})$ & $584 \mathrm{~min}( \pm 80 \mathrm{~min})$ \\
\hline Etapa 2 - semana & $21: 25 \mathrm{~h}( \pm 111 \mathrm{~min})$ & $06: 59 \mathrm{~h}( \pm 60 \mathrm{~min})^{\star}$ & $574 \mathrm{~min}( \pm 105 \mathrm{~min})$ \\
\hline Etapa 2 - fim de semana & $21: 26 \mathrm{~h}( \pm 108 \mathrm{~min})$ & $06: 18 \mathrm{~h}( \pm 84 \mathrm{~min})$ & $532 \mathrm{~min}( \pm 111 \mathrm{~min})$ \\
\hline Etapa 3 - semana & $21: 44 \mathrm{~h}( \pm 69 \mathrm{~min})^{\star}$ & $07: 19 \mathrm{~h}( \pm 62 \mathrm{~min})$ & $570 \mathrm{~min}( \pm 91 \mathrm{~min})^{\star}$ \\
\hline Etapa 3 - fim de semana & $22: 19 \mathrm{~h}( \pm 74 \mathrm{~min})$ & $07: 21 \mathrm{~h}( \pm 65 \mathrm{~min})$ & $537 \mathrm{~min}( \pm 93 \mathrm{~min})$ \\
\hline
\end{tabular}

Os asteriscos $\left(^{*}\right)$ indicam diferenças significativas entre semana e fim de semana na mesma etapa (Teste $t$ de Student para amostras dependentes).

Considerando apenas as segundas e terças-feiras, não encontramos diferenças significativas entre as etapas. Quando comparamos os sábados e domingos entre as três etapas, observamos diferenças significativas entre o início de sono nos finais de semana da primeira etapa e o início de sono nos finais de semana da terceira etapa (Teste ANOVA de Friedman, $p=0,046$ ), com horários mais tardios na última. Existe também diferença significativa entre a segunda e a terceira etapas nos horários de despertar nos finais de semana (Teste $t$ de Student para amostras dependentes, $p=0,000$ ), novamente com horários mais tardios na última etapa.

Nas pesquisas disponíveis na literatura sobre o padrão de restriçãoextensão do sono de adolescentes são consideradas as diferenças entre os horários de sono nos dias letivos e nos finais de semana de estudantes. A tabela 5 refere-se à distribuição dos horários médios de início, fim e duração 
de sono nas etapas 2 e 3 dos estudantes indígenas, separando os dias letivos dos finais de semana.

Tabela 5: horários médios de início e fim de sono e duração de sono, nos dias da semana e nos finais de semana, dos estudantes, nas etapas 2 e 3.

\begin{tabular}{llll}
\hline & Início de sono & Fim de sono & Duração de sono \\
\hline Etapa 2 - semana & $21: 34 \mathrm{~h}( \pm 67 \mathrm{~min})$ & $06: 51 \mathrm{~h}( \pm 68 \mathrm{~min})$ & $577 \mathrm{~min}( \pm 77 \mathrm{~min})$ \\
\hline Etapa 2 - fim de semana & $20: 59 \mathrm{~h}( \pm 98 \mathrm{~min})$ & $06: 13 \mathrm{~h}( \pm 90 \mathrm{~min})$ & $554 \mathrm{~min}( \pm 123 \mathrm{~min})$ \\
\hline Etapa 3 - semana & $21: 57 \mathrm{~h}( \pm 51 \mathrm{~min}){ }^{\star}$ & $07: 21 \mathrm{~h}( \pm 67 \mathrm{~min})$ & $586 \mathrm{~min}( \pm 77 \mathrm{~min})^{\star}$ \\
\hline Etapa 3 - fim de semana & $22: 48 \mathrm{~h}( \pm 65 \mathrm{~min})$ & $07: 29 \mathrm{~h}( \pm 60 \mathrm{~min})$ & $548 \mathrm{~min}( \pm 84 \mathrm{~min})$ \\
\hline
\end{tabular}

Os asteriscos $\left(^{*}\right)$ indicam diferenças significativas entre semana e fim de semana na mesma etapa (Teste $t$ de Student para amostras dependentes).

Entre os estudantes, os horários de início de sono na terceira etapa foram mais tardios nos finais de semana do que nos dias letivos (Teste $t$ de Student para amostras dependentes, $p=0,005)$ e a duração do sono nos finais de semana foi menor do que durante a semana (Teste $t$ de Student para amostras dependentes, $p=0,021)$.

\subsection{Ciclo Atividade/Repouso}

Os actogramas que representam as participações individuais dos sujeitos, no que diz respeito ao uso do actímetro de punho, estão dispostos no anexo H. As representações gráficas dos horários médios de início, fim e duração de repouso de cada sujeito, nas três etapas, estão dispostas abaixo 
(figuras 20, 22 e 24), assim como as médias e desvios padrão daqueles participantes que estiveram em mais de uma etapa da pesquisa (21, 23 e 25).

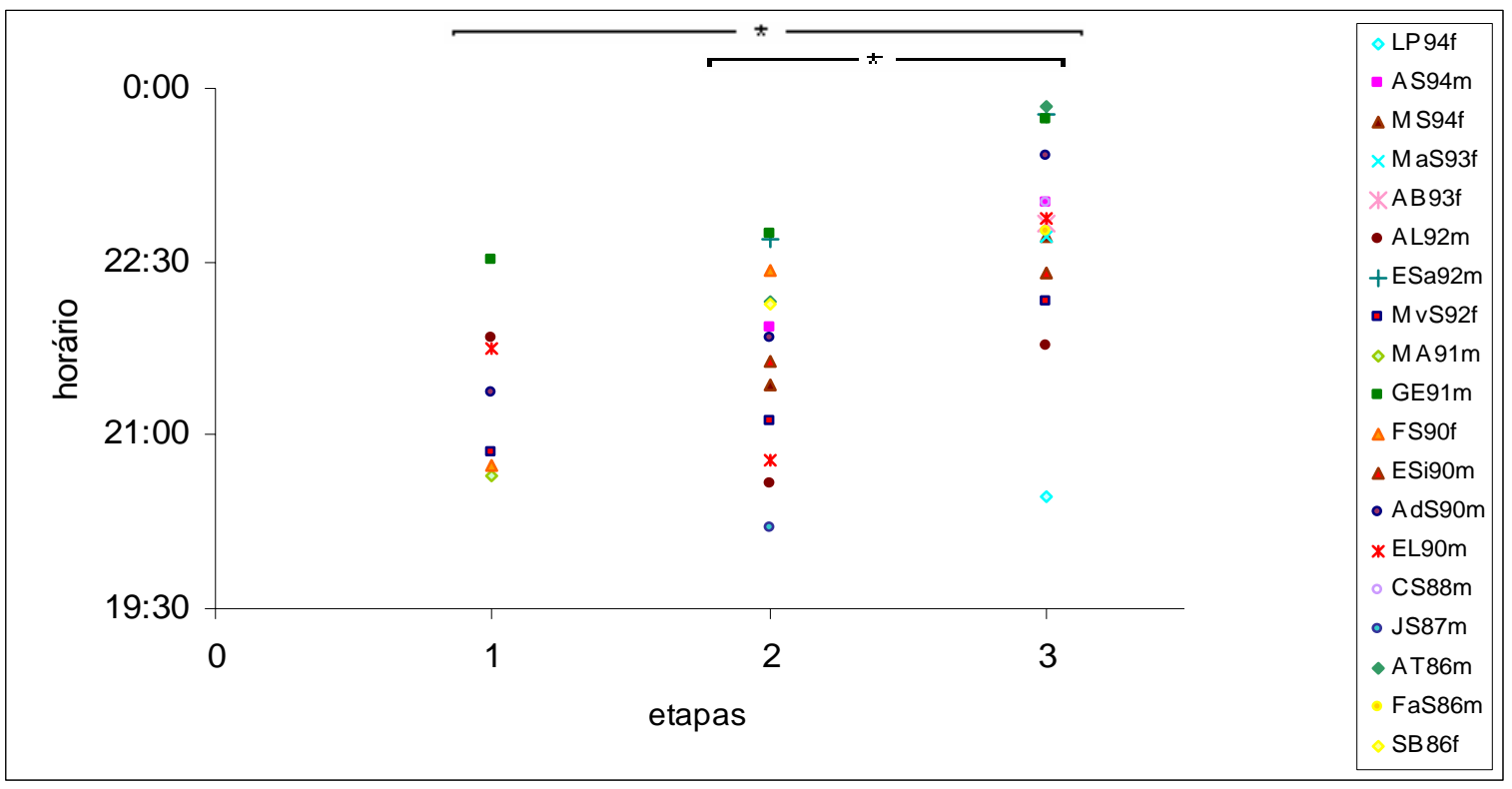

Figura 20: horários médios de início de repouso, individuais, por etapa $(n=19)$. Os asteriscos indicam diferenças significativas.

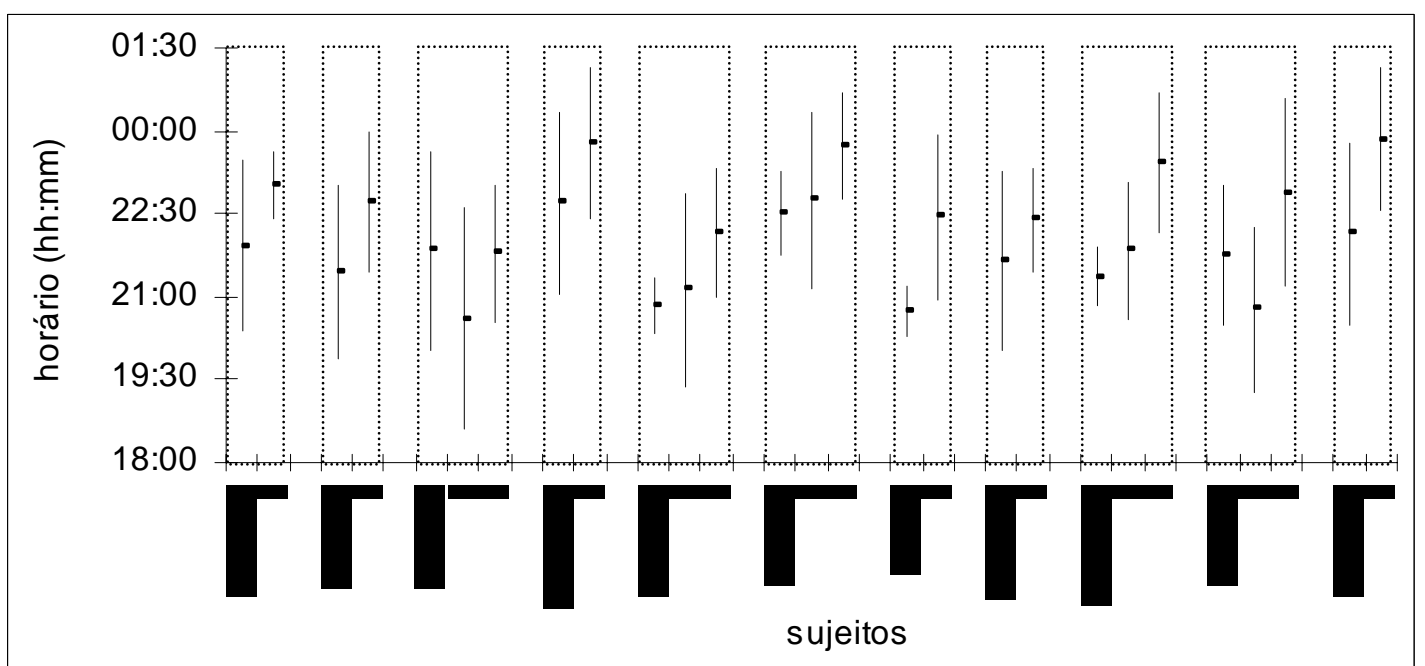

Figura 21: médias e desvios padrão do início do repouso para todos os sujeitos que tiveram mais de uma etapa $(n=11)$. Os retângulos pontilhados delimitam os resultados do mesmo sujeito nas diferentes etapas. 
Na figura 21 observamos que não existe uma tendência de variação vinculada à idade de início de repouso entre os participantes, contudo há variações no horário de início de repouso entre as etapas, quando consideramos os horários individuais. Há diferença significativa no horário de início do repouso entre a primeira e a terceira etapa (Teste $t$ de Student para amostras dependentes, $p=0,008$ ) e entre a segunda e a terceira etapa (Teste $t$ de Student para amostras dependentes, $\mathrm{p}=0,000$ ), sempre indicando que 0 início do repouso foi mais tardio na terceira etapa do que nas demais (figura 20).

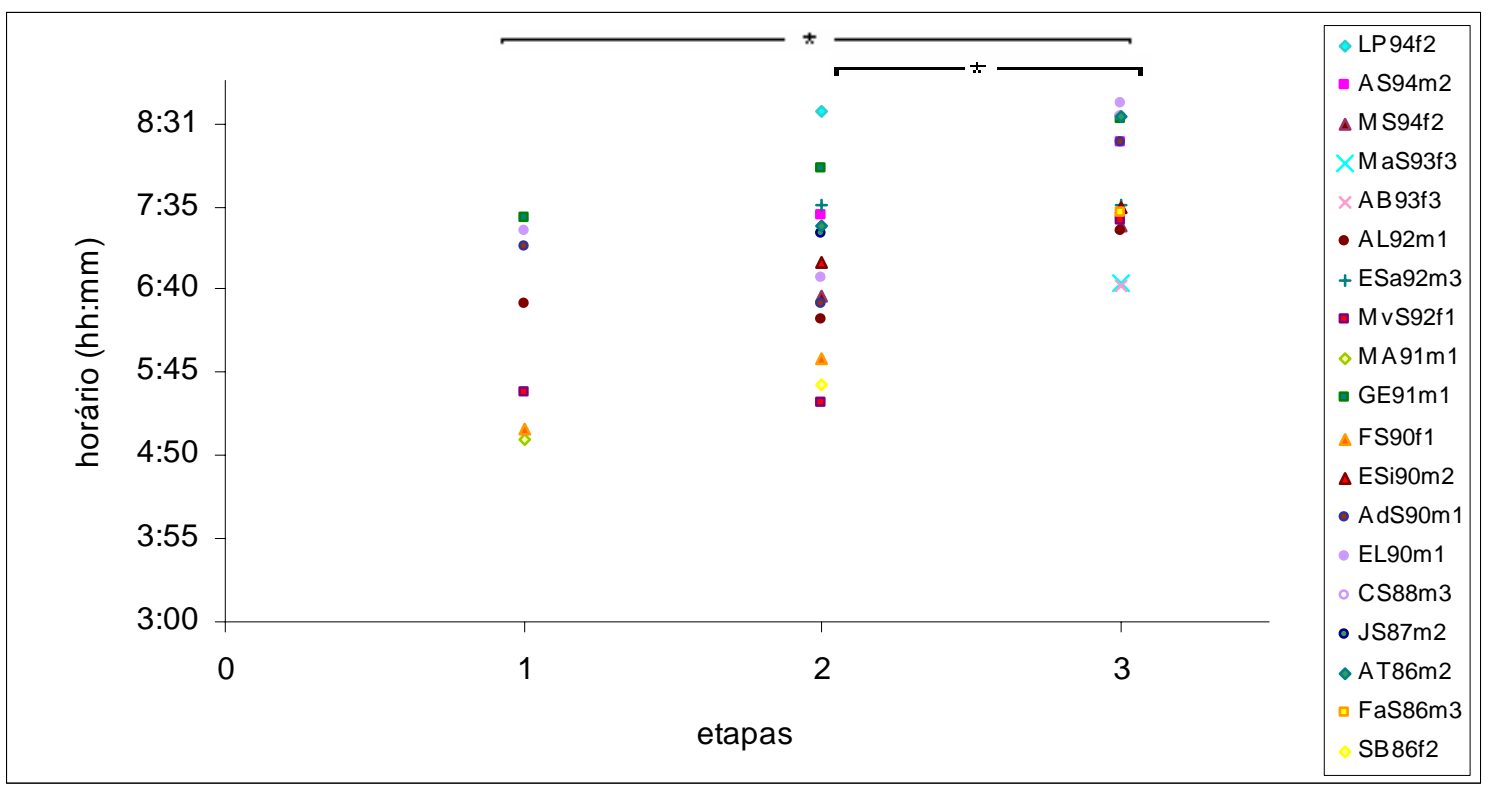

Figura 22: horários médios de fim de repouso, individuais, por etapa $(n=19)$. Os asteriscos indicam diferenças significativas. 


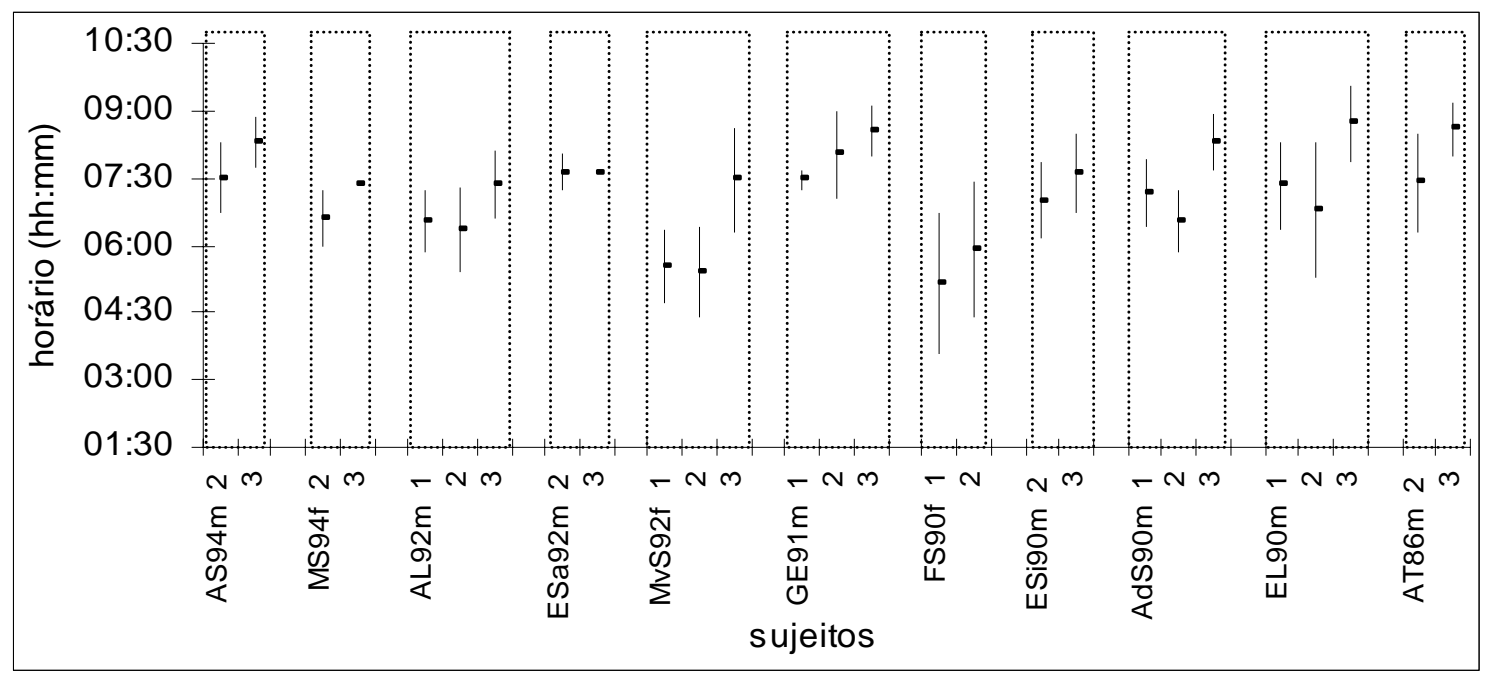

Figura 23: médias e desvios padrão do fim do repouso para todos os sujeitos que tiveram mais de uma etapa $(n=11)$. Os retângulos pontilhados delimitam os resultados do mesmo sujeito nas diferentes etapas.

Não há correlação entre as idades dos participantes e os horários de fim de repouso (figura 23). Considerando as diferentes etapas do grupo, observamos que há diferença significativa entre os horários de fim de repouso na primeira e na terceira etapas (Teste $t$ de Student para amostras dependentes, $p=0,000$ ), assim como entre os horários de fim de repouso na segunda etapa e na terceira etapas (Teste $t$ de Student para amostras dependentes, $p=0,000$ ) indicando que, também em relação ao fim do repouso, os horários foram mais tardios na última coleta do que nas etapas anteriores (figura 22). 


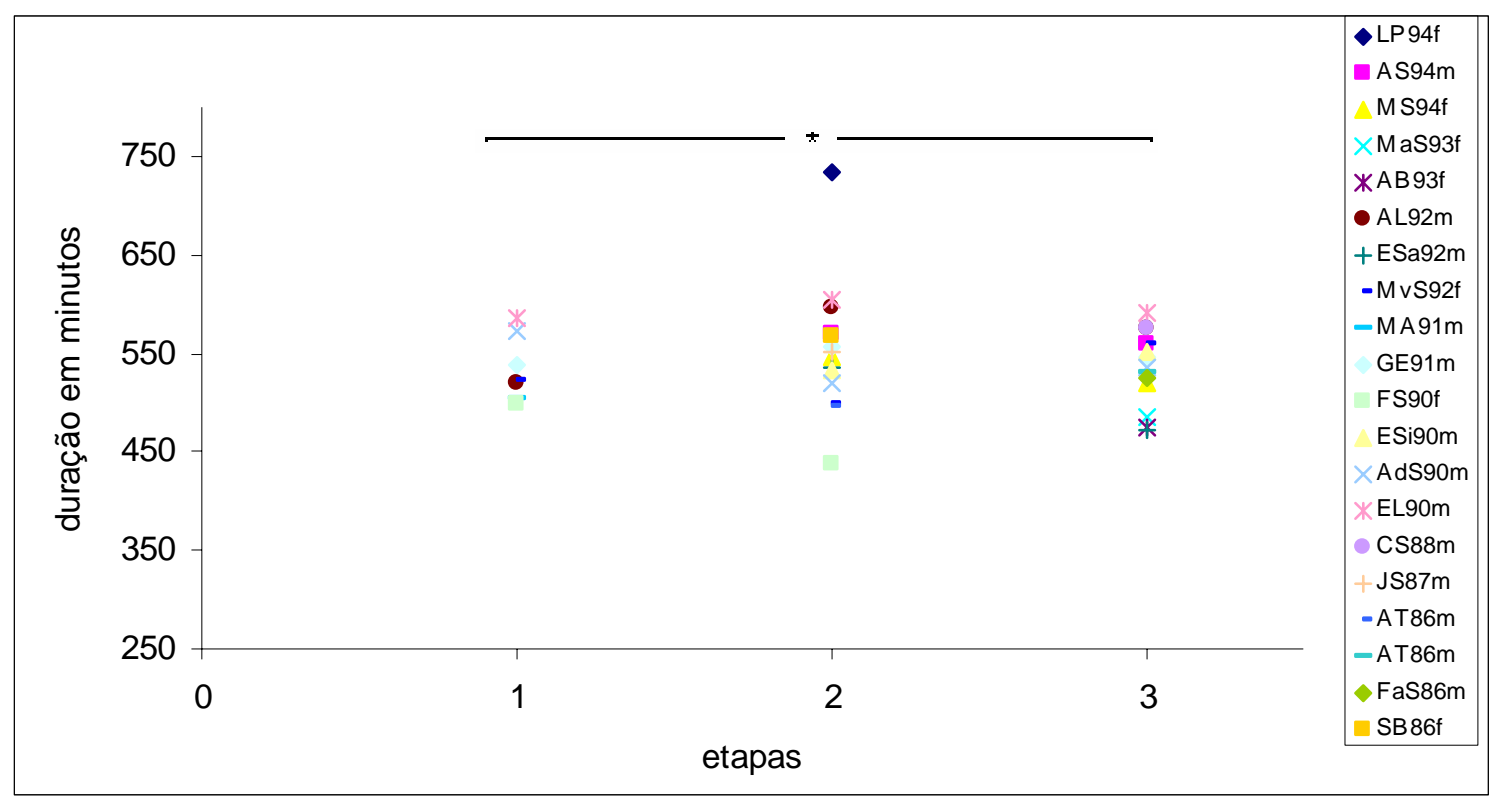

Figura 24: durações médias do repouso, individuais, por etapa $(n=19)$. O asterisco indica diferença significativa.

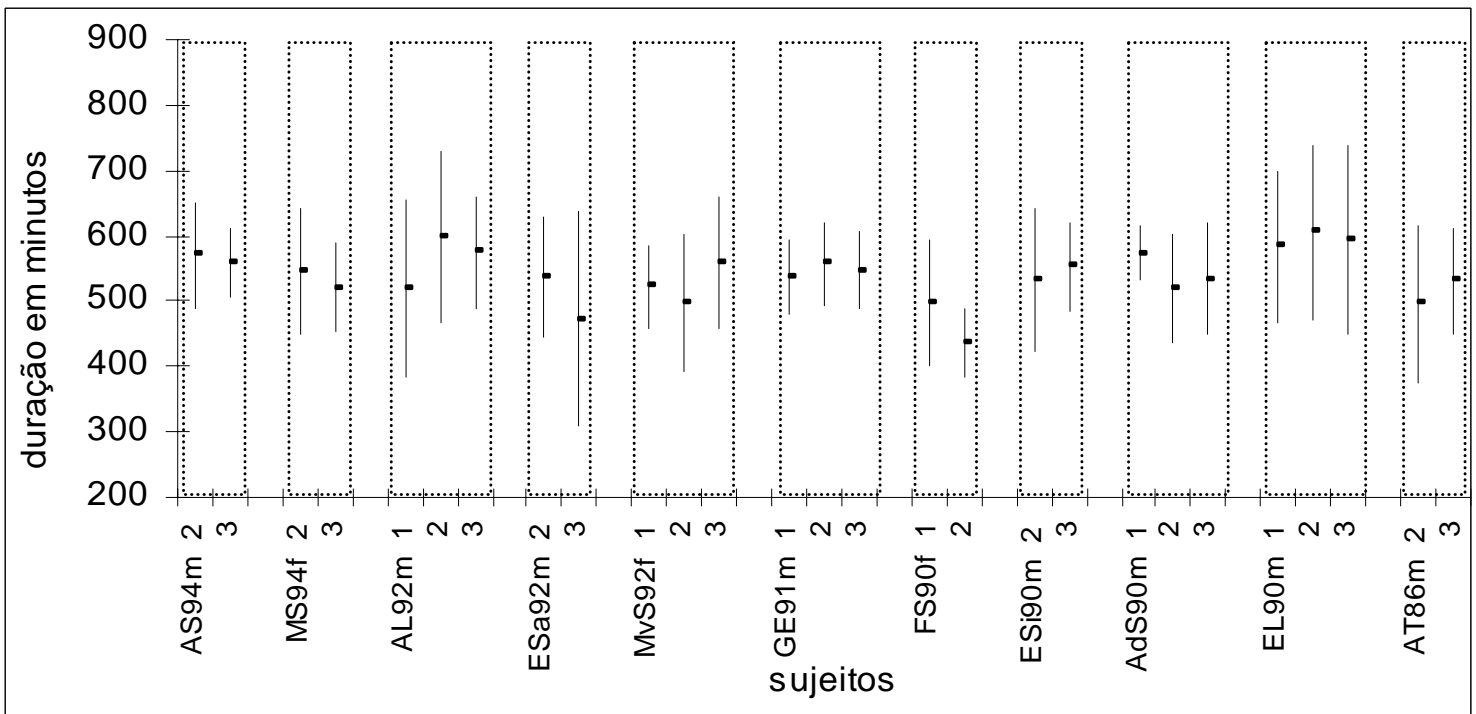

Figura 25: médias e desvios padrão da duração do repouso para todos os que tiveram mais de uma etapa $(n=11)$. Os retângulos pontilhados delimitam os resultados do mesmo sujeito nas diferentes etapas.

A exemplo de outras variáveis relacionadas a sono e repouso, considerando os resultados individuais por etapa, não existe tendência etária na duração de repouso (figura 25). Houve diferença na duração do repouso apenas entre as etapas 1 e 3 (Teste $t$ de Student para amostras 
dependentes, $p=0,030$ ), no sentido de maior duração do sono na etapa 3 do que na primeira etapa (figura 24).

Tabela 6: correlações entre horário de início, fim e duração de repouso em cada etapa.

\begin{tabular}{llll}
\hline & $\begin{array}{l}\text { Etapa 1 } \\
\text { (Pearson } r)\end{array}$ & $\begin{array}{l}\text { Etapa 2 } \\
\text { (Pearson } r)\end{array}$ & $\begin{array}{l}\text { Etapa 3 } \\
\text { (Pearson } r)\end{array}$ \\
\hline início e fim de repouso & n.s. & n.s. & n.s. \\
\hline início e duração de repouso & $r=-0,6$ & $r=-0,7$ & $r=-0,7$ \\
\hline Fim e duração de repouso & $r=0,6$ & n.s. & n.s. \\
\hline
\end{tabular}

n.s. não significativo para $p<0,05$

Na tabela 6, observamos que existe tendência à correlação negativa entre horários início e duração de repouso na etapa 1 (Pearson $r=-0,6)$ e correlações negativas entre horários de início do repouso e a duração de repouso nas etapas 2 e 3 (Pearson $r=-0,7$ e $r=-0,7$, respectivamente, com p<0,5). Há também tendência à correlação positiva entre duração e final de repouso na primeira etapa (Pearson $r=0,6, p<0,05)$.

Dividindo o grupo entre estudantes e não estudantes nas etapas 2 e 3 (tabela 7), observamos que há diferença significativa no início do repouso entre as duas etapas, tanto no grupo que estuda (Teste $t$ de Student para amostras dependentes, $\mathrm{p}=0,000$ ) quanto naquele que não estuda (Teste $t$ de Student para amostras dependentes, $p=0,000$ ), indicando que os horários de início do repouso foram mais tardios na terceira etapa do que na segunda em ambos grupos. Também encontramos diferença significativa nos dois grupos em relação aos horários de fim de repouso (Teste $t$ de Student para amostras 
dependentes, $p=0,000$ para os dois grupos), mais uma vez indicativa de horários mais tardios na última etapa. Não há diferença entre as duas etapas no que se refere à duração do repouso.

\begin{tabular}{lccc}
\hline $\begin{array}{l}\text { Tabela 7: horários médios de início e fim de repouso e duração de repouso dos } \\
\text { participantes que estudam e que não estudam, nas etapas } 2 \text { e 3. }\end{array}$ \\
\hline & Início de repouso & Fim de repouso & Duração de repouso \\
\hline Etapa 2 - estuda & $21: 22 \mathrm{~h}( \pm 102 \mathrm{~min})^{\star}$ & $06: 33 \mathrm{~h}( \pm 61 \mathrm{~min})^{\star}$ & $552 \mathrm{~min}( \pm 105 \mathrm{~min})$ \\
\hline Etapa 3 - estuda & $22: 38 \mathrm{~h}( \pm 75 \mathrm{~min})$ & $07: 46 \mathrm{~h}( \pm 50 \mathrm{~min})$ & $549 \mathrm{~min}( \pm 79 \mathrm{~min})$ \\
\hline Etapa 2 - não estuda & $21: 47 \mathrm{~h}( \pm 101 \mathrm{~min})^{\star}$ & $07: 14 \mathrm{~h}( \pm 71 \mathrm{~min})$ & $544 \mathrm{~min}( \pm 117 \mathrm{~min})$ \\
\hline Etapa 3 - não estuda & $23: 15 \mathrm{~h}( \pm 81 \mathrm{~min})$ & $08: 24 \mathrm{~h}( \pm 54 \mathrm{~min})$ & $555 \mathrm{~min}( \pm 86 \mathrm{~min})$ \\
\hline
\end{tabular}

Os asteriscos $\left(^{*}\right)$ indicam diferenças significativas entre as etapas do mesmo grupo (Teste $t$ de Student para amostras dependentes).

Comparando, na mesma etapa, semana (segundas e terças-feiras) com os finais de semana (sábados e domingos) no que tange aos horários de início e fim de repouso, assim como a duração de repouso (tabela 8), observamos que há diferença significativa na duração de repouso durante a terceira etapa (Teste $t$ de Student para amostras dependentes, $p=0,044$ ), indicando que a duração do repouso é menor nos finais de semana do que durante a semana, havendo também nesta mesma etapa uma tendência à diferença entre semana e fim de semana nos horários de início do repouso (Teste $t$ de Student para amostras dependentes, $p=0,058$ ), indicativa de horários de início de repouso mais tardio nos finais de semana. 
Tabela 8: horários médios de início e fim de repouso e duração de repouso, nos dias da semana e nos finais de semana, nas três etapas.

\begin{tabular}{llll}
\hline & Início de repouso & Fim de repouso & Duração de repouso \\
\hline Etapa 1 - semana & $22: 41 \mathrm{~h}( \pm 74 \mathrm{~min})$ & $06: 10 \mathrm{~h}( \pm 75 \mathrm{~min})$ & $451 \mathrm{~min}( \pm 134 \mathrm{~min})$ \\
\hline Etapa 1 - fim de semana & $21: 39 \mathrm{~h}( \pm 82 \mathrm{~min})$ & $06: 15 \mathrm{~h}( \pm 60 \mathrm{~min})$ & $531 \mathrm{~min}( \pm 146 \mathrm{~min})$ \\
\hline Etapa 2 - semana & $21: 07 \mathrm{~h}( \pm 96 \mathrm{~min})$ & $06: 50 \mathrm{~h}( \pm 63 \mathrm{~min})$ & $582 \mathrm{~min}( \pm 124 \mathrm{~min})$ \\
\hline Etapa 2 - fim de semana & $21: 18 \mathrm{~h}( \pm 104 \mathrm{~min})$ & $06: 25 \mathrm{~h}( \pm 88 \mathrm{~min})$ & $540 \mathrm{~min}( \pm 110 \mathrm{~min})$ \\
\hline Etapa 3 - semana & $22: 56 \mathrm{~h}( \pm 89 \mathrm{~min})^{\star \star}$ & $07: 59 \mathrm{~h}( \pm 81 \mathrm{~min})$ & $545 \mathrm{~min}( \pm 124 \mathrm{~min})^{\star}$ \\
\hline Etapa 3 - fim de semana & $23: 28 \mathrm{~h}( \pm 92 \mathrm{~min})$ & $07: 46 \mathrm{~h}( \pm 68 \mathrm{~min})$ & $500 \mathrm{~min}( \pm 94 \mathrm{~min})$ \\
\hline
\end{tabular}

Um asterisco $\left(^{*}\right)$ indica diferença significativa entre semana e fim de semana na mesma etapa, enquanto dois asteriscos $\left.{ }^{(*}\right)$ indicam tendência à diferença (Teste $t$ de Student para amostras dependentes).

Considerando as segundas e terças-feiras de cada etapa, observamos que há diferença significativa entre o início de repouso da primeira e da terceira etapas (Teste ANOVA de Friedman, $p=0,025$ ), no sentido de início de repouso mais tardio nestes dias da semana durante a terceira etapa. Quando comparamos as segundas e terças-feiras das etapas 2 e 3, observamos que os horários de início e de fim do repouso foram mais tardios na última etapa (Teste ANOVA de Friedman, $p=0,005$ e $p=0,000$, respectivamente).

O fim do repouso no final de semana (sábado e domingo) foi significativamente mais tardio na terceira etapa do que na primeira (Teste ANOVA de Friedman, $p=0,025)$. Além disso, os horários de início e de fim do repouso foram mais tardios nos finais de semana da terceira etapa em relação à segunda (Teste ANOVA de Friedman, $p=0,000$ em ambos). 


\subsection{Relações entre Ciclo Vigília/Sono e Atividade/Repouso}

Os horários médios de início e fim de sono e repouso, assim como seus respectivos desvios padrão, estão representados na figura 26.

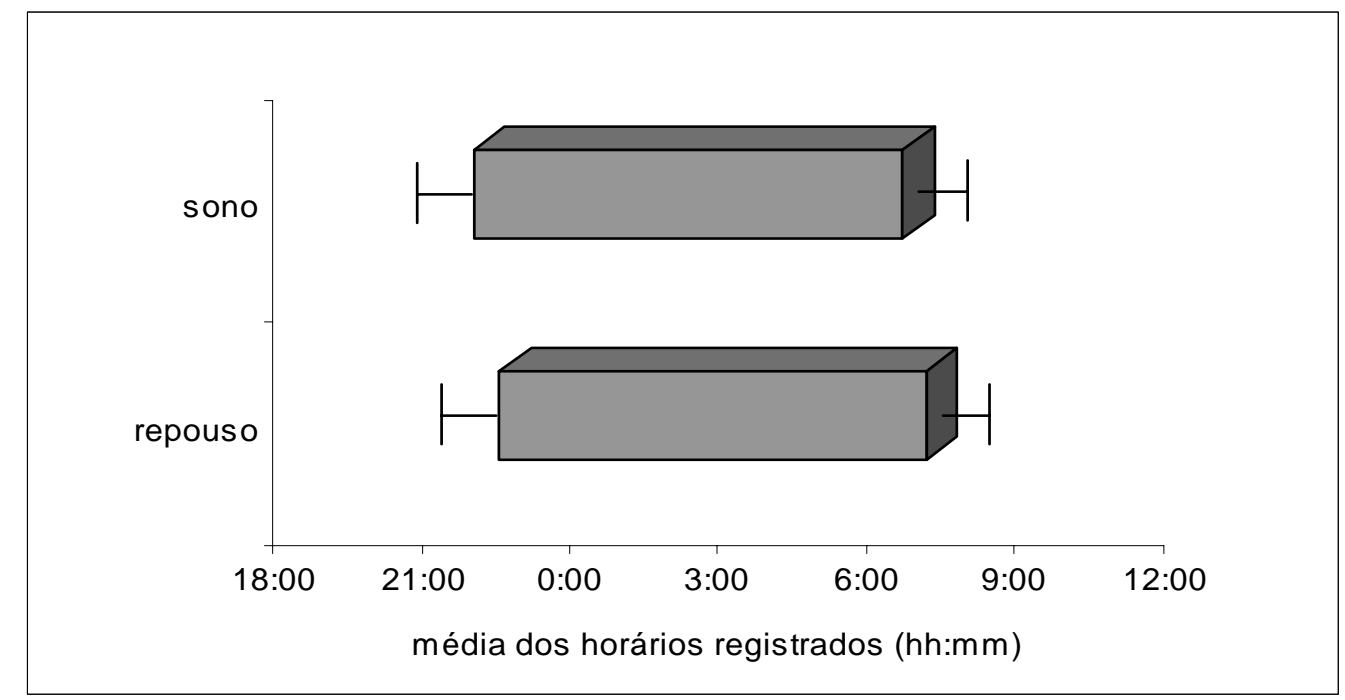

Figura 26: médias e desvios padrão dos horários de início e fim de sono e de repouso de todos os participantes em todas as etapas ( $n=20$ para sono e $\mathrm{n}=19$ para repouso).

Na primeira etapa encontramos correlação positiva entre os horários de fim de sono e fim de repouso (Spearman, $r=0,8, p=0,000$ ) e entre duração de sono e de repouso (Spearman, $r=0,8, p=0,000$ ). Nas etapas 2 e 3 não há correlações entre variáveis de sono e repouso. Não há diferenças significativas entre início, fim e duração de sono e repouso nas etapas 1 e 2 . Contudo existem diferenças significativas entre actimetria e diário de sono na etapa 3, no que diz respeito aos horários de início de sono e repouso e horários de fim de sono e repouso (Teste $t$ de Student, $\mathrm{p}=0,000$ em ambas análises), sendo que os registros actimétricos indicavam horários mais tardios 
tanto para início como para fim de repouso em relação aos registros nos diários de sono.

\section{Discussão}

4.1. Condições de moradia, saúde e hábitos de sono

Quanto às condições gerais de moradia, é interessante notar que há uma grande concentração de co-habitantes que dormem no mesmo cômodo (em média 4 pessoas), se compararmos com os dados do Censo 2000, realizado pelo IBGE, em que consta que a média de habitantes por residência na população brasileira é de 3,4 pessoas por família e de 1,9 pessoas compartilhando o dormitório (http://www.ibge.gov.br/censo).

É importante ressaltar que os membros de comunidades Guarani mudam freqüentemente de casas e até mesmo de aldeias, sozinhos ou com parte da família, o que resulta em mudanças no número de pessoas em cada casa também com bastante freqüência, conforme verificamos em entrevistas. Poderíamos supor que tais condições de moradia resultariam em dificuldades específicas em manter boa qualidade de sono, manifestas principalmente por queixas decorrentes de incômodos no quarto, mas isto não foi detectado.

Entre os participantes, alguns tiveram doenças infecciosas pulmonares na infância. Na Aldeia Boa Vista, segundo dona Íris Araújo Barbosa (comunicação pessoal em fevereiro de 2004), muitas crianças eram 
internadas por complicações respiratórias, mas o índice de hospitalizações e óbitos por tais problemas tem sido reduzido desde que começaram as campanhas de vacinação contra gripe.

Os participantes afirmaram em questionário que costumam dormir e acordar mais tardiamente nos finais de semana do que nos demais dias, tanto aqueles que estudavam quando os demais, desde a primeira aplicação do questionário. O atraso dos horários de dormir nos finais de semana em relação aos demais dias foi confirmado em diários de sono e actimetria apenas na terceira etapa. Na segunda etapa, os horários de fim de sono foram mais tardios durante a semana, conflitando com a informação dos Questionários de Hábitos de Sono.

A diferença entre os horários de despertar entre dias da semana e finais de semana, relatada em questionários, não foi confirmada pelos resultados em diário de sono e actimetria, o que pode estar vinculado às especificidades dos momentos em que as coletas foram realizadas, sempre em feriados prolongados e fim de férias escolares, o que coincide com maior fluxo de turistas na cidade e, portanto, maior empenho dos Guarani em sair da aldeia nas manhãs de domingo para vender palmito e artesanato, o que restringe as possibilidades de acordar mais tardiamente nos finais de semana.

É interessante notar que a forma mais comum de despertar relatada em questionário é a espontânea, mesmo entre aqueles que estudam na escola local. Isto foi confirmado em diários de sono, sendo que a luz do sol pela manhã e barulhos foram citados como causa mais freqüente. 


\subsection{Cronotipo}

Os resultados sobre o cronotipo dos participantes devem ser considerados com cautela, tendo em vista que não houve uma coerência entre as duas aplicações, o que pode ser decorrente da dificuldade de compreensão de perguntas que levam em conta o plano hipotético. Mesmo assim, é interessante notar que a diferença entre as aplicações foi no sentido de escores menores na segunda aplicação, ou seja, indicativa de maior vespertinidade nos jovens seis meses após a primeira aplicação, tendência esta que é corroborada por trabalhos em que a avaliação do cronotipo foi feita comparando jovens em diferentes idades (Roenneberg et al., 2004).

Uma segunda hipótese explicativa para as diferenças entre as duas aplicações pode ser baseada no fato de que a primeira foi realizada no inverno, enquanto a segunda foi feita no verão, quando as altas temperaturas favorecem preferências mais vespertinas. É perfeitamente provável que os participantes tenham respondido considerando a situação climática presente no momento da entrevista. Outra possível explicação sobre esta maior vespertinidade na segunda aplicação pode estar no fato de que, na cultura Guarani, a preferência por horários mais matutinos é bem vista pelos mais velhos. Considerando o estreitamento gradual do contato dos jovens com a pesquisadora, apenas ao final de um ano e meio de pesquisa suas respostas refletiam suas reais preferências, enquanto no começo apenas reproduziam aquilo que é culturalmente desejável.

A última hipótese explicativa para as diferenças entre as aplicações leva-nos a crer que a segunda pontuação no cronotipo é mais fidedigna, o 
que pode ser plausível, tendo em vista que somente quando consideramos a pontuação na segunda aplicação, os horários mais tardios de início de repouso evidenciaram correlação com a maior tendência à vespertinidade, como seria de se esperar entre indivíduos mais vespertinos.

\subsection{Estagiamento puberal}

O estagiamento puberal não evidenciou estar correlacionado significativamente a nenhuma variável. Tal análise física não foi muito bem aceita pelos participantes e é provável que o resultado seja decorrente disto.

A médica responsável pelo exame disse, ao final da terceira etapa, que alguns preferiram apontar no desenho qual o estágio que era mais parecido com suas características físicas e, além disso, a própria médica teve dificuldades em assinalar o estágio puberal dos adolescentes indígenas, tendo em vista que suas características sexuais secundárias (pêlos pubianos e formato das mamas) são diferentes daquelas observadas em outros grupos étnicos, aos quais os desenhos apresentados são mais apropriados.

\subsection{Ritmo de temperatura oral}

O fato de não terem sido detectadas influências do fator idade sobre os horários de acrofase da temperatura oral era esperado, tendo em vista que a alocação da acrofase da temperatura oral depende do cronotipo dos 
indivíduos e das peculiaridades de suas rotinas, as quais foram bastante variados no grupo estudado.

A tendência para horários mais tardios de ocorrência da acrofase de temperatura oral ao longo das etapas é indicativa de atraso de fase deste ritmo. O fato de que, entre os seis integrantes do grupo com acrofase identificada, o sujeito mais velho não apresentou mudanças nos horários de ocorrência da acrofase só reforça a idéia de que o atraso pode estar relacionado a fatores puberais, tendo em vista que ele já considerado adulto e é pai, ou seja, provavelmente concluiu seu desenvolvimento puberal e, portanto, não teria motivos biológicos para apresentar o atraso. Este resultado confirma a hipótese de Roenenberg e colaboradores sobre o retorno à uma tendência menos vespertina ao final da adolescência (Roennenberg et al., 2004), pois o atraso da fase da temperatura oral não se manifestou num participante já no final da adolescência.

As hipóteses a respeito das causas do atraso da fase de temperatura oral devem ser cautelosamente consideradas, tendo em vista o fato de que não houve correlação entre as acrofases e estágio puberal, idade ou cronotipo. É bastante plausível que tais resultados sejam decorrentes do número restrito de dados. Todavia, é importante salientar que há indícios de que os horários de início do repouso, fim do sono e fim do repouso tendiam a ocorrer mais tardiamente entre aqueles cujas acrofases de temperatura oral aconteciam em horários também mais tardios, o que é esperado em indivíduos que estão sincronizados internamente, ou seja, que apresentam uma relação de fase estável entre seus ritmos. 


\subsection{Ritmo de temperatura periférica}

É interessante ressaltar a persistência da ritmicidade encontrada entre os participantes desta pesquisa, além do fato de que as acrofases de temperatura periférica coincidirem na madrugada para todos os participantes, num momento oposto ao horário médio de ocorrência da acrofase da temperatura oral, o que é esperado se considerarmos a dinâmica da regulação térmica fisiológica. Assim, é possível que o horário de ocorrência da acrofase de temperatura periférica seja próximo ao horário de ocorrência da batifase da temperatura oral, porém não temos coletas noturnas de temperatura oral para confirmar tal hipótese.

Apesar de obtermos resultados rítmicos a partir de quase todas as medidas de temperatura periféricas realizadas, nenhum parâmetro foi correlacionado a tais ritmos, nem mesmo os ritmos dos sujeitos nas diferentes etapas foram correlacionados.

Um estudo mais profundo sobre as características do ritmo de temperatura na região do punho está sendo realizado em nosso grupo e, a partir dos resultados deste estudo, poderemos verificar se a ausência de correlações foi específica da amostra aqui estudada ou se isto se expande para outras populações (Arêas, 2005). 


\subsection{Ciclo vigília/sono e ciclo atividade/repouso}

Quando o grupo foi dividido entre estudantes e não estudantes, encontramos o atraso de fase do sono e do repouso entre a segunda e a terceira etapas nos dois subgrupos. Assim, podemos dizer que o fenômeno observado independe do fator escola e deve estar vinculado realmente a mudanças relacionadas ao desenvolvimento biológico dos participantes ao longo das etapas. Num recorte transversal do grupo estudado, não encontramos tendências relacionadas à idade que o caracterizassem. Tal resultado deve estar relacionado ao fato de que a amostra estudada é pequena e as idades não estão homogeneamente representadas.

Se levarmos em conta apenas os resultados de diários de sono do subgrupo que estuda, verificamos que o horário médio de início de sono durante os dias letivos foi 21:34 horas ( \pm 67 minutos) na segunda etapa e de 21:57 horas ( \pm 51 minutos) na terceira etapa. Ao compararmos estes resultados com aqueles apresentados por Louzada e Menna-Barreto (2003), num estudo sobre o CVS de adolescentes com horários escolares matutinos em contexto urbano e rural, podemos dizer que os horários de início de sono durante os dias letivos entre os estudantes indígenas são intermediários entre aqueles observados nos adolescentes de regiões urbanas e rurais do Estado de São Paulo.

Nossa hipótese inicial era que os adolescentes indígenas, por falta de estímulos relacionados à energia elétrica em suas residências, apresentariam horários de início de sono mais precoces do que os adolescentes de regiões urbanas e de regiões rurais com energia elétrica, contudo tal hipótese não foi 
confirmada. Nossos resultados, indicativos de horários de início de sono intermediários, podem ser explicados pelo fato de que os indígenas estudados participam freqüentemente de rituais noturnos diários na casa de reza que podem avançar pela madrugada, ou seja, não há luz elétrica, porém há outro estímulo social que propicia horários mais tardios de início de sono.

Os adolescentes indígenas relataram que geralmente acordam com a luz do sol ou com barulhos, talvez provocados pelos familiares e cães nos arredores das casas, dificilmente são chamados por alguém. Considerando tal flexibilidade do horário de acordar, é interessante notar que os estudantes não tiveram diferenças nos horários de acordar entre semana e final de semana e, além disso, os horários mais tardios de acordar aconteceram nos finais de semana da etapa 3 e correspondiam, em média, às 7:29 horas da manhã ( \pm 60 minutos). No estudo de Louzada e Menna-Barreto (2003), houve diferença significativa nos horários de acordar entre dias letivos e finais de semana, tanto no grupo rural como no grupo urbano, sendo que os horários de acordar nos finais de semana eram posteriores às 8 e às 9 horas da manhã no grupo rural e no grupo urbano, respectivamente, ou seja, sempre mais tardios do que os horários observados no grupo indígena estudado.

Nos dias letivos, os adolescentes Guarani acordavam, em média, mais tardiamente do que os adolescentes de regiões rurais e urbanas estudados anteriormente, todavia finalizam o sono mais cedo quando não há demanda escolar. Este resultado indica que os adolescentes indígenas não apresentavam um padrão de restrição-extensão do sono e, portanto, provavelmente não estão privados de sono e apresentam melhor qualidade do sono do que adolescentes de outras regiões, o que se expressa pela 
maior estabilidade na duração do duração de sono ao longo da semana entre os adolescentes Guarani.

É provável que a estabilidade na duração do sono e repouso noturnos dos jovens indígenas nas primeiras etapas tenham sido proporcionadas por uma estimulação social noturna muito distinta daquela observada em outras populações já estudadas, tendo em vista que na Aldeia Boa Vista não havia equipamentos com funcionamento noturno associados à energia elétrica até o início de 2005, sendo que os rituais na casa de reza sempre aconteceram independentemente do dia da semana.

Alguns adolescentes relataram que, desde que a energia elétrica chegou na escola indígena, no início de 2005, quase todos os jovens vão até o local nas noites de sexta para sábado, e muitas vezes de sábado para domingo, para assistir filmes em fitas de vídeo. Com esta informação, podemos compreender melhor o deslocamento dos horários de início de sono e de repouso para horários mais tardios nos finais de semana apenas nesta etapa.

Ao selecionarmos dois dias da semana (segundas e terças-feiras) e contrastarmos com os finais de semana (sábado e domingo), encontramos uma diferença significativa apenas na terceira etapa. Este resultado pode ser um exemplo da influência de estímulos sociais sobre o ciclo vigília/sono e ciclo atividade/repouso nesta faixa etária - foi nesta fase que eles passaram a assistir filmes nas noites de finais de semana na escola local.

É interessante notar que, na terceira etapa, constatamos menor duração do sono e do repouso nos finais de semana, num padrão de restrição-extensão do sono oposto àquele descrito em adolescentes por 
Carskadon e colaboradores em 1980. Tal resultado possivelmente deriva dos horários mais tardios de início de sono e repouso nos finais de semana desta etapa, além do fato já mencionado de que havia uma demanda ainda grande de venda de palmitos e artesanato nos finais de semana a turistas.

É importante lembrar que, apesar desta forte e nova influência de um estímulo social, ela por si só não explicaria o atraso de fase do sono encontrado, tendo em vista que houve atraso de fase do início do repouso longitudinalmente também quando consideramos só as segundas e terçasfeiras das etapas, dias em que eles não alugavam filmes. Além disso, vale ressaltar aqui que houve atraso de fase do horário da acrofase da temperatura oral daqueles que tiveram tal ritmo observado, ou seja, num ritmo mais rígido, pouco influenciável por mudanças não prolongadas de rotinas, também houve atraso de fase.

A importância da estimulação social noturna sobre a estabilidade da duração de sono e repouso fica bem demonstrada pela mudança de rotina constatada a partir do momento em que os adolescentes Guarani estudados puderam manter o televisor da escola ligado nas noites de finais de semana, como observamos na terceira etapa, e passaram a apresentar uma menor duração de sono nos finais de semana, padrão contrário ao de restriçãoextensão do sono observado em adolescentes de regiões urbanas. Esse padrão de "extensão-restrição" do sono pode ser decorrente do conflito entre a necessidade de acordar cedo nos finais de semana para a realização de atividades comerciais na cidade de Ubatuba, rotina observada desde a primeira etapa da pesquisa, e o novo hábito de assistir filmes na escola nas noites de sexta e sábado. 


\section{Conclusões e considerações finais}

Diante dos padrões dos ciclos atividade/repouso, vigília/sono e temperatura observados, podemos concluir que houve atraso longitudinal da fase do sono e da temperatura oral no grupo estudado, independentemente da existência de uma rotina escolar, sem que fossem detectadas correlações entre os atrasos de fase e a idade ou o estágio puberal dos participantes.

O contexto sociocultural no qual estes adolescentes estão envolvidos não é favorável ao atraso de fase dos ritmos biológicos durante esta etapa da vida, pois culturalmente é apreciado aquele indivíduo que consegue ser mais matutino e, mesmo com tal valorização agregada à falta de energia elétrica nas casas, o atraso de fase foi detectado, o que fornece indícios de que fenômenos relacionados ao desenvolvimento puberal, que não foram substancialmente avaliados neste trabalho, podem estar relacionados a tal padrão de atraso de fase.

É importante salientar que o padrão de "extensão-restrição" observado na terceira etapa, ou seja, menor duração de sono e de repouso nos finais de semana, relaciona-se a horários mais tardios de início de sono e de repouso nesta etapa por decorrência do novo hábito de assistir filmes nas noites de sexta para sábado e de sábado para domingo. Assim, ressaltamos que o atraso da fase de ritmos circadianos humanos durante a adolescência é decorrente de uma somação de fatores biológicos e ambientais - os primeiros sendo favorecidos ou não pelos últimos.

Nossos resultados apontam para a interação entre fatores biológicos e sociais presente na adolescência, que produz um padrão de restrição- 
extensão do sono em adolescentes do meio urbano e nos adolescentes indígenas estudados produz um padrão de "extensão-restrição" do sono. Se por um lado os adolescentes de regiões urbanas - que apresentam o atraso da fase do sono, têm diversos estímulos sociais noturnos e estudam pela manhã - prolongam a duração do sono nos finais de semana, os adolescentes indígenas - que apresentam atraso de fase de sono, passaram a ter um estímulo social noturno em suas rotinas e têm atividades matutinas nos finais de semana - reduzem a duração de sono. Desta forma, podemos dizer que as tensões entre tendências biológicas e fatores sociais acontecem de diferentes maneiras, dependendo do contexto sociocultural, e são resolvidas, no que tange aos hábitos de sono, também de maneiras distintas.

A continuidade desta pesquisa após a implantação da energia elétrica nas casas da aldeia seria interessante para observar mais detalhadamente se há mudanças de rotina relacionadas aos novos estímulos noturnos que atuem sobre os ritmos biológicos destes adolescentes. 
ANEXOS 
Anexos A - Parecer do Conselho Nacional de Ética em Pesquisa

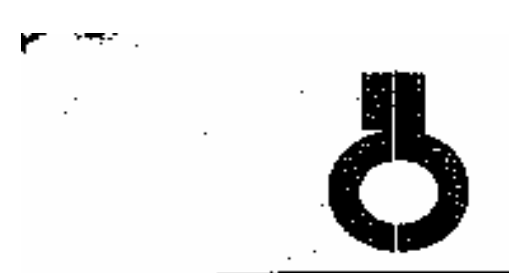

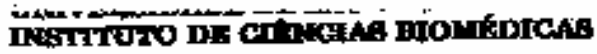

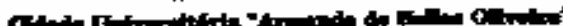

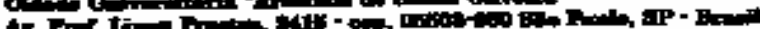

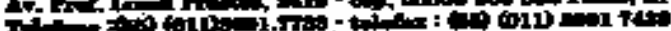

Thint

Of.OFPSH. 201.03

BEs Pnula, 22 de cotembio do 2005

Preseda Senhara,

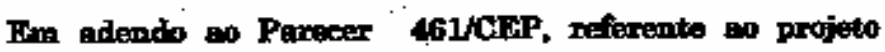

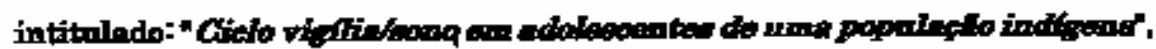

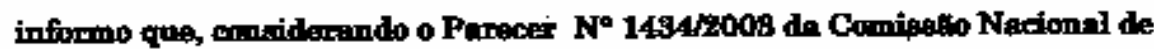

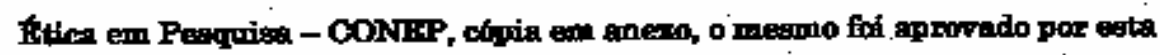
Comisto on ma trigtoima berta ramilo.

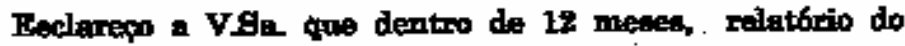
referido projeto depert car encrminhado a Secrotatia deste CEP.

Carifinlments.

$$
\text { - } / 4 a / d a r
$$

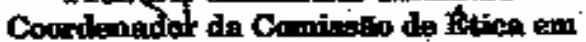

Pesquian coin Berea Humanos - IOB JUAP

Dima. Sra.

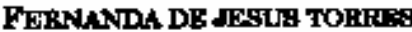

Departamenta de Firiologin e Bioflyiun

Instituto de Gitincias Binmetiras - UJP

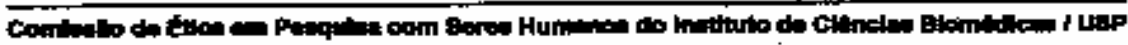

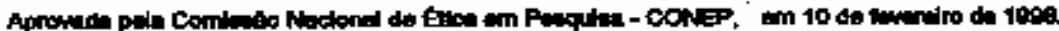




\section{PARECER N 1434RAa}

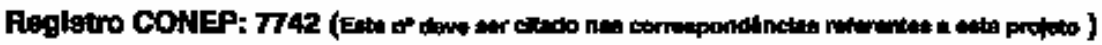
Reglatro CEP: 476

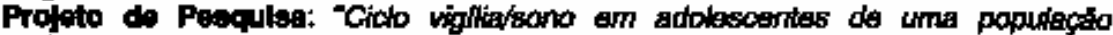
indfgens"

Pagqulogdor Responafwel: Fernenda de Jegas Torres ( mestranta)

- Inottulcho: Insttuto de Clenckas Biombedicas - ICBMSP

Area Temttles Eepectal; Poputacóos Indigenes

Ao ge proceder à ańlise das reapostas an Parecar 1003/200a, ralativo ao projeto em questio, conerderou-se que:

a) forem atendides as soicitaçes do referido parecer;

b) o projeto presenche ca requisitos fundementeis des Fesciuçoos GNS 190 as a 30400 sobre Diretrtzes e Nomas Regulamentadoras de Pesclisis Enwolvento Sanes Humanos;

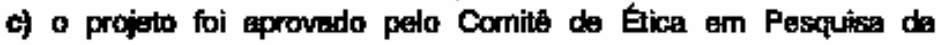
Institulçlo supractada .

Dhnte do exponto, a Comlanifo Nactond de Etica em Penquipp -

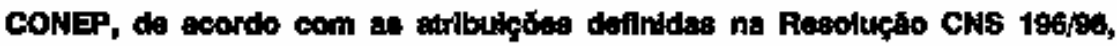

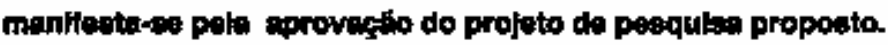

Stupepto : Projeto aprovado

Brasilia, on de setembro de 2003

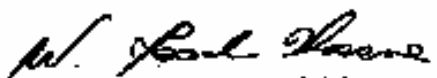

MUUAM SAAD HOSSINE Coordenador da CONEP/CNS/MS 
ANEXOS B - Parecer da Fundação Nacional do Índio

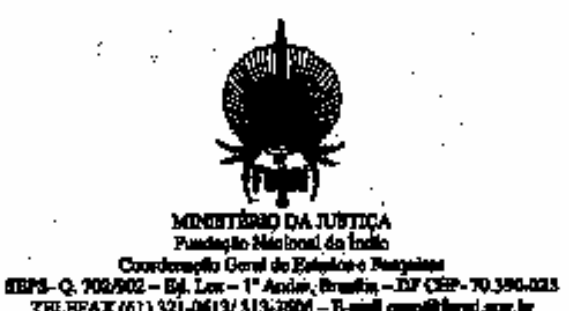

OFICION. 25 RGEPRA

Bradra, 15 do fowantro de 2004.

A Eemhar:

Fomonde de Jedus Tome

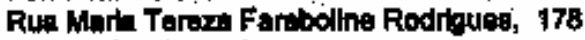

Pyrque Coalingtal

Eto Pasto-9P

CEP $059270-000$

Absunto: Inqroese ne T1 God Vothubatube-SP

Propeda Sonhora,

i.

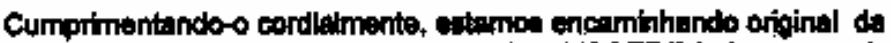

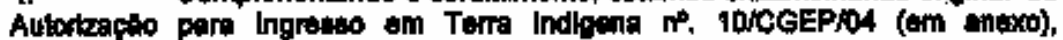

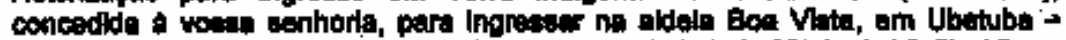

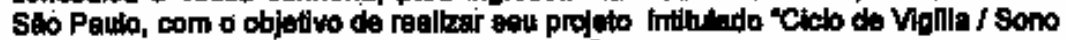
am Adolaceentes de uma Populgato Indigen.".

Aternibuamente

Oítín dét Santos Romero

Coodenator Ceral de Eahudos a Panqulara

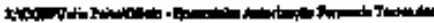




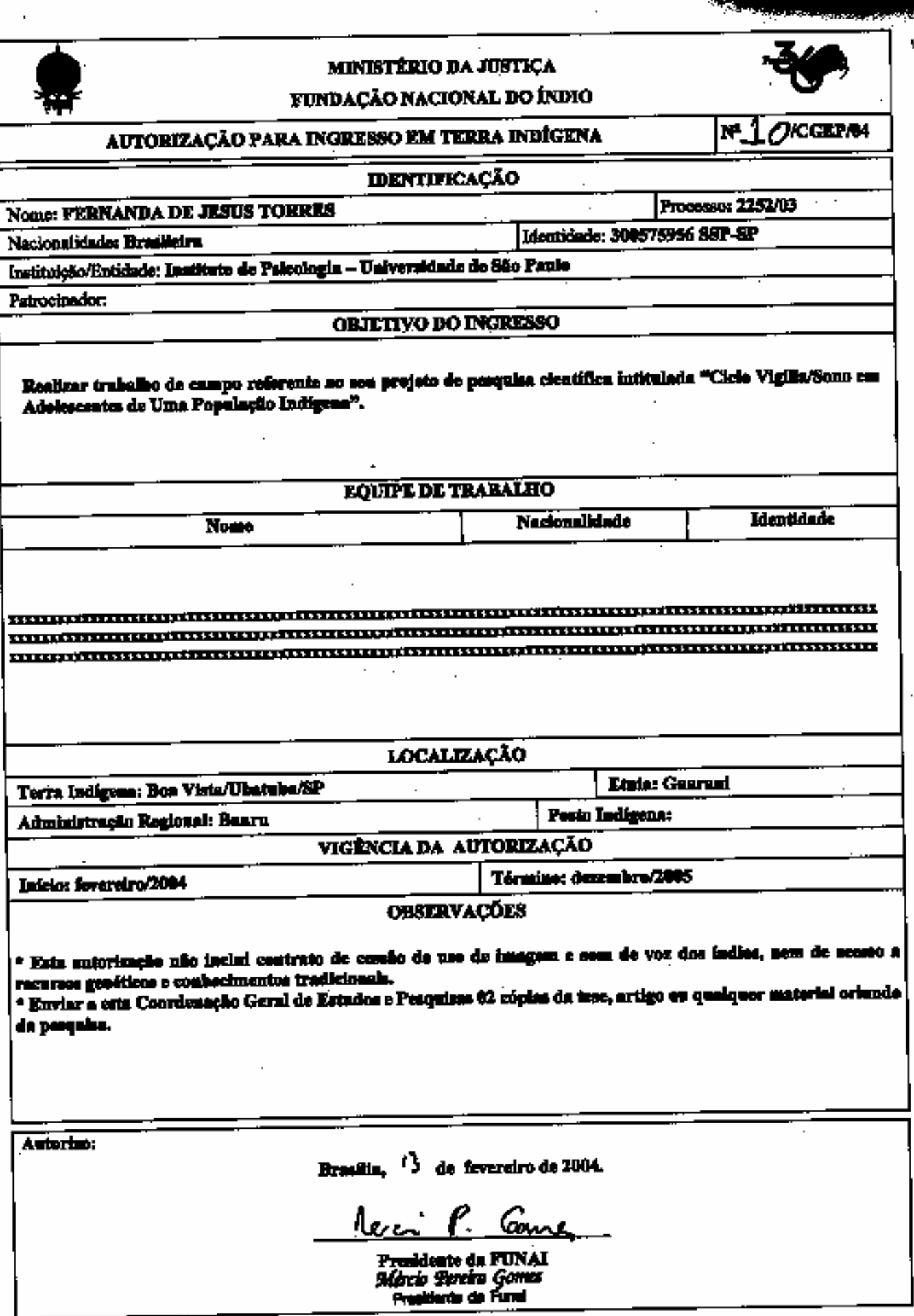


ANEXO C - Termo de Consentimento Livre e Esclarecido do Instituto de Ciências Biomédicas

\section{Universidade de São Paulo}

Instituto de Ciências Biomédicas

TERMO DE CONSENTIMENTO LIVRE E ESCLARECIDO

(menores de 18 anos)

ESTUDO: Ciclo Vigília/Sono em Adolescentes de uma População Indígena

Seu filho está sendo convidado a participar do projeto de pesquisa acima citado. O documento abaixo contém todas as informações necessárias sobre a pesquisa que estamos fazendo, então leia atentamente e caso tenha dúvidas, vou esclarecê-las (se não souber ler, fique tranqüilo(a) que leio para você). Se concordar, o documento será assinado e só então daremos início a pesquisa. Sua colaboração neste estudo será muito importante para nós, mas se desistir a qualquer momento, isso não causará nenhum prejuízo a você, nem ao seu (sua) filho(a).

Eu

RG , abaixo assinado(a), concordo de livre e espontânea vontade que meu(minha) filho(a)

nascido(a) em I , seja voluntário do estudo "Ciclo Vigília/Sono em Adolescentes de uma População Indígena", afirmo que obtive todas informações necessárias e fui esclarecido(a) de todas as dúvidas apresentadas.

Estou ciente que: 
I) O estudo se faz necessário para que possam descobrir as possíveis causas do "atraso de fase do sono", que é a tendência que os jovens têm de dormir e acordar mais tarde;

II) Logo no primeiro dia de pesquisa, meu(minha) filho(a) e eu responderemos a 35 questões sobre suas atividades de rotina e sobre seus hábitos de sono. Logo em seguida, meu(minha) filho(a) responderá a outro questionário, com 19 perguntas, a respeito de suas preferências de sono;

III) Meu (minha) filho(a) participará de 3 etapas de 14 dias coletas de dados de temperatura oral; de registros de sua rotina de atividade e uso de actímetro;

IV) Em cada dia de pesquisa, ele(a) vai medir a temperatura oral cinco vezes, só enquanto estiver acordado(a), vai responder uma vez às questões sobre sua atividade em um caderno e vai usar durante todo o dia o actímetro, que é um aparelho que deve ser mantido no punho do(a) meu(minha) filho(a), sendo retirado só para o banho;

V) Essas coletas serão feitas apenas para este estudo e em nada influenciará nas demais atividades diárias de meu(minha) filho(a);

VI) A participação do meu(minha) filho(a) neste projeto não tem objetivo de submetê-lo a um tratamento terapêutico e será sem custo algum para mim;

VII) Eu e meu(minha) filho(a) temos a liberdade de desistir ou interromper a colaboração neste estudo no momento em que desejarmos, sem necessidade de qualquer explicação;

VIII) A desistência não causará nenhum prejuízo a mim, nem ao(a) meu (minha) filho(a);

IX) Os resultados obtidos serão mantidos em sigilo, mas concordo que sejam divulgados em publicações científicas, desde que o meu nome o nome de meu filho não sejam mencionados;

X) Caso eu desejar, poderei tomar conhecimento dos resultados ao final desta pesquisa:

( ) Desejo conhecer os resultados desta pesquisa.

( ) Não desejo conhecer os resultados desta pesquisa. 
Ubatuba, de de 2004.

( ) Participante / ( ) Responsável:

Testemunha 1:

Nome / RG / Telefone

Testemunha 2:

Nome / RG / Telefone

Responsável pelo Projeto:

FERNANDA DE JESUS TORRES 
ANEXO D - Questionário de matutinidade e vespertinidade adaptado

GRUPO MULTIDISCIPLINAR DE DESENVOLVIMENTO E RITMOS BIOLÓGICOS

DEPARTAMENTO DE FISIOLOGIA E BIOFÍSICA

INSTITUTO DE CIÊNCIAS BIOMÉDICAS

UNIVERSIDADE DE SÃO PAULO

QUESTIONÁRIO PARA IDENTIFICAÇÃO DE INDIVÍDUOS MATUTINOS E VESPERTINOS

INSTRUÇÕES:

1. Vou fazer algumas perguntas para você.

2. Tente responder todas perguntas e, se não ententer pode pedir que eu explico novamente.

3. Responda de acordo com o que você realmente prefere.

4. Se você quiser fazer alguma pergunta para mim, pode fazê-la em qualquer momento.

- Traduzido e adaptado de HORNE, J.A.; OSTBERG, $O$. A self-assessment questionnaire to determine morningness-eveningness in human circadian rhythms. International Journal of Chronobiology, v.4, p. 97-110, 1976. 
1. Pense apenas no seu bem e imagine que você pode fazer o que quiser no dia, não precisa ir à escola ou fazer as atividades que você tem que fazer todo dia. Consegue imaginar? Agora, me diz a que horas você se levantaria se seu dia pudesse ser assim?

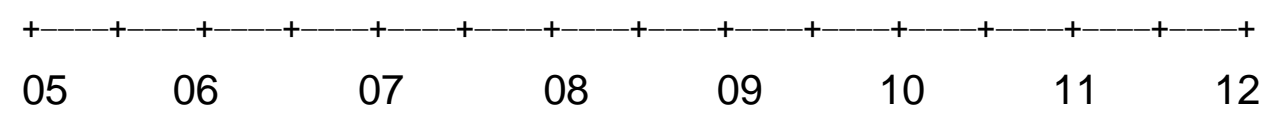

2. Continue pensando apenas no seu bem e imaginando que você pode fazer o que quiser no dia, não precisa ir à escola ou fazer as atividades que você tem que fazer todo dia. Consegue imaginar? Agora, me diz a que horas você se deitaria para dormir se seu dia pudesse ser assim?

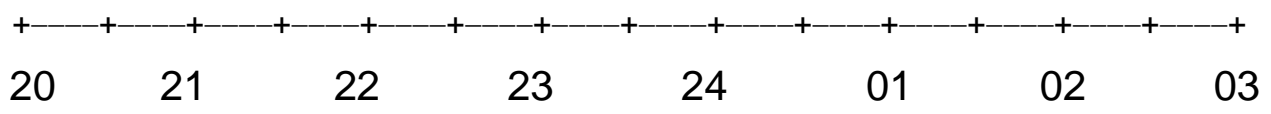

3. Você usa despertador para acordar? Se sim, até que ponto você depende do despertador para acordar de manhã?

1. Nada dependente

2. Não muito dependente

3. Bastante dependete

4. Muito dependente

4. Você acha fácil acordar de manhã?

1. Nada fácil

2. Não muito fácil

3. Bastante fácil

4. Muito fácil

5. Você se sente alerta, bem, com energia, durante a primeira meia hora depois de acordar?

1.Nada alerta

2.Não muito alerta

3.Bastante alerta

4. Muito alerta

6. Como é o sua vontade de comer durante a primeira meia hora depois de acordar?

1. Muito ruim 
2. Não muito ruim

3. Bastante boa

4. Muito boa

7. Durante a primeira meia hora depois de acordar você se sente cansado?

1. Muito cansado

2. Não muito cansado

3. Bastante descansado

4. Nada cansado

8. Pense no seu horário de ir dormir de todos os dias e imagine que você não tem nada para fazer amanhã seguinte a que horas você gostaria de ir deitar hoje?

1. Não deitaria mais tarde

2. Deitaria menos que uma hora mais tarde

3. Deitaria entre uma e duas horas mais tarde

4. Deitaria mais do que duas horas mais tarde

9. Você decidiu fazer exercícios físicos. Um amigo sugeriu o horário das 07h00 às 08h00 da manhã, duas vezes por semana. Considerando apenas seu bem-estar pessoal, o que você acha de fazer exercícios nesse horário?

1. Estaria em boa forma

2. Estaria razoavelmente em forma

3. Acharia isso difícil

4. Acharia isso muito difícil

10. A que horas da noite você se sente cansado e com vontade de dormir?

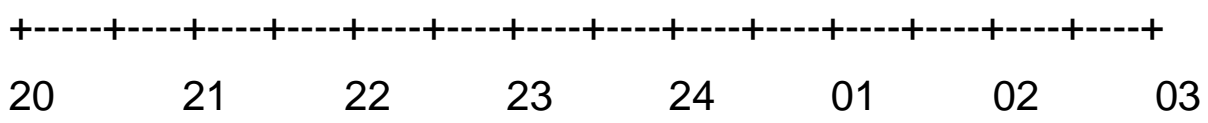

11. Agora quero que você imagine que a professora vai dar uma prova e você quer ir muito bem. A prova dura duas horas e você sabe que ficará cansado quando terminar. Imagine também que a professora deixou você escolher o horário para a prova. Qual desses horários você escolheria? 
1. Das $08: 00$ às $10: 00$ horas

2. Das $11: 00$ às $13: 00$ horas

3. Das $15: 00$ às $17: 00$ horas

4. Das $19: 00$ às $21: 00$ horas

12. Se você fosse deitar às 23:00 horas em que nível de cansaço você se sentiria?

1. Nada cansado

2. Um pouco cansado

3. Bastante cansado

4. Muito cansado

13. Imagine que teve reza até mais tarde e você participou até o fim e foi dormir várias horas mais tarde do que é seu costume. Se no dia seguinte você não tiver hora certa para acordar, o que aconteceria com você?

1. Acordaria na hora normal, sem sono

2. Acordaria na hora normal, com sono

3. Acordaria na hora normal e dormiria novamente

4. Acordaria mais tarde do que seu costume

14. Se você tiver que ficar acordado das 04:00 às 06:00 horas para cortar palmito e não tiver nada para fazer depois disso, o que você faria?

1. Só dormiria depois de fazer cortar palmito

2. Tiraria uma soneca antes de cortar palmito e dormiria depois

3. Dormiria bastante antes e tiraria uma soneca depois

4. Só dormiria antes de cortar palmito

\section{Se você tiver que cortar lenhas por duas horas e considernado apenas o o que você prefere, qual destes horários você escolheria?}

1. Das $08: 00$ às $10: 00$ horas

2. Das $11: 00$ às $13: 00$ horas

3. Das $15: 00$ às $17: 00$ horas 
16. Você decidiu jogar futebol (ou peteca, caso seja menina). O(a) Fulano(a) sugeriu o horário das 22:00 às 23:00 horas, duas vezes por semana porque ele(a) tem como colocar luz no campinho. Considerando apenas a sua vontade como você se sentiria com a proposta de horário para jogar que o Fulano(a) disse?

1. Estaria ótimo para jogar nesse horário

2. Estaria bem para jogar nesse horário

3. Acharia isso difícil

4. Acharia isso muito difícil

17. (Pergunto para a pessoa qual atividade na aldeia ela gosta ou gostaria de fazer, aqui está um exemplo) Se você trabalhasse como agente de saúde no posto médico e a médica dissesse que você tem que trabalhar cinco horas por dia, mas você pode escolher o seu próprio horário de trabalho. Imagine que você vai ganhar pelo quantidade de trabalho que você fizer por dia. Qual o horário que você escolheria para começar a cada dia?

\begin{tabular}{|l|l|l|l|l|l|l|l|l|l|l|l|l|l|l|l|l|l|l|l|l|l|l|l|l|}
\hline 24 & 01 & 02 & 03 & 04 & 05 & 06 & 07 & 08 & 09 & 10 & 11 & 12 & 13 & 14 & 15 & 16 & 17 & 18 & 19 & 20 & 21 & 22 & 23 & 24 \\
\hline
\end{tabular}

18. A que hora do dia você atinge seu melhor momento de bem-estar, de disposição?

\begin{tabular}{|l|l|l|l|l|l|l|l|l|l|l|l|l|l|l|l|l|l|l|l|l|l|l|l|l|}
\hline 24 & 01 & 02 & 03 & 04 & 05 & 06 & 07 & 08 & 09 & 10 & 11 & 12 & 13 & 14 & 15 & 16 & 17 & 18 & 19 & 20 & 21 & 22 & 23 & 24 \\
\hline
\end{tabular}

19.Fala-se em pessoas matutinas e vespertinas (as primeiras gostam de acordar cedo e dormir cedo, as segundas de acordar tarde e dormir tarde). Com qual desses tipo você se identifica?

1. Tipo matutino

2. Mais matutino que vespertino

3. Mais vespertino que matutino

4. Tipo vespertino

20. Qual estação do ano você gosta mais?

1. Primavera

2. Verão

3. Outono

4. Inverno 
NOME

SEXO $M($ ) $F()$

IDADE _ ANOS

PROFISSÃO

HORÁRIO HABITUAL DE TRABALHO

( use o verso se necessário, especialmente se tiver atividades fora da rotina)

DATA

CIDADE 
ANEXO E - Questionário de Hábitos de Sono

\section{Questionário de Hábitos de Sono}

Questionário respondido no dia: /2003.

Nome do responsável:

Nome do(a) participante:

Data de nascimento do(a) participante:

Sexo do(a) participante: ( ) Feminino ( ) Masculino

\section{GOSTARÍAMOS DE SABER UM POUCO SOBRE SUA CASA E SUA FAMÍLIA.}

1. Quantas pessoas moram na sua casa?

Em minha casa moram pessoas.

2. Quantas pessoas dormem no mesmo quarto do seu (sua) filho(a)? Meu (minha) filho(a) dorme com mais pessoas no mesmo quarto.

3. O quarto onde seu (sua) filho(a) dorme durante a noite tem:
a) ( ) muito barulho
b) ( ) pouco barulho
c) ( ) nenhum barulho

4. Existe alguma coisa no quarto do seu (sua) filho(a) que o(a) incomoda quando ele (ela) está dormindo?
a) não ( )
b) $\operatorname{sim}($ ) qual?

5. Seu (sua) filho(a) mudou de casa ou de quarto de dormir recentemente?
a) não ( )
b) $\operatorname{sim}($ ) há quanto tempo? 
6. Houve alguma mudança no número de pessoas que moram na sua casa recentemente?
a) não ( )
b) $\operatorname{sim}($ ) há quanto tempo?

\section{AGORA ALGUMAS INFORMAÇÕES SOBRE A SAÚDE DO SEU FILHO(A):}

8. Seu (sua) filho(a) tem algum problema de saúde?
a) não ( )
b) $\operatorname{sim}($ ) qual?
há quanto tempo?

9. Seu (sua) filho(a) está tomando algum remédio?
a) não ( )
b) $\operatorname{sim}($ ) qual?
há quanto tempo?

10. Seu (sua) filho(a) está fazendo algum tratamento médico?
a) não ( )
b) $\operatorname{sim}($ ) qual?
há quanto tempo?

11. Seu (sua) filho(a) costuma beber café, chá (mate ou preto) ou refrigerante? Se ele/ela beber, responda abaixo o quanto ele/ela bebe:
a) café
todo dia ( ) às vezes ( ) nunca ( )
b) chá, qual?
todo dia ( ) às vezes ( ) nunca ( )
c) refrigerante
todo dia ( ) às vezes ( ) nunca ( )

\section{AGORA QUEREMOS SABER ALGUMAS COISAS SOBRE O SONO DO SEU(SUA) FILHO(A)}


12. Você acha que seu (sua) filho(a) tem algum problema de sono?
a) não ( )
b) $\operatorname{sim}()$
qual?

há quanto tempo?

13. Seu (sua) filho(a) sente dificuldade para conseguir pegar no sono à noite?
a) nunca ( )
b) às vezes ( )
c) sempre ( ) há quanto tempo?

14. Seu (sua) filho(a) sente muito sono durante o dia?
a) nunca ( )
b) às vezes ( )
c) sempre ( ) há quanto tempo?

15. Seu (sua) filho(a) acorda no meio da noite e tem dificuldade para voltar a dormir?
a) nunca

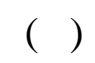
b) às vezes
c) sempre ( )
há quanto tempo?

16. Caso seu(sua) filho acordasse no meio da noite você escutaria?
a) sim, com certeza ( )
b) talvez
c) não

17. Seu (sua) filho(a) costuma ter pesadelos durante o sono?
a) nunca ( )
b) às vezes ( )
c) sempre ( ) há quanto tempo?

18. Seu (sua) filho(a) costuma acordar com a sensação de estar sufocado?
a) nunca ( )
b) às vezes ( ) 

d) sempre ( ) há quanto tempo?

19. Marque com um $\mathbf{X}$ se seu (sua) filho(a) costuma fazer algumas dessas coisas durante o sono:
a) ranger os dentes
( )
b) mexer-se muito
( )
c) falar dormindo
( )
d) roncar
( )
e) andar dormindo
( )
h) gritar dormindo

20. A que horas seu (sua) filho(a) normalmente vai dormir nos dias de semana à noite?

Ele/ela costuma dormir às horas.

21. A que horas seu (sua) filho(a) normalmente acorda nos dias de semana? Ele/ela costuma acordar às horas.

22. De que forma seu (sua) filho(a) acorda pela manhã nos dias de semana?
a) com despertador ( )
b) alguém o(a) chama ( )
c) ele/ela acorda sozinho ( )

23. É difícil para seu (sua) filho(a) acordar pela manhã nos dias de semana?
a) muito difícil
( )
b) um pouco difícil ( )
c) fácil
( )

24. A que horas seu (sua) filho(a) normalmente vai dormir nos fins de semana? Ele/ela costuma dormir às horas nos fins de semana.

25. A que horas seu (sua) filho(a) normalmente acorda nos fins de semana? Ele/ela costuma acordar às horas nos fins de semana. 
26. De que forma seu(sua) filho(a) acorda nos fins de semana?
a) com despertador
( )
b) alguém o(a) chama ( )
c) ele/ela acorda sozinho ( )

27. É difícil para seu (sua) filho(a) acordar nos fins de semana?
a) muito difícil
( )
b) um pouco difícil
c) nada difícil
( )

28. Seu (sua) filho(a) costuma dormir ou cochilar durante o dia?
a) nunca
( )
b) de vez em quando
( )
d) todos os dias
( )
e) não sei

29. A que horas seu (sua) filho(a) costuma cochilar durante o dia? Ele/ela costuma cochilar das às horas e das às horas.

30. Alguém da sua família tem algum problema de sono?
a) não ( )
b) $\operatorname{sim}($ ) qual?

ALGUMAS INFORMAÇÕES SOBRE AS ATIVIDADES DIÁRIAS DO SEU(SUA) FILHO(A)

31. Seu (sua) filho(a) está estudando?
a) não ( )
b) $\operatorname{sim}($ ) em que horário?

32. Que meio de transporte seu (sua) filho(a) usa para ir para a escola todos os dias?

( ) carro 

( ) ônibus
( ) a pé
( ) outros

quais?

33. Quanto tempo seu (sua) filho(a) leva para ir da sua casa até a escola? Ele/ela leva aproximadamente

34. Seu (sua) filho(a) faz algum curso fora da escola?
a) não ( )
b) $\operatorname{sim}($ ) qual tempo?
em que horário?

? há

quanto

35. Seu (sua) filho(a) trabalha?
c) não ( )
d) $\operatorname{sim}($ tempo?

)

onde? há quanto

em que horário?

Muito obrigada por sua colaboração 
ANEXO F - Diário de sono

\title{
Adolescência
}

\author{
e \\ Sono
}

Diário de sono

Nome: 


\section{Instruções gerais}

Este caderno é o seu diário de sono. Nele serão registrados sua temperatura oral, seus horários e maneiras de dormir, acordar e cochilar durante nove dias seguidos. Lembre-se:

- O termômetro digital deve ser usado somente para medir sua temperatura oral, que deve ser registrada no próprio diário ( $7^{\circ}$ item), cinco vezes ao dia.

- Por favor, anote ocorrências que possam alterar sua temperatura, como gripes e atividades físicas. Evite fazer refeições pesadas ou tomar banhos quentes antes das medidas.

- Lembramos que é necessário anotar tais dados durante o fim de semana.

- Ao final do preenchimento do diário de sono, a pesquisadora irá recolhê-lo, juntamente com o termômetro.

Qualquer dúvida, entre em contato com Fernanda Torres.

Muito obrigada pela colaboração 
Data: /2004 Dia da semana:

1. A que horas você foi dormir ontem? horas

2. Quanto tempo você demorou para pegar no sono?

Demorei

3. A que horas você acordou hoje? horas

4. Você acordou durante a noite?

( ) não ( ) sim vezes

5. Como você foi acordado(a):

Despertador ( )

Alguém chamou ( )

Sozinho ( )

Barulho ( )

6. Você dormiu durante o dia?:

( ) não ( ) sim

Duração do(s) cochilo(s): 
7. Medidas de temperatura (não são necessárias medidas durante o sono)

\begin{tabular}{|l|l|l|}
\hline Horário & $\begin{array}{l}\text { Temperatura } \\
\left({ }^{\circ} \mathrm{C}\right)\end{array}$ & Observações \\
\hline & & \\
\hline & & \\
\hline & & \\
\hline & & \\
\hline & & \\
\hline & & \\
\hline
\end{tabular}

OBSERVAÇÕES: 
ANEXO G - Fotografias de actímetro, termômetro digital e Thermocron ${ }^{\circledR}$
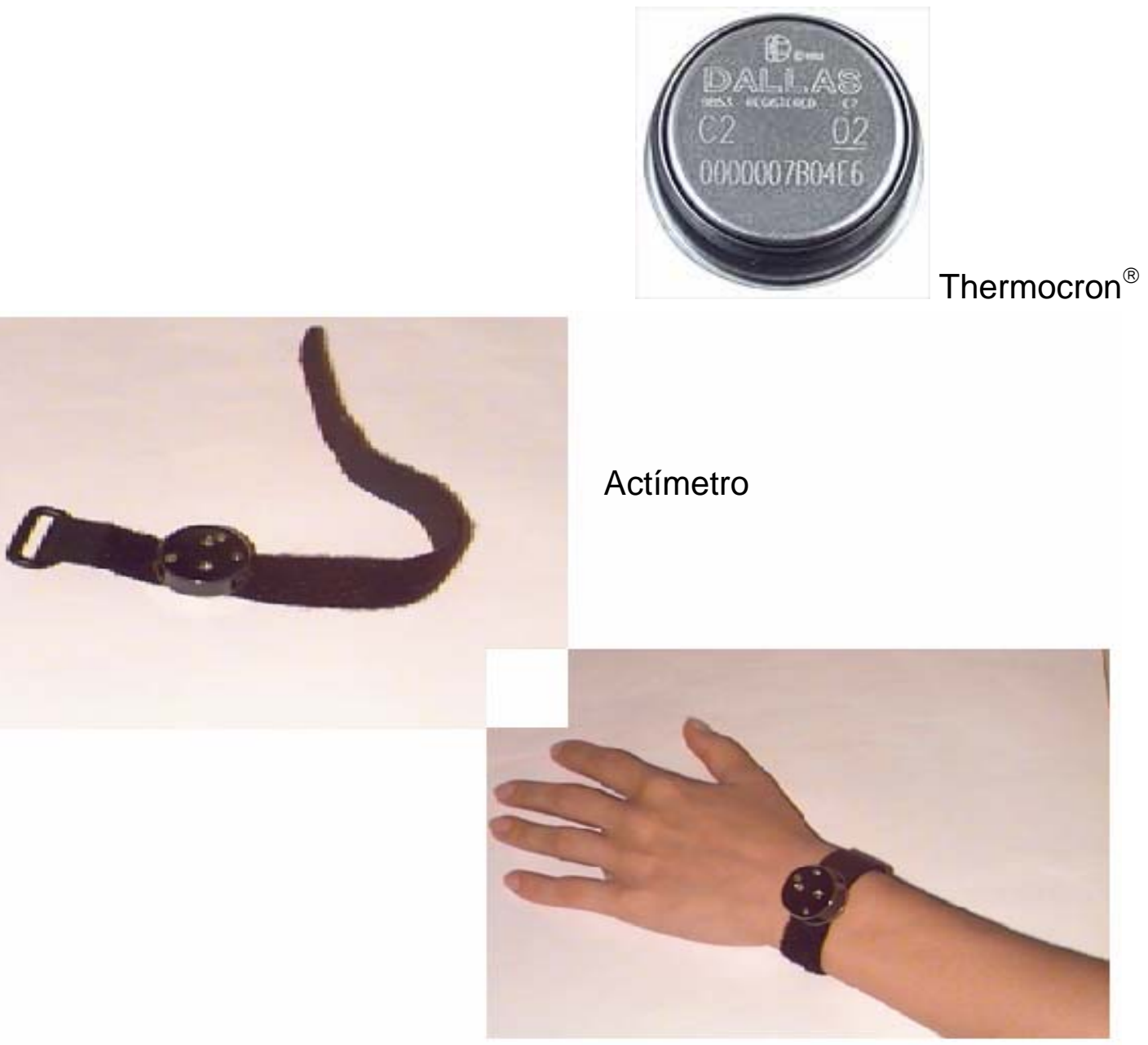

Termômetro digital 
ANEXO H: Actogramas de diários de sono e actímetro

\section{LP94fEi}

\section{LP94f2}

Diário de sono

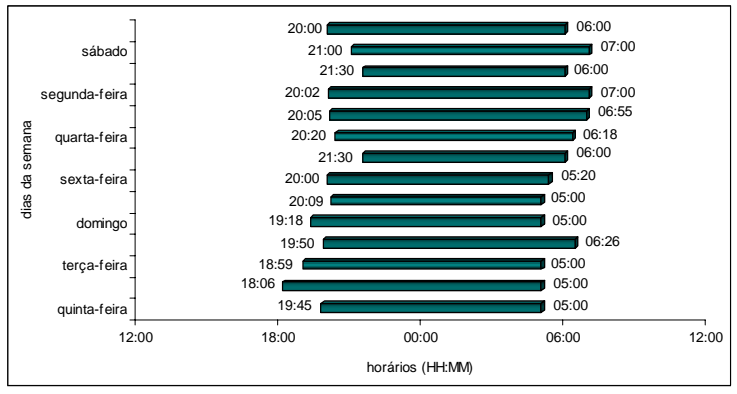

Actímetro

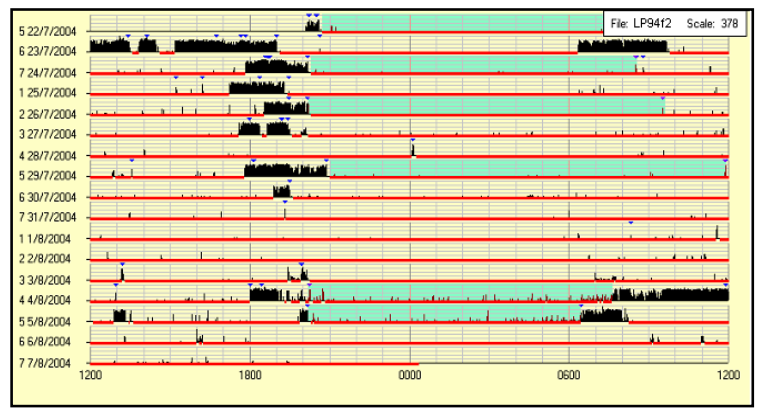




\section{AS94mEi}

AS94m2

Diário de sono

Actímetro

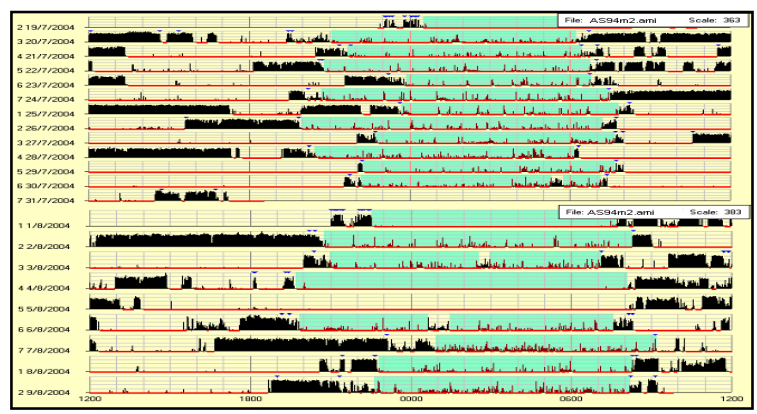

\section{AS94m3}

Diário de sono

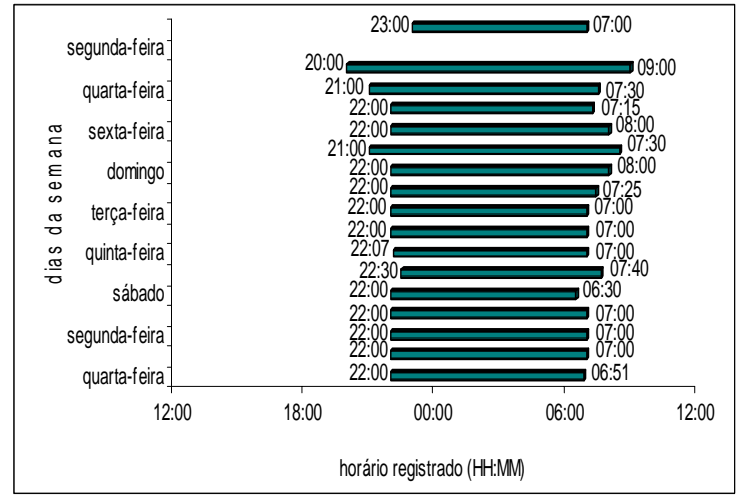

Actímetro

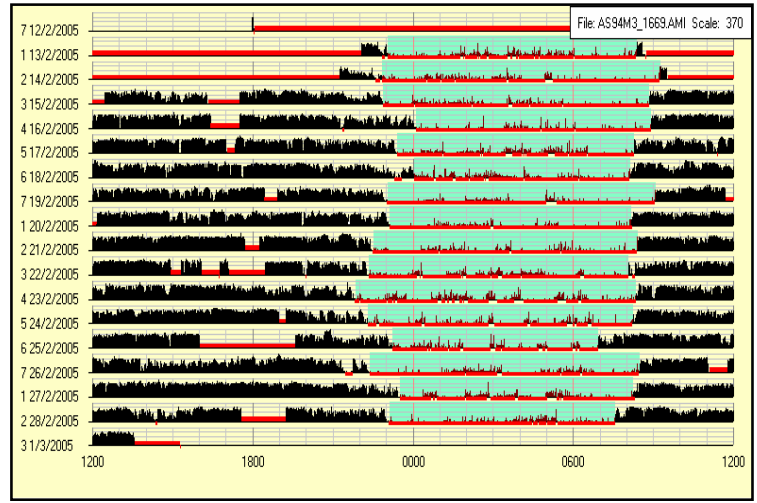




\section{MS94fEi}

\section{MS94f2}

Diário de sono

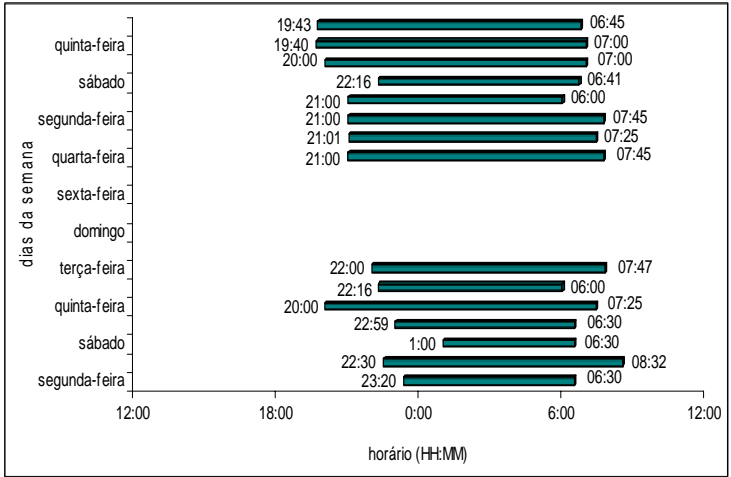

Actímetro

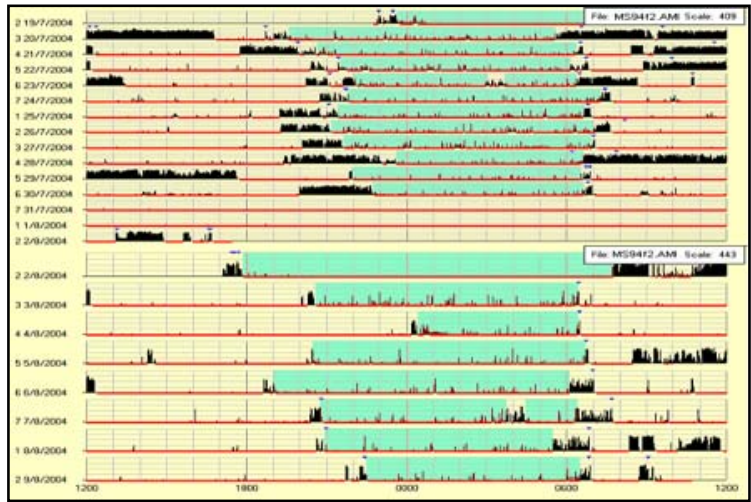

\section{MS94f3}

Diário de sono

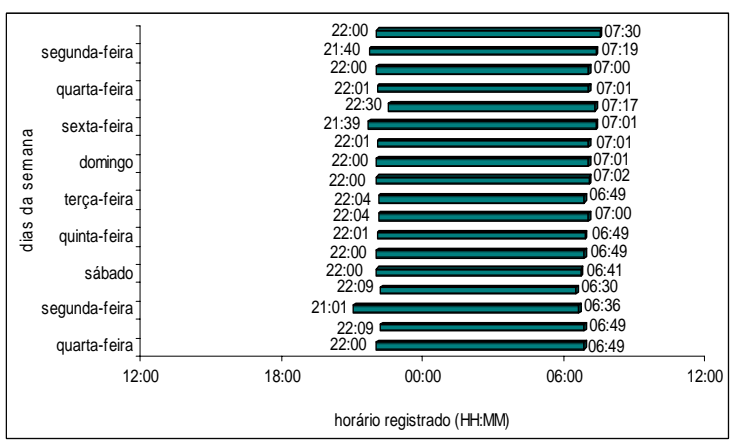

Actímetro

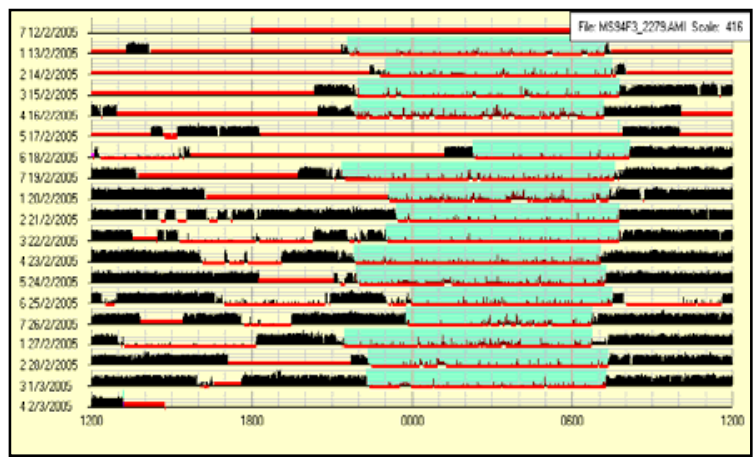


MaS93fEi

\section{MaS93f3}

Diário de sono

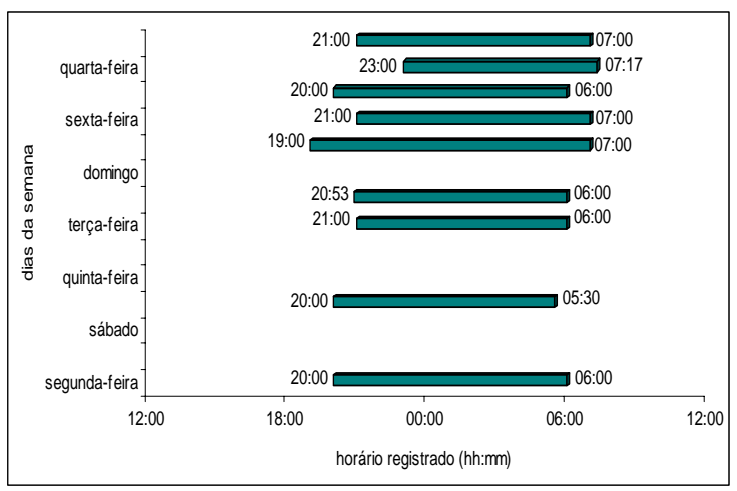

Actímetro

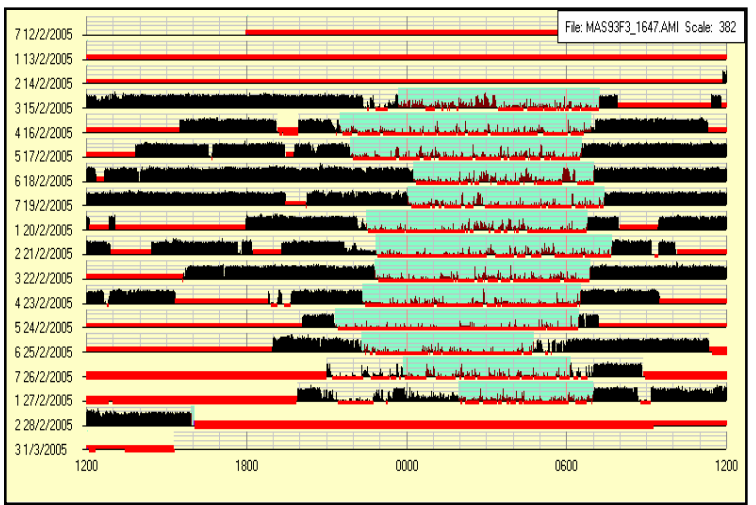


AB93Ei

AB93f3

Diário de sono

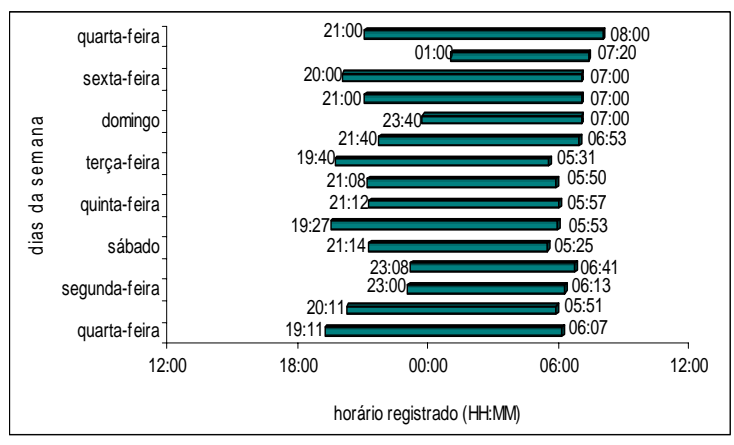

\section{Actímetro}

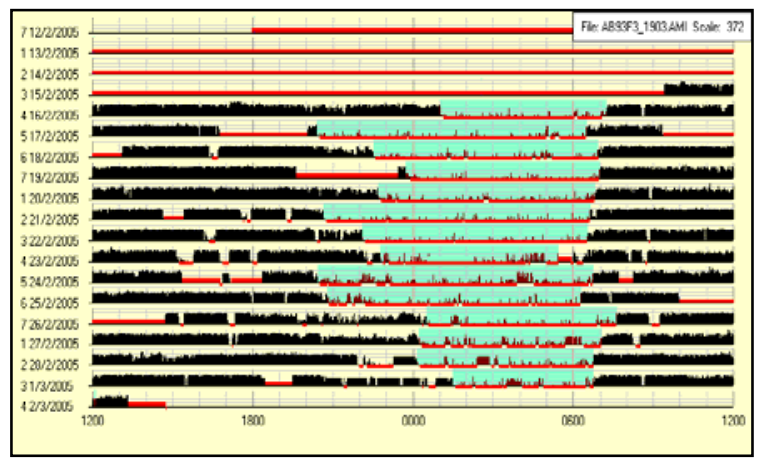




\section{AL92mEi}

AL92m1

Diário de sono

\section{Actímetro}

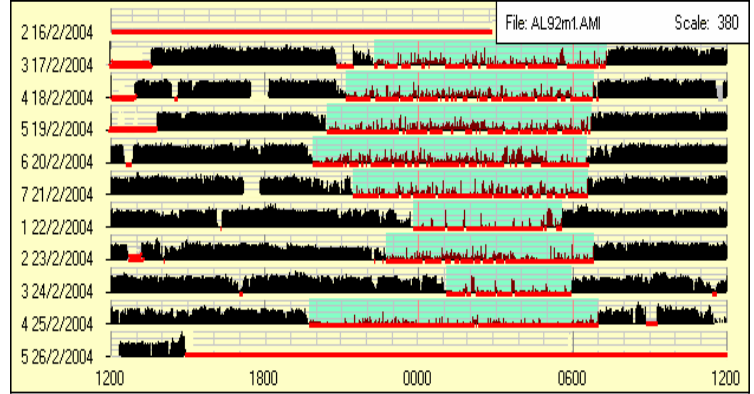

\section{AL92m2}

Diário de sono

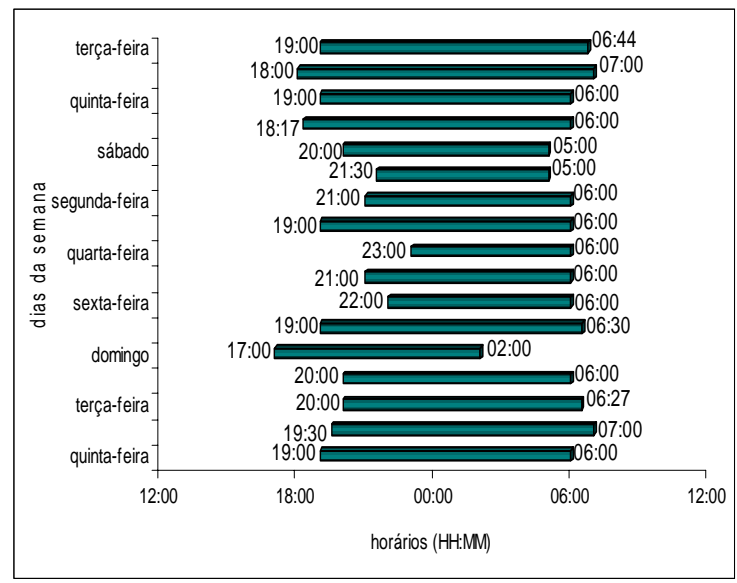

\section{Actímetro}

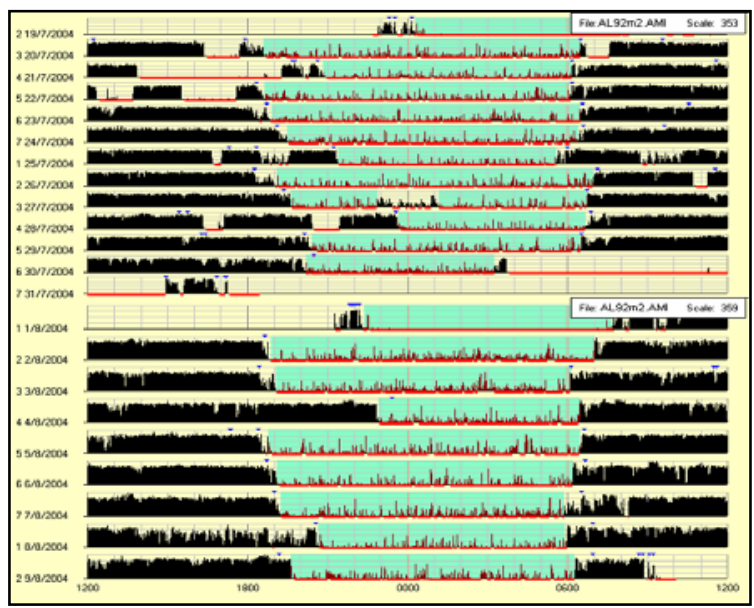

AL92m3

Diário de sono

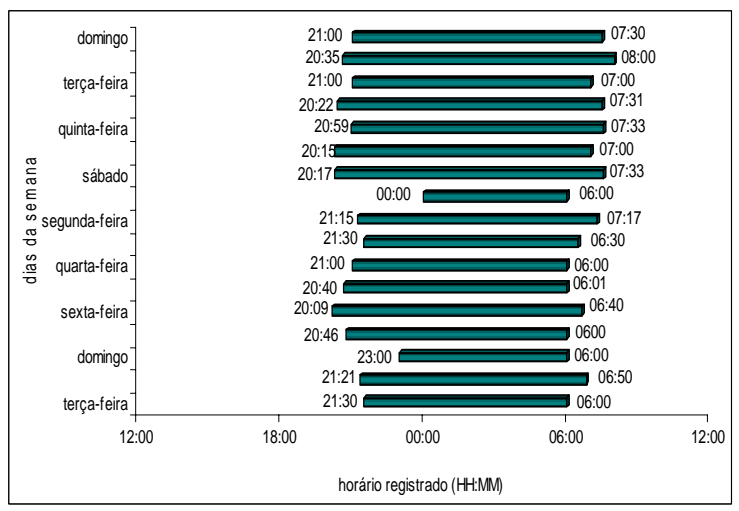

Actímetro

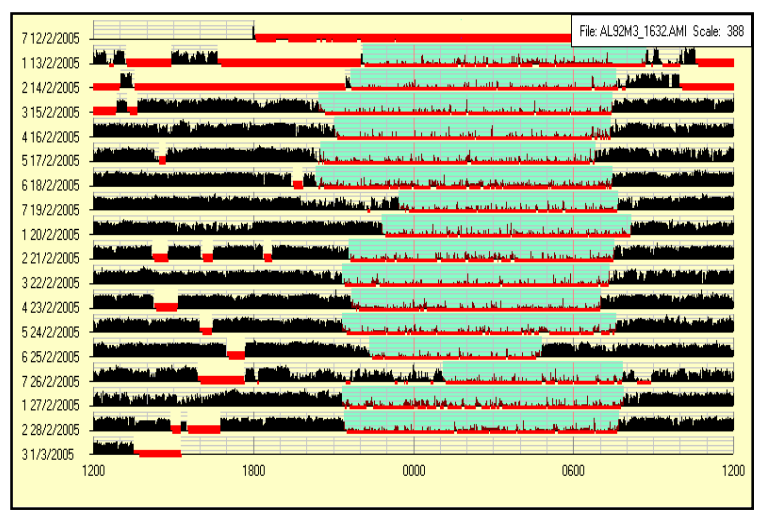




\section{Esa92mEi}

Esa92m2

Diário de sono

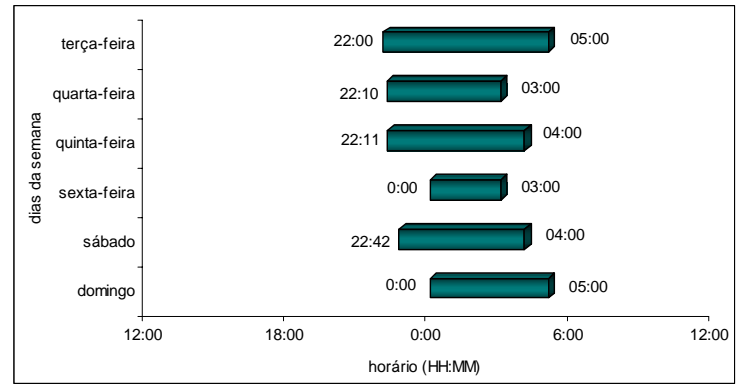

\section{Actímetro}

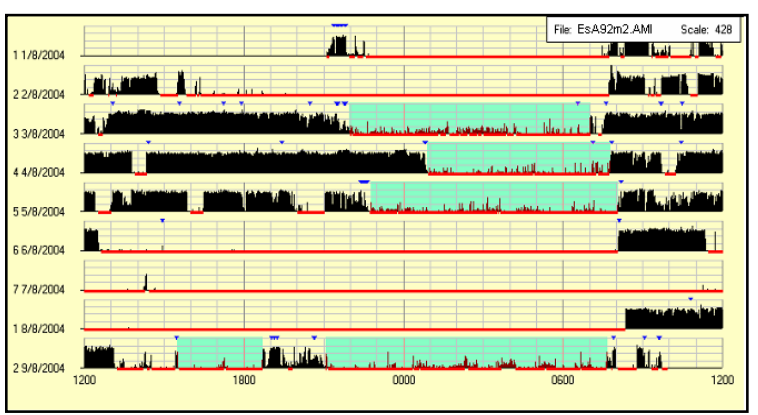

ESa92m3

Diário de sono

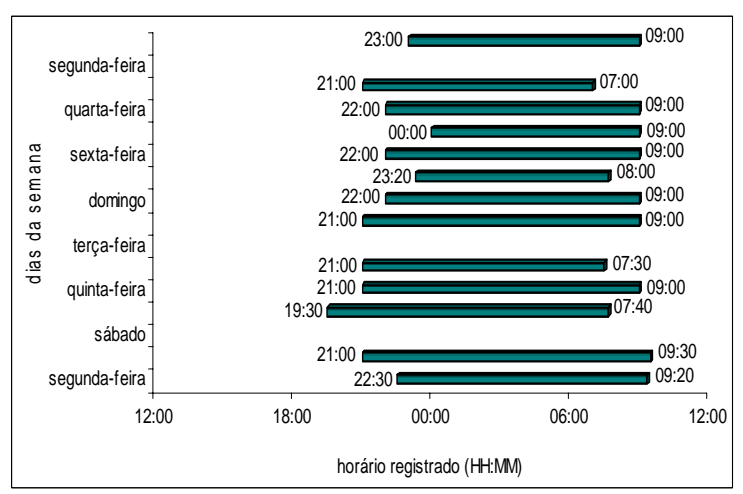

\section{Actímetro}

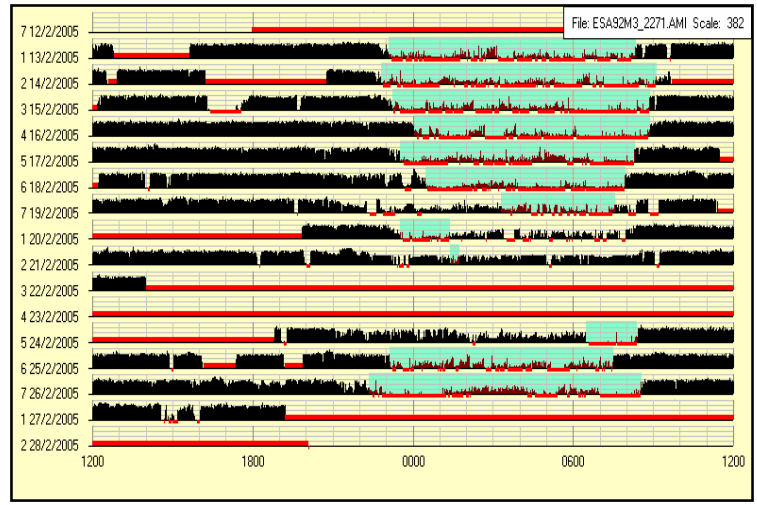




\section{Mv92fEp}

MvS92f1

Diário de sono

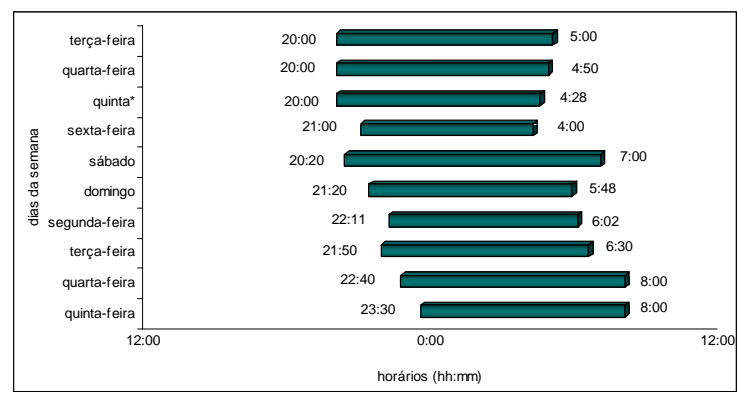

Actímetro

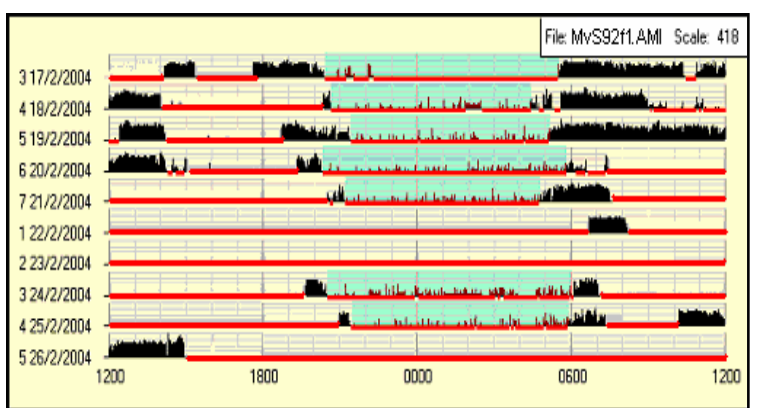

MvS92f2

\section{Diário de sono}

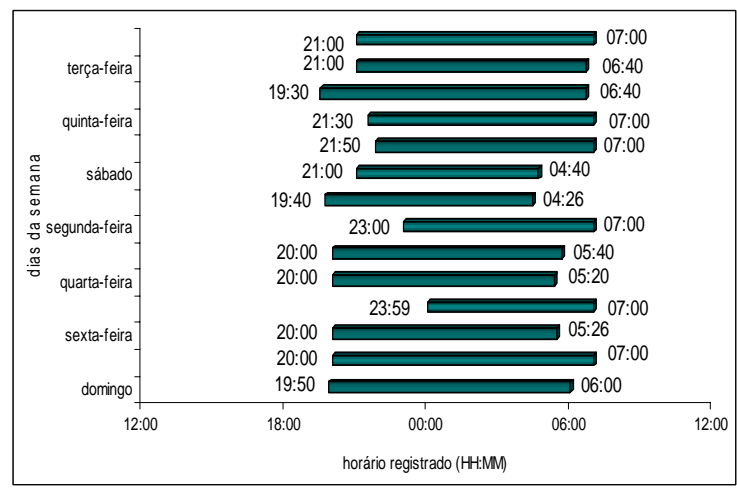

\section{Actímetro}

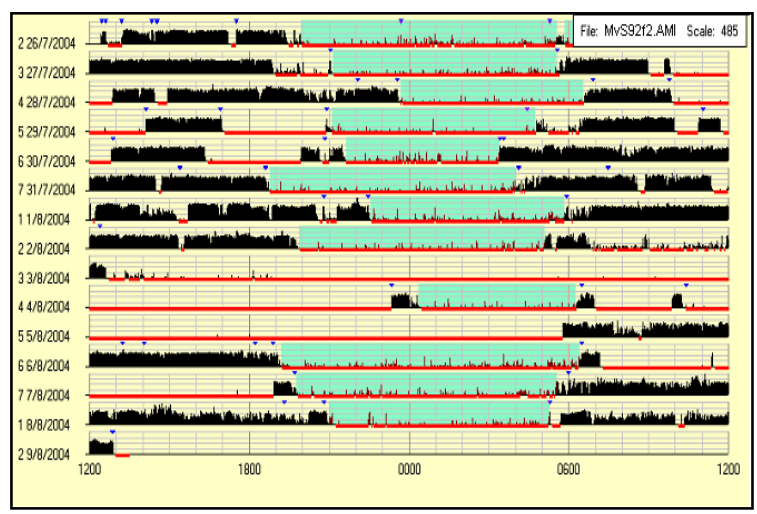

\section{MvS92f3}

Diário de sono

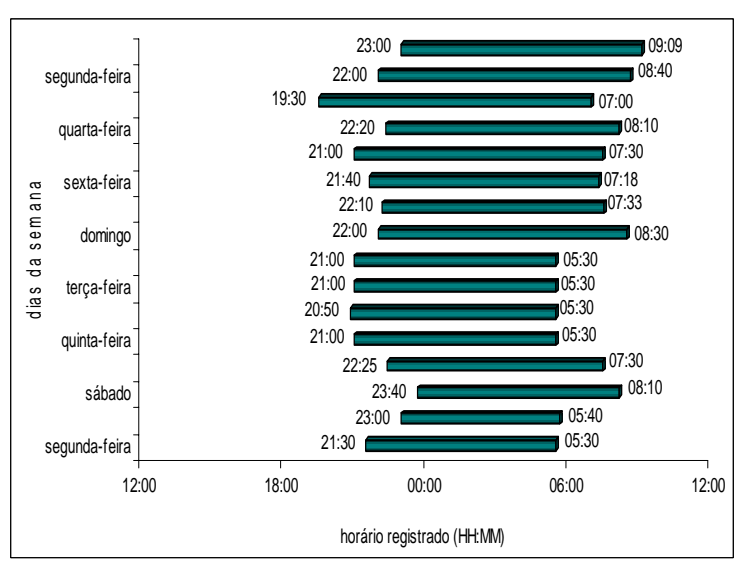

Actímetro

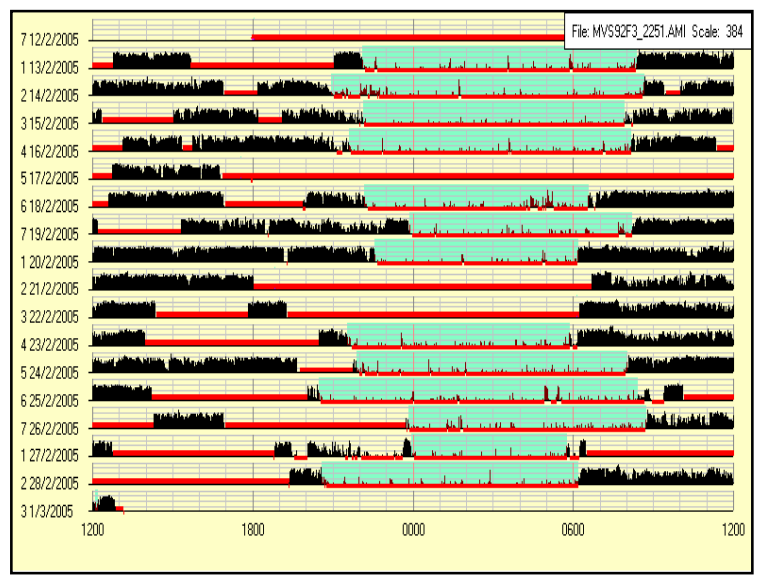




\section{MA91mEp}

MA91m1

Diário de sono

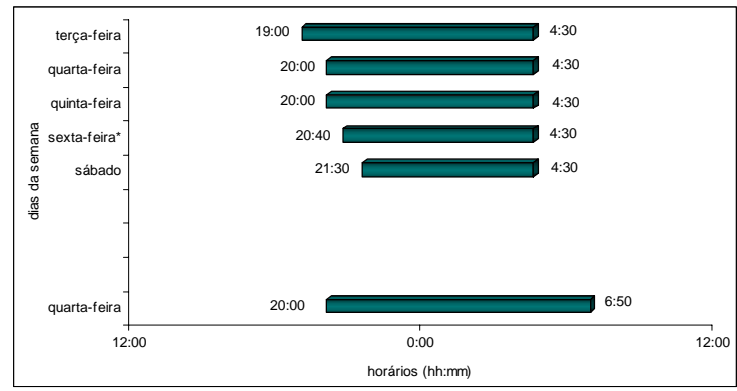

Actímetro

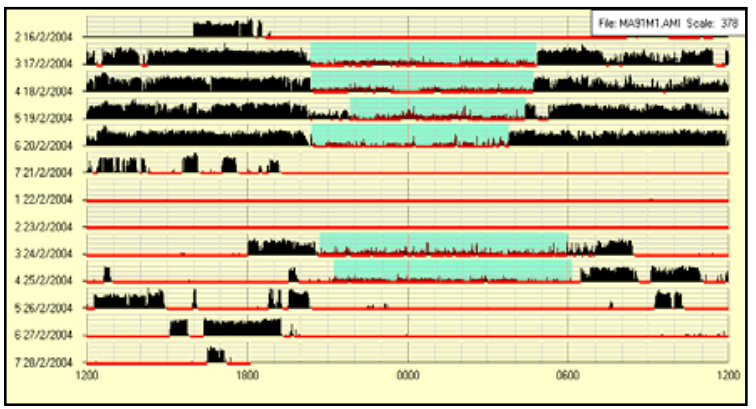

MA91m2

Diário de sono

\section{Actímetro}

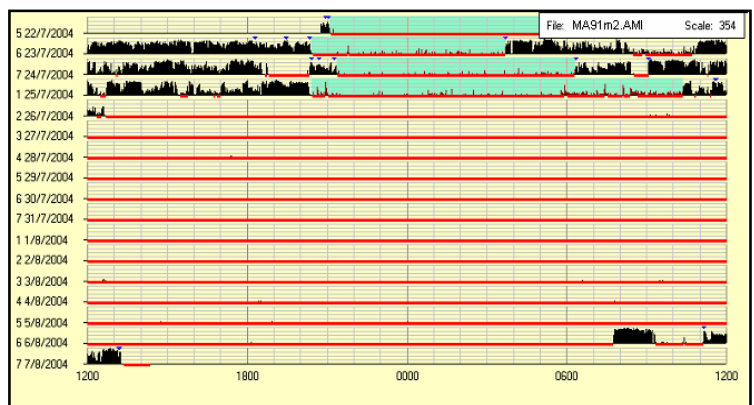




\section{AS91mN}

AS91m1

Diário de sono

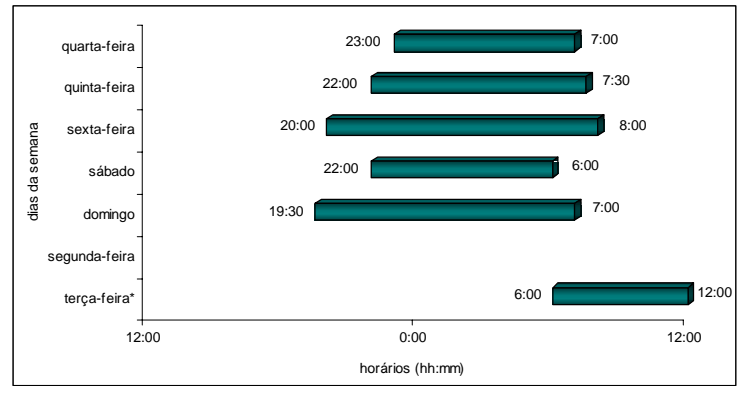

\section{Actímetro}

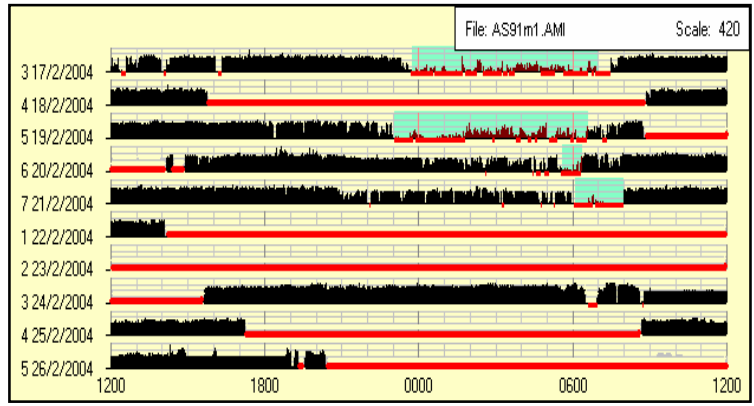

AS91m2

Diário de sono

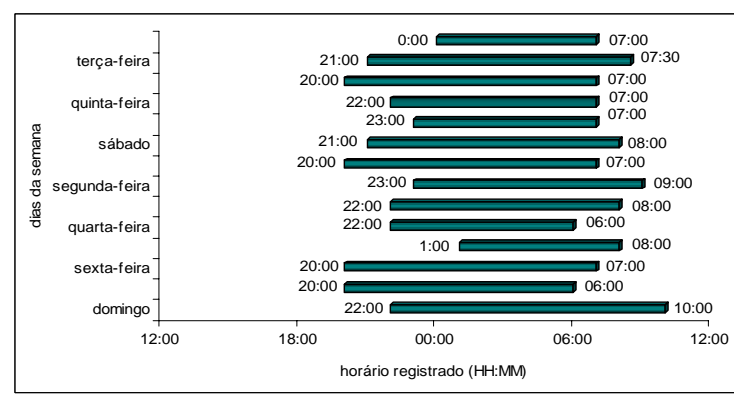

Actímetro

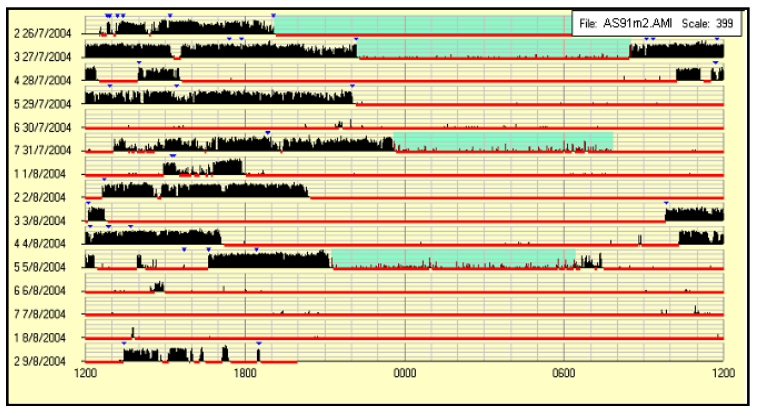




\section{GE91mN}

GE91m1

GE91m2

Actímetro

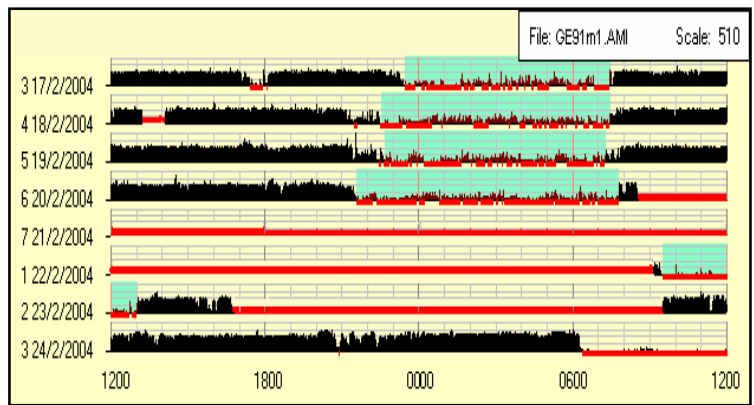

Diário de sono

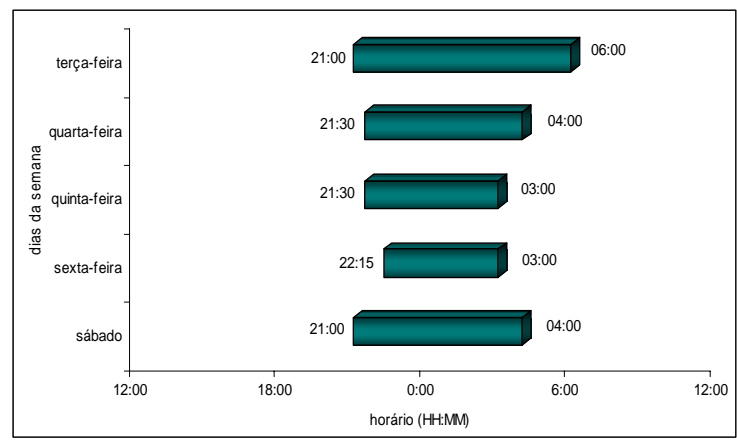

\section{GE91m3}

Diário de sono

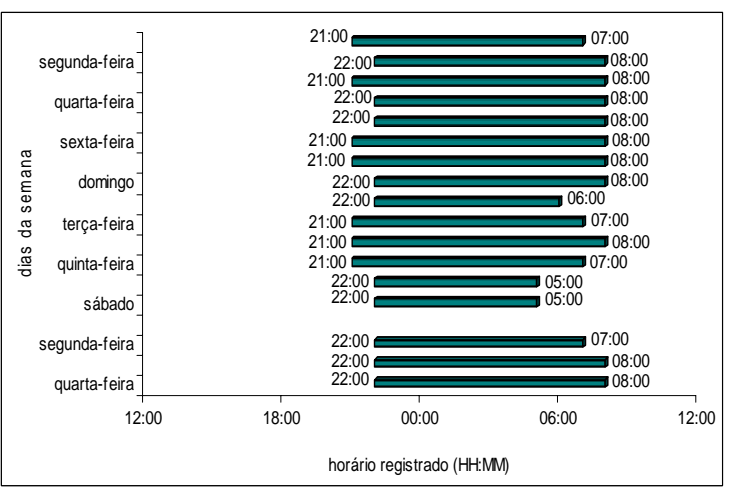

\section{Actímetro}

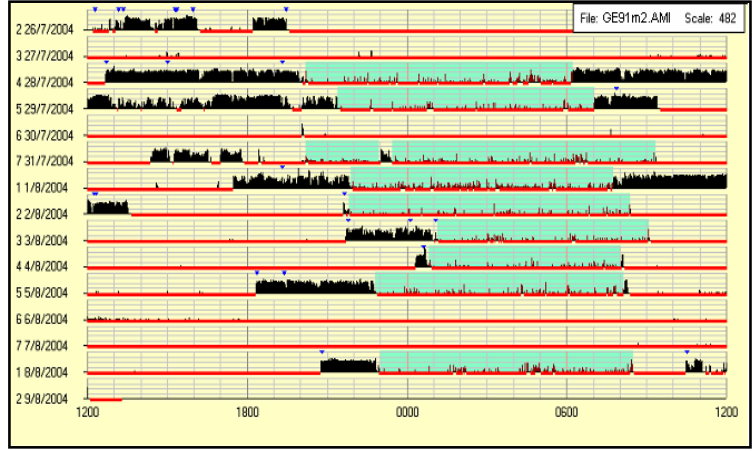

Actímetro

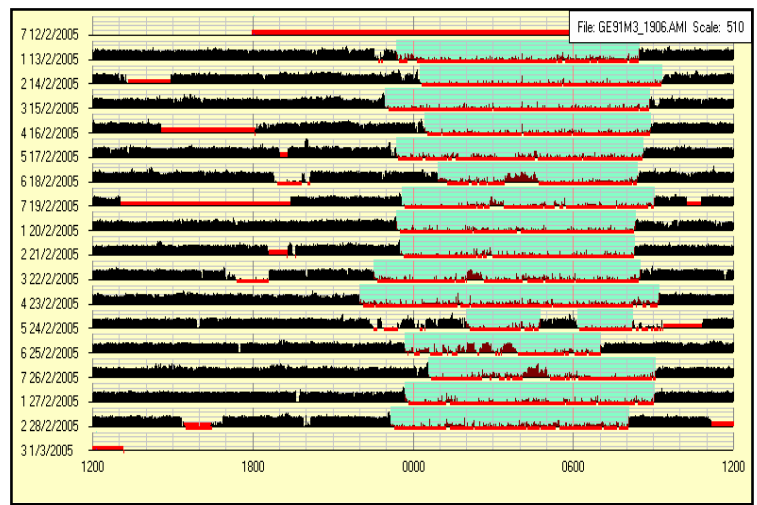




\section{FS90fEp}

FS90f1

Diário de sono

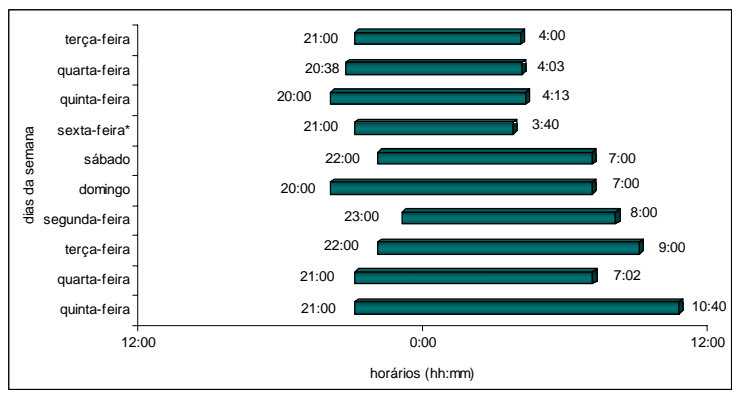

Actímetro

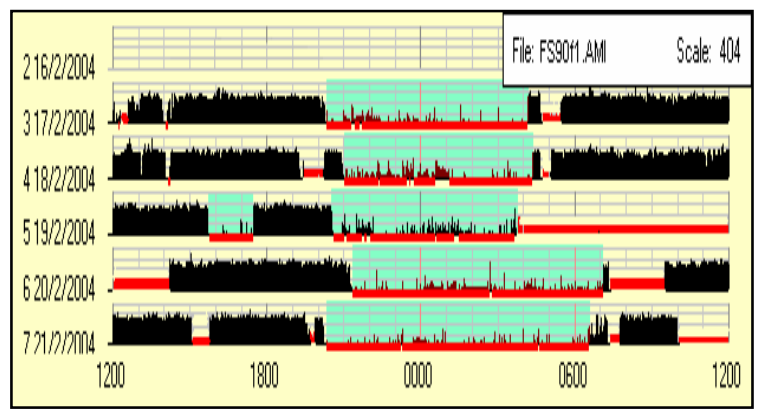

FS90f2

Actímetro

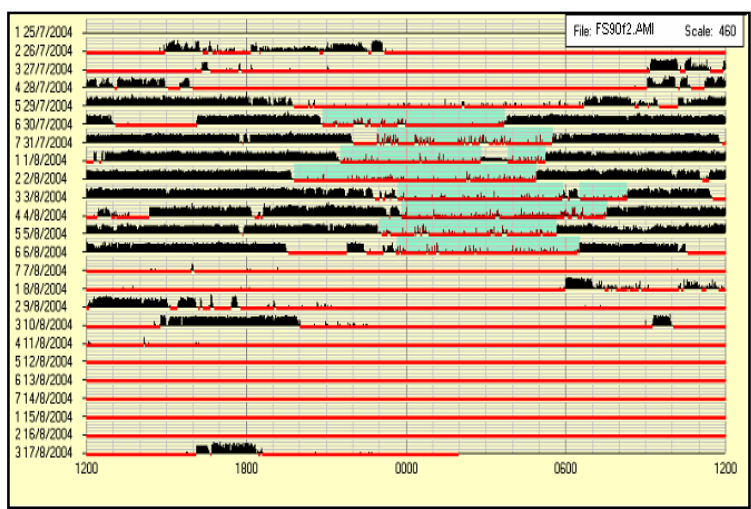




\section{Esi90mEp/N}

Esi90m1

\section{Actímetro}

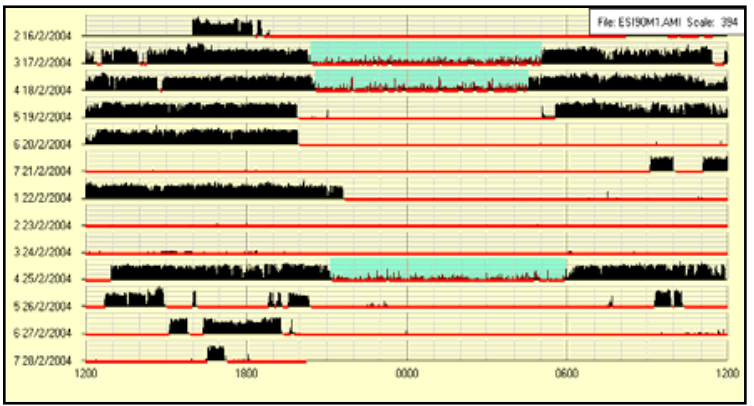

\section{Esi90m2}

\section{Diário de sono}

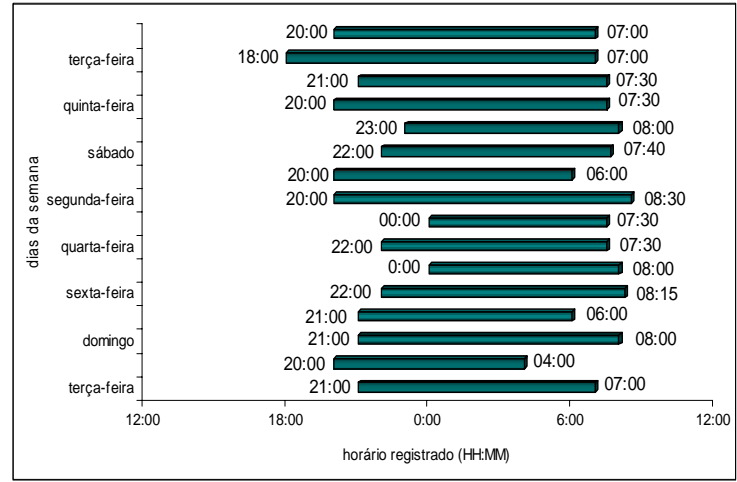

\section{Actímetro}

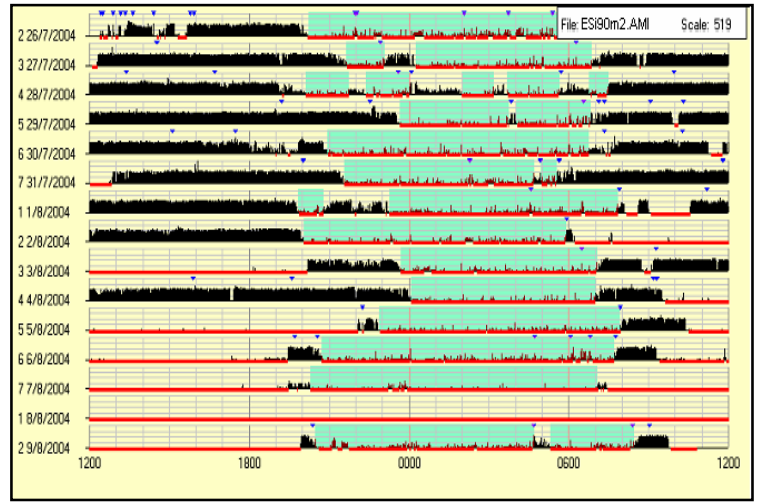

\section{Esi90m3}

\section{Diário de sono}

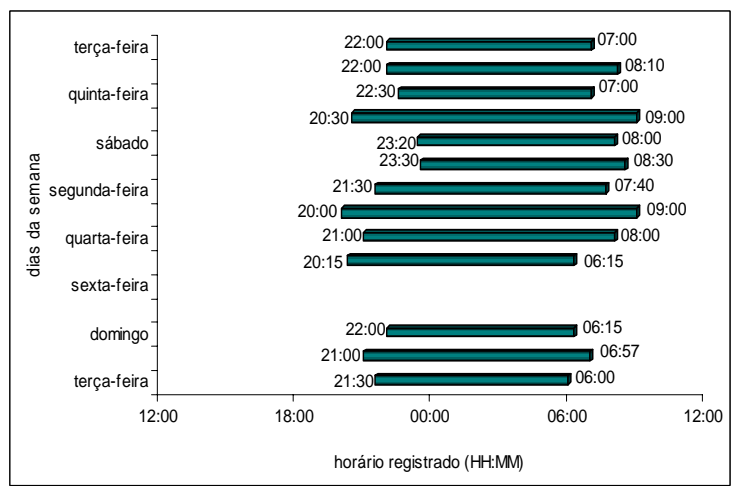

\section{Actímetro}

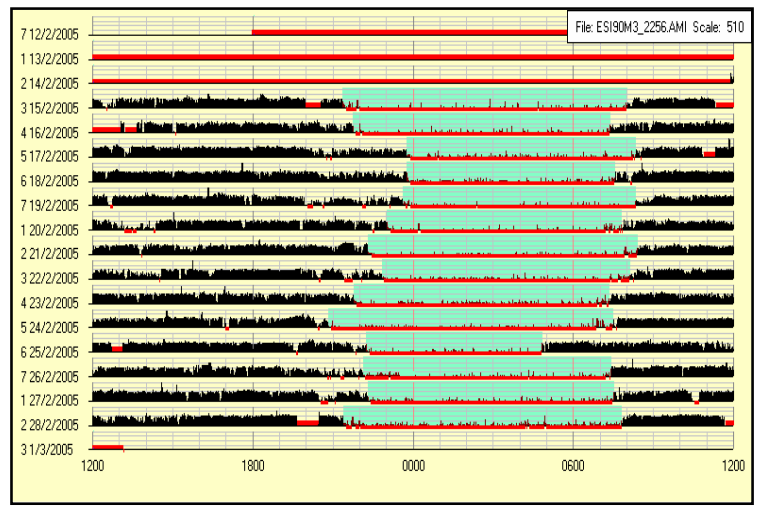




\section{AdS90mEi}

AdS90m1

Diário de sono

\section{Actímetro}

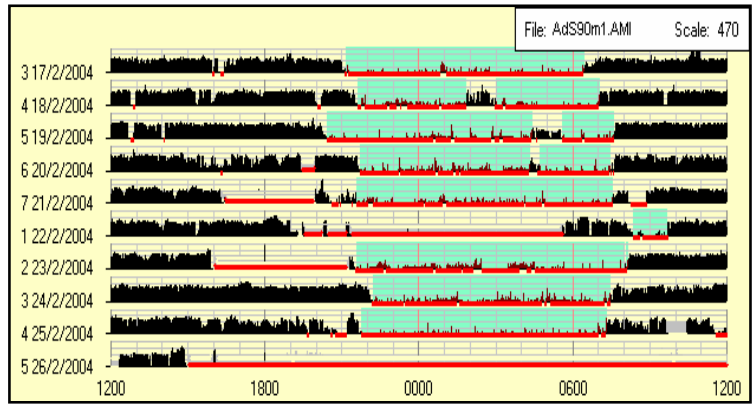

AdS90m2

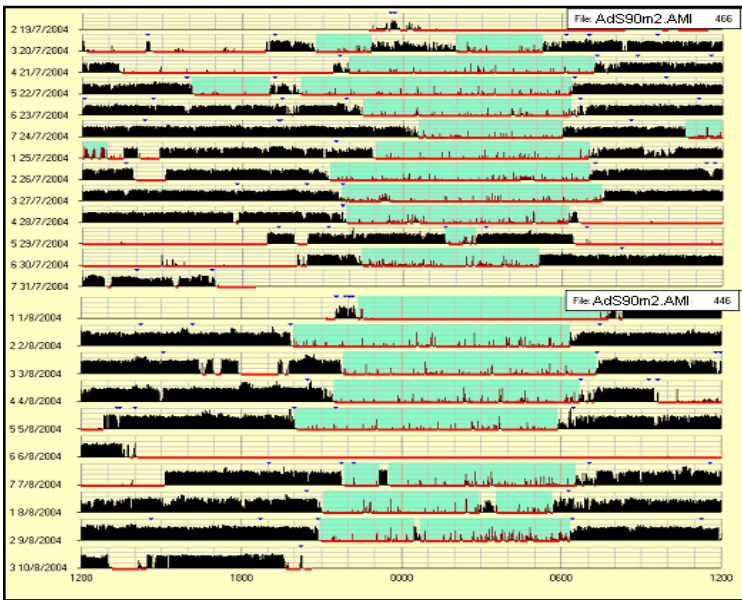

Actímetro

AdS90m3

Diário de sono

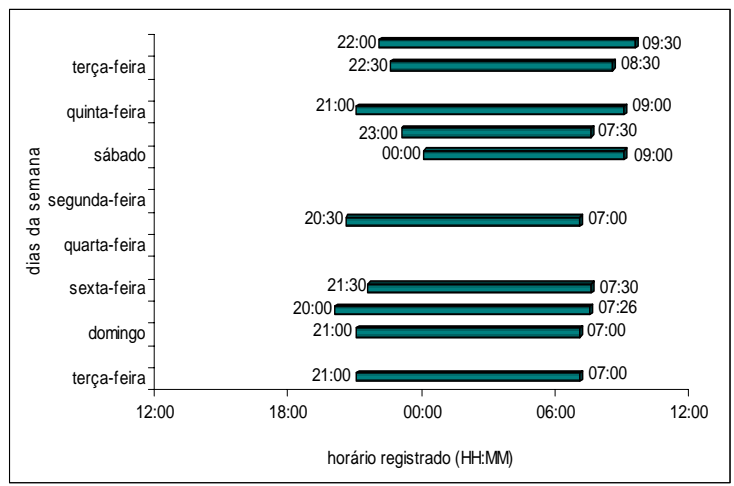

Actímetro

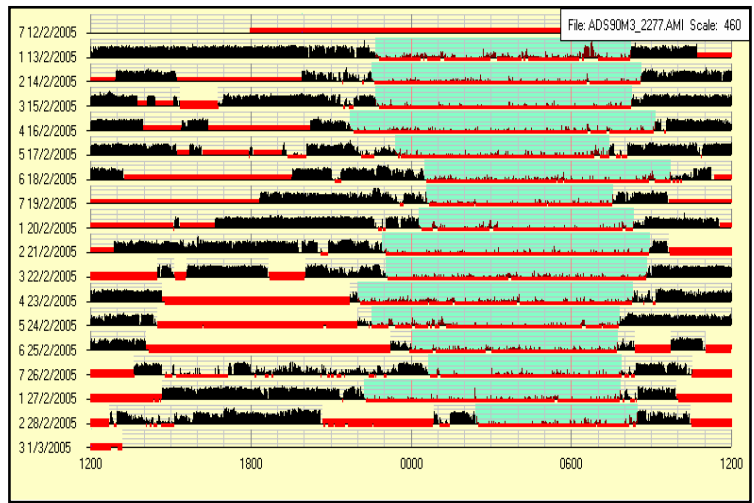




\section{EL90mN}

\section{EL90m1}

Diário de sono

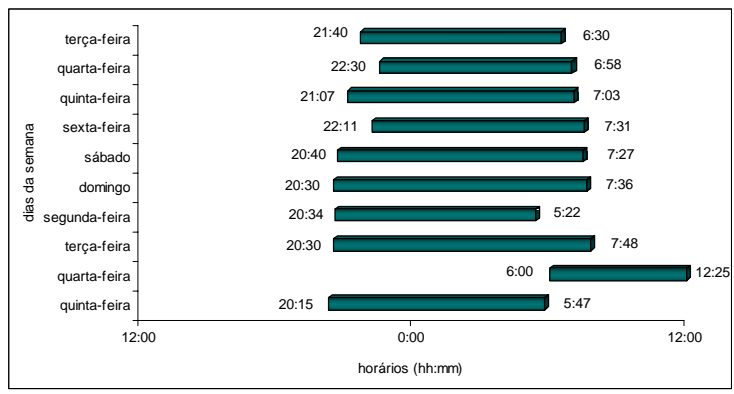

EL90m2

\section{Actímetro}

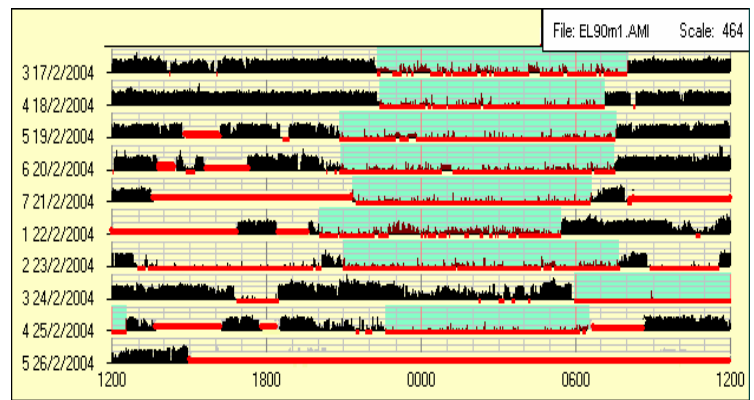

\section{Actímetro}

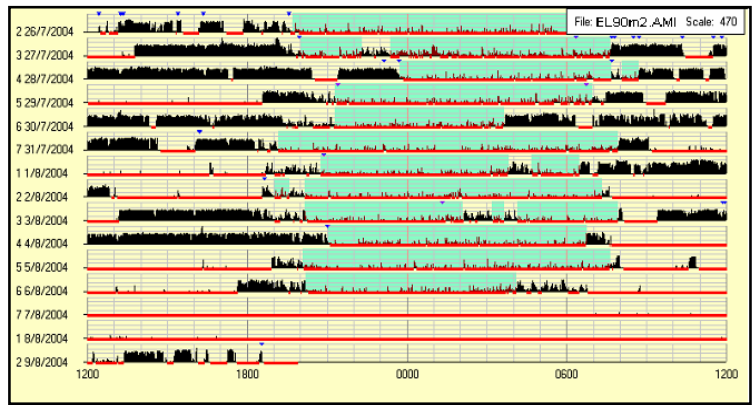

\section{EL90m3}

Diário de sono

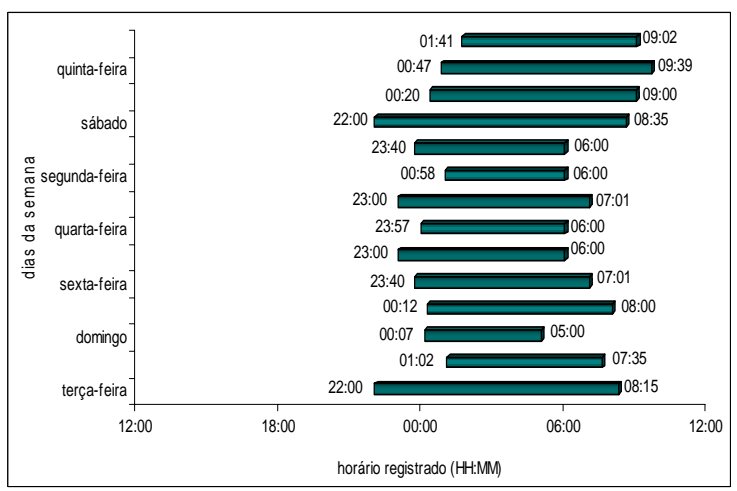

\section{Actímetro}

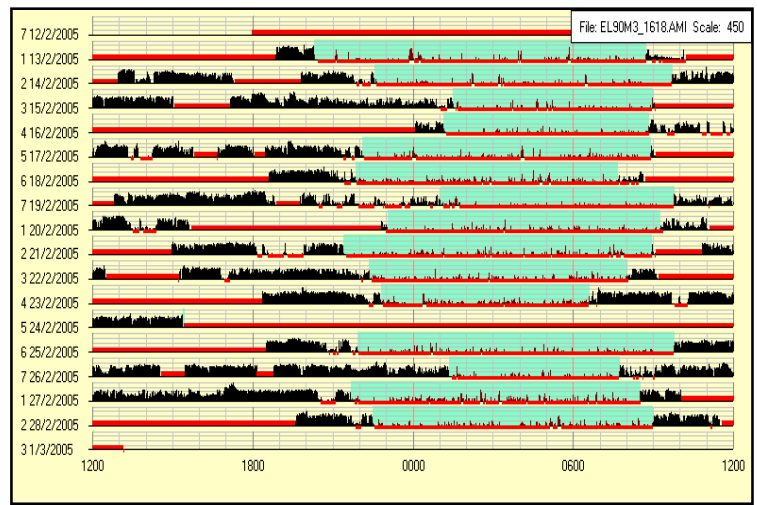




\section{VB89mEi}

VB89m1

Diário de sono

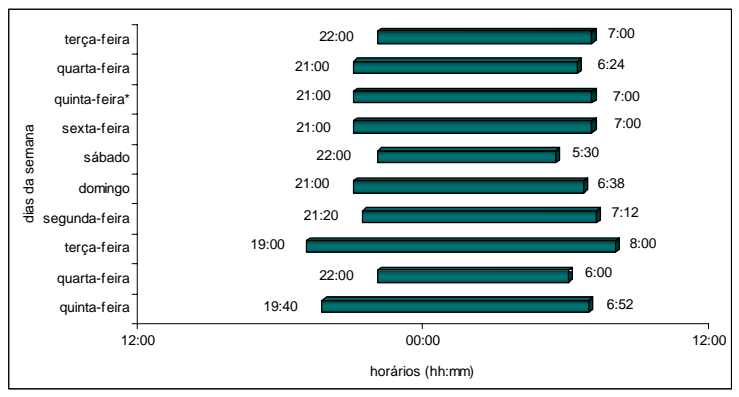


CS88mN

CS88m3

Diário de sono

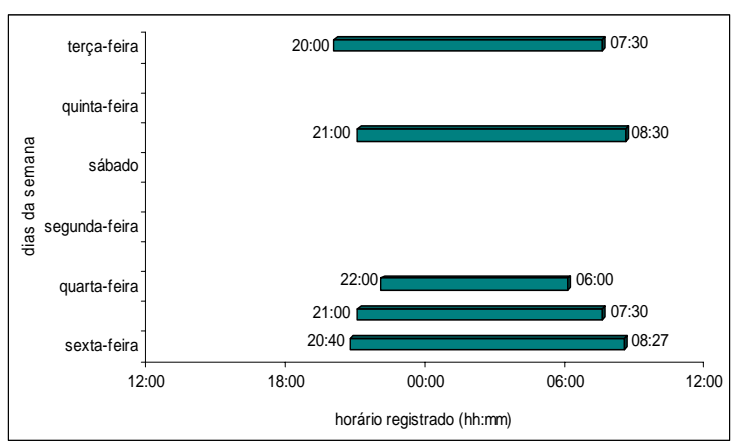

\section{Actímetro}

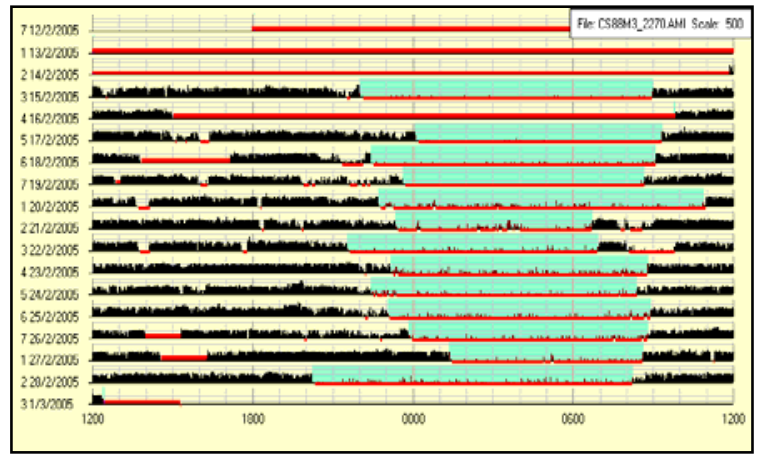




\section{JS87mN}

JS87m2

Diário de sono

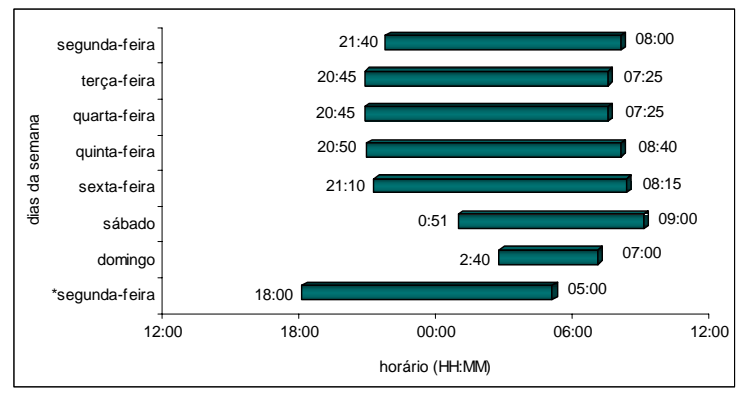

\section{Actímetro}

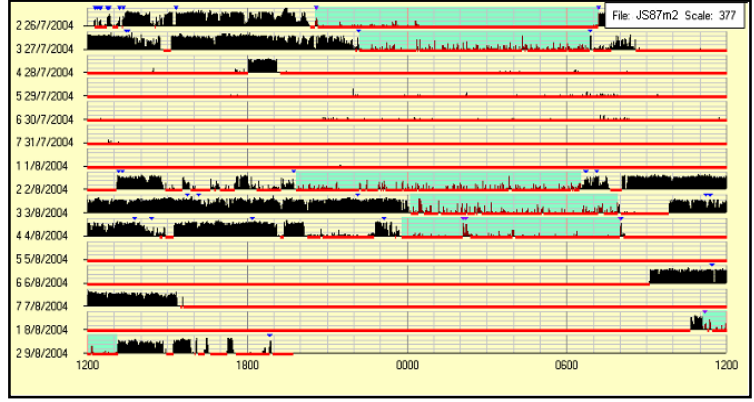

\section{JS87m3}

Diário de sono
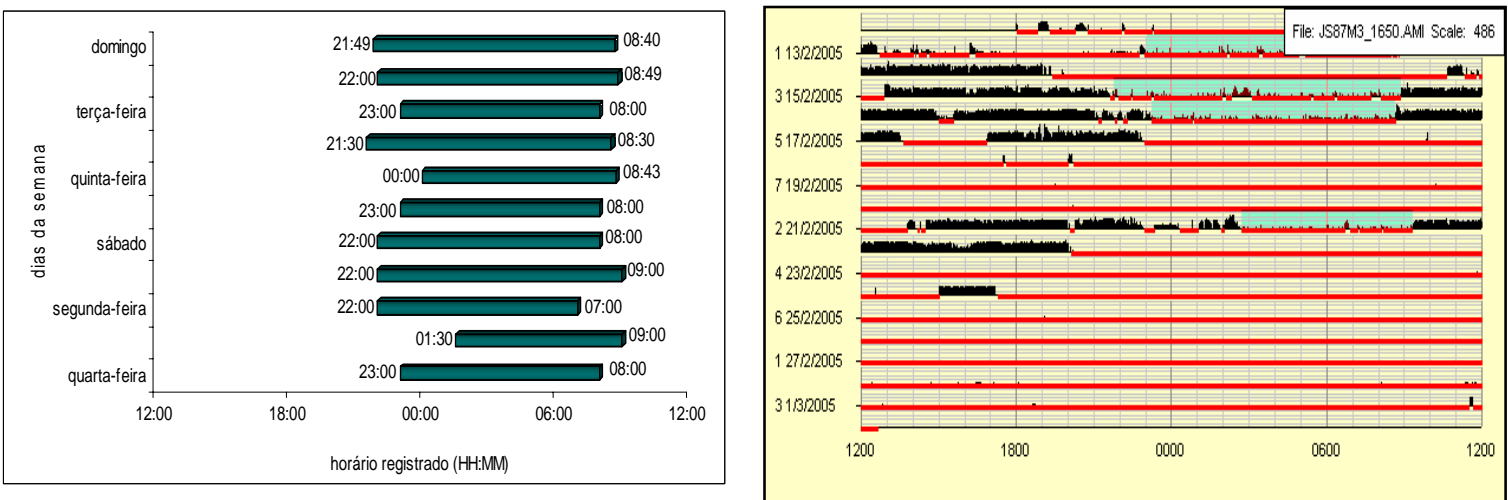


\section{AT86mN}

AT86m2

Diário de sono

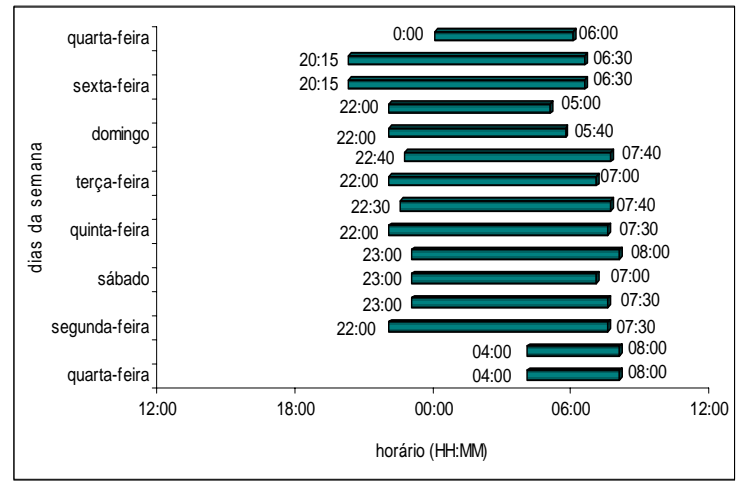

\section{AT86m3}

Diário de sono

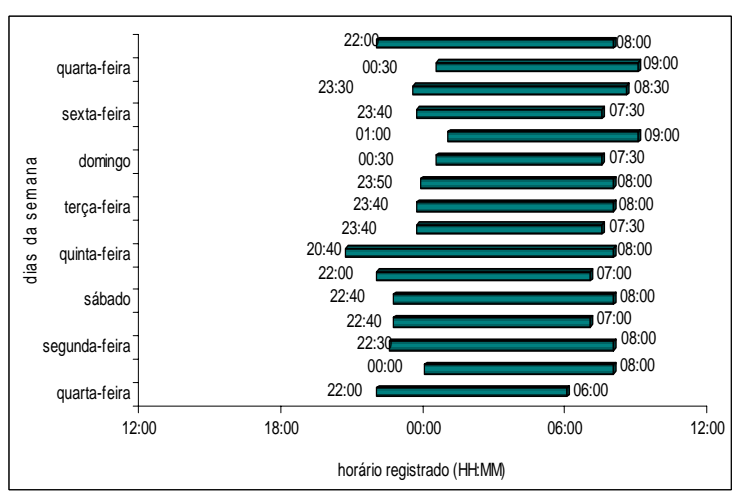

Actímetro

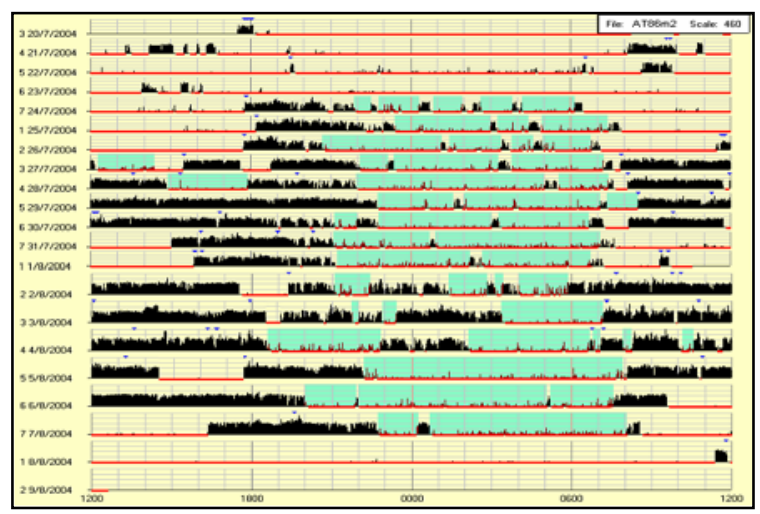

\section{Actímetro}

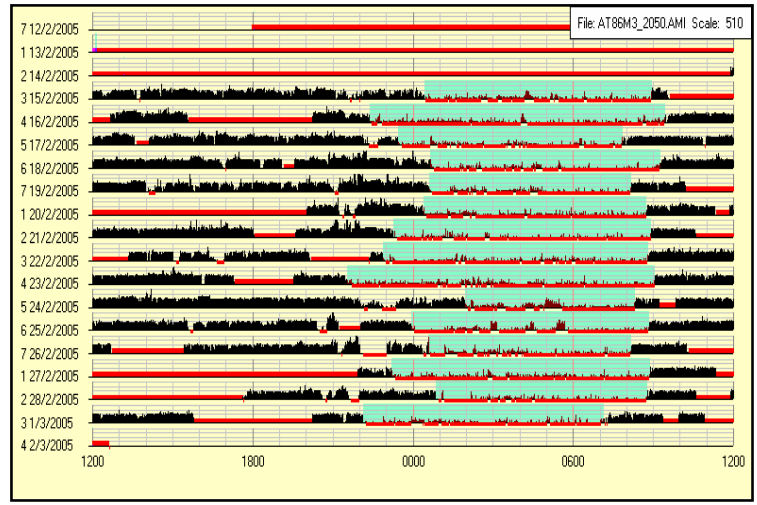


FaS86mN

FaS86m3

Diário de sono

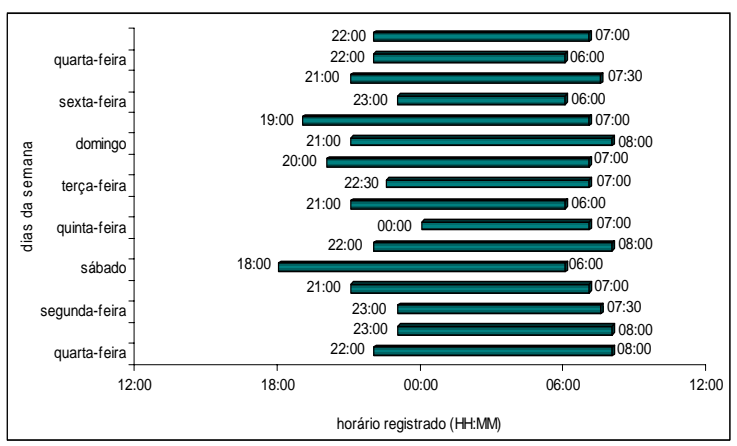

Actímetro

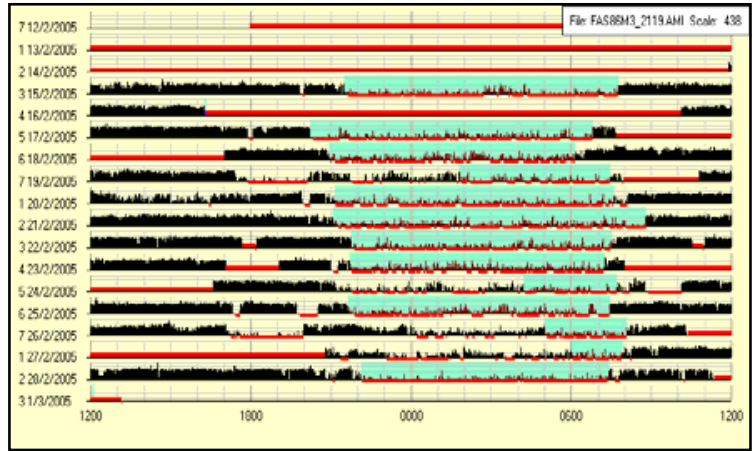




\section{SB86fN}

SB86f2

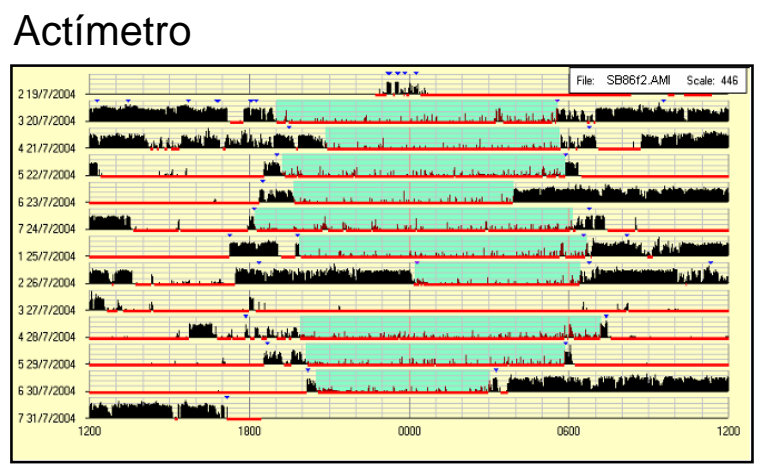


ANDRADE, M.M.M.; Ciclo vigília/sono de adolescentes: um estudo longitudinal. São Paulo, 1991, 121p. Dissertação (Mestrado) - Instituto de Ciências Biomédicas, Universidade de São Paulo.

ANDRADE, M.M.M.; BENEDITO-SILVA, A.A.A.; DOMENICE, S.; ARNHOLD, I.J.P., MENNA-BARRETO, L. Sleep characteristics of adolescents: a longitudinal study. Journal of Adolescent Health, v.14, n.4, p. 401-406, 1993.

ANDRADE, M.M.M. Padrões temporais de expressão de sonolência em adolescentes. São Paulo, 1997, 166p. Tese (Doutorado) - Instituto de Ciências Biomédicas, Universidade de São Paulo.

ARAKAWA, M.; TAIRA, K.; TANAKA, H.; YAMAKAWA, K.; TOGUCHI, H.; KADEKARU, H.; YAMAMOTO, Y.; UEZU, E.; SHIRAKAWA, S. A survey of junior high school students sleep habit and lifestyle in Okinawa. Psychiatry and Clinical Neurosciences, v.55, p.211-212, 2001.

ARÊAS, R.; DUARTE, L.; MENNA-BARRETO, L.S. Análise comparativa de parâmetros rítmicos da temperatura corporal em seres humanos medidas com a utilização de termístor com memória e termômetro digital. FeSBE Expo 2005. Resumo disponível na Internet: http://www.fesbe.org.br/reuniao.php?rno=2\&templ=busca resumo [27 jul. 2005]. 
BENEDITO-SILVA, A.A.A. Aspectos metodológicos da cronobiologia. In: Marques, N. ; Menna-Barreto, L. (eds). Cronobiologia: princípios e aplicações. São Paulo: Edusp, 2003. p.297-320.

CARDOSO, A.M., MATTOS, I. E.; KOIFMAN, R.J. Prevalence of risk factors for cardiovascular disease in the Guaraní-Mbyá population of the State of Rio de Janeiro. Caderno Saúde Pública, Mar./Apr. 2001, vol.17, n.2, p.345-354.

CARSKADON, M.A.; HARVEY, K.; DUKE, P.; ANDERS, T.F.; LITT, I.F.; DEMENT, W.C. Pubertal changes in daytime sleepiness. Sleep, v.2, n.4, p. 453-460, 1980.

CARSKADON, M.A. Patterns of sleep and sleepiness in adolescents. Pediatrician, v.17, p.5-12, 1990.

CARSKADON, M.A.; VIEIRA, C.; ACEBO, C. Association between puberty and delayed phase preference. Sleep, v.16, n.3, p.258-262, 1993.

CARSKADON, M.A.; WOLFSON, A.R.; ACEBO, C.; TZISCHINSKY; O.; SEIFER, R. Adolescent sleep patterns, circadian timing, and sleepiness at a transition to early school days. Sleep, v.21, n.8, 1998.

CARSKADON, M.A.; LABYAK, S.E.; ACEBO, C.; SEIFER, R. Intrinsic circadian period of adolescent humans measured in conditions of forced desynchrony. Neuroscience Letters, v.260, p.129-132, 1999.

CARSKADON, M.A. (Editor). Adolescent sleep patterns: biological, social, and psychological influences. Cambridge University Press, Cambridge, 2002. 297p. 
CARSKADON, M.A.; WOLFSON, A.R. Understanding adolescents' sleep patterns and school performance: a critical appraisal. Sleep Medicine Reviews, v.7, n.6, p.491-506, 2003.

CARSKADON, M.A.; ACEBO, C.; JENNI O.G. Regulation of adolescent sleep: Implications for behavior. Annals of the New York Academy of Sciences, v.1021, p.292-293, 2004.

CARSKADON, M.A. Sleep difficulties in young people. Archives of Pediatrics and Adolescent Medicine, v.158, p.597-598, 2004.

CHEBIOM, M. Os índios Guarani do litoral do estado de São Paulo: análise antropológica de uma situação de contato. São Paulo, FFLCH/USP, Coleção Antropologia, 1986, 204p.

DAAN, S.; BEERSMA D.G.; BORBÉLY, A.A. Timing of human sleep: recovery process gated by a circadian pacemaker. American Journal of Physiology, v.246, R161-183, 1984.

DAHL, R.E.; LEWIN, D.S. Pathways to adolescent health: sleep regulation and behavior. The Journal of Adolescent Health, v.31, s.6, p.175-184, 2002.

ELIASSON, A.; KING, J.; GOULD, B. Association of sleep and academic performance. Sleep Breath, v.6, n.1, p. 45-48, 2002.

FALLONE, G.; OWENS, J.A.; DEANE, J. Sleepiness in children and adolescents: clinical implications. Sleep Medicine Reviews, v.6, n.4, p.287-306, 2002.

FUKUDA, F.; ISHIHARA, K. Age-related changes of sleeping pattern during adolescence. Psychiatry and Clinical Neurosciences, v.55, p.231-232, 2001. 
GAU, S.F.; SOONG, W.T. The transition of sleep-wake patterns in early adolescence. Sleep, v.26, p.449-454, 2003.

GIANNOTTI, F.; CORTESI, F.; SEBASTIANI, T.; OTTAVIANO, S. Circadian preference, sleep and daytime behavior in adolescence. Journal of Sleep Research, v.11, p.191-199, 2002.

GRADISAR, M.; LACK, L. Relationships between the circadian rhythms of finger temperature, core temperature, sleep latency, and subjective sleepiness. Journal of Biological Rhythms, v.19, n.2, p. 157-163, 2004.

GUIMARÃES, S.M.F. Os Guarani-Mbyá e a Superação da Condição Humana. Brasília, 2001. 151p. Dissertação (Mestrado) - Departamento de Antropologia da Universidade de Brasília.

HANSEN, M.; JANSSEN, I.; SCHIFF, A.; Zee, P.C.; DUBOCOVICH, M.L. The impact of school daily schedule on adolescent sleep. Pediatrics, v.115, i.6, p.1555-1557, 2005.

HORNE, J.; OSTBERG, O. A self-assessment questionnaire to determine morningness-everningness in human circadian rhythms. International Journal of Chronobiology, v.4, n.2, p.97-110, 1976.

IGLOWSTEIN, I.; JENNI, O.G.; MOLINARI, L.; LARGO, R.H. Sleep duration from infancy to adolescence: reference values and generational trends. Pediatrics, v.111, p.302-307, 2003.

JENNI O.G.; CARSKADON, M.A. Spectral analysis of the sleep electroencephalogram during adolescence. Sleep, v.27, n.4, p.774-83, 2004. 
KIM, S.; DUEKER, G.L.; HASHER, L.; GOLDSTEIN, D. Children's time of day preference: age, gender and ethnic differences. Personality and Individual Differences, v.33, p.1083-1090, 2002.

LABERGE, L.; PETIT, D.; SIMARD, C.; VITARO, F.; TREMBLAY, R.E.; MONTPLAISIR, J. Development of sleep patterns in early adolescence. Journal of Sleep Research, v.10, p.59-67, 2001.

LADEIRA, M.I. Comunidades Guarani da Barrragem e de Krukutu e a linha de transmissão de 750 KV Itaberá - Tijuco Preto III. Relatório de Interferências, 68 p., São Paulo: CTI - Centro de Trabalho Indigenista, 2000.

LADEIRA, M.I. Os usos das terras e das águas. Seminário "Tolerância", UNESCO - USP, 1997.

LADEIRA , M.I.; AZANHA, G. Os índios da Serra do Mar: a presença Mbyá-Guarani em São Paulo. São Paulo, Editora Nova Stella, 1988, 70p. LADEIRA, M.I.; MATTA, P. (organizadoras). Seminário: Terras Guarani no litoral: Ka'agüy oreramói kuéry ojou rive vaekue y (As matas que foram reveladas aos nossos antigos avós). São Paulo: CTI - Centro de Trabalho Indigenista, 115p., 2004.

LEBOUGEOIS, M.K.; GIANNOTTI, F.; CORTESE, F.; WOLFSON, A.; HARSH, J. Sleep hygiene and sleep quality in Italian and American adolescents. Annals of the New York Academy of Sciences, v.1021, p.352-554, 2004.

LEVY, D.; GRAY-DONALD, K.; LEECH, J.; ZVAGULIS, I.; PLESS, B. Sleep patterns and problems in adolescents. Journal of Adolescent Health Care, v.7, n.6, p.386-389, 1986. 
LIU, X. Sleep and adolescent suicidal behavior. Sleep, v.27, n.7, p.13511358, 2004.

LOUZADA, F.M. Um estudo sobre a expressão da ritmicidade biológica em diferentes contextos socioculturais: o ciclo vigília/sono de adolescentes. São Paulo, 2000. 144p. Tese (Doutorado) - Instituto de Psicologia, Universidade de São Paulo.

LOUZADA, F.; MENNA-BARRETO, L. Sleep-wake cycle expression in adolescence: influences of social context. Biological Rhythm Research, v.34, n.2, p.129-136, 2003.

LOUZADA, F.M.; INÁCIO, A.M., SOUZA, F.H.M.; MORENO, C.R.C. Exposure to light versus way of life: effects on sleep patterns of a teenager - case report. Chronobiology International, v.21, n.3, p.497-499, 2004.

MELLO, L.C.; A influência dos horários escolares sobre a ritmicidade biológica de adolescentes. São Paulo, 1999. Dissertação (Mestrado) Instituto de Psicologia, Universidade de São Paulo.

MELLO, L.C.; LOUZADA, F.; MENNA-BARRETO, L. Effects of school schedule transition on sleep-wake cycle of Brazilian adolescents. Sleep and Hypnosis, v. 3, n.3, p.106-111, 2001.

MENNA-BARRETO, L.; RODRIGUES, I. School schedule change and adolescent's rhythms. In: $\mathbf{1}^{\text {ST }}$ WORLD CONGRESS OF CHRONOBIOLOGY, 2003, Sapporo. Abstracts. Sapporo: Japanese Society for Chronobiology, 2003, p.54, res. C1-4.

MERCER, P.W.; MERRITT, S.L.; COWELL, J.M. Differences in reported sleep need among adolescents. Journal of Adolescent Health, v.23, p.259-263, 1998. 
MILLMAN, R.P. Excessive sleepiness in adolescents and young adults: causes, consequences, and treatment strategies. Pediatrics, v. 115, n.6, p.1774-1786, 2005.

MONK, T.H.; REYNOLDS, C.F.; MACHEN, M.A.; KUPFER, D.J. Daily social rhythms in the elderly and their relationship to objetively recorded sleep. Sleep, v.15, n.4, p.322-329, 1992.

MONK, T.H.; REYNOLDS, C.F.; BUYSSE, D.J.; DEGRAZIA, J.M.; KUPFER, D.J. The relationship between regularity and subjective sleep quality. Chronobiology International, v.20, n.1, p.97-107, 2003.

MONTAGNER, H.; RESTOIN, A.; DE ROQUEFEUIL, G.; DJAKOVIC, M. Biological, behavioral and intellectual activity rhythms of the child during its development in different educational environments. In: TOUITOU, Y.; HAUS, E., eds. Biologic rhythms in clinical and laboratory medicine. 2.ed. Berlin, Springer-Verlag, 1994. p.214-229.

MURDEY, I.D; CAMERON, N.; BIDDLE, S.J., MARSHALL, S.J.; GORELY, T. Pubertal development and sedentary behaviour during adolescence. Annals of Human Biology, v.31, n.1, p.75-86, 2004.

NATELE, V.; SANSAVINI, A.; TROMBINI, E.; ESPOSITO, M.J.; ALESSANDRONI, R.; Relationship between preterm birth and circadian typology in adolescence. Neuroscience Letters, v. 382(1-2), p.139-142, 2005.

NELSON, W., TONG, Y.L., LEE, J.K. and HALBERG, F. Methods for cosinorrhythmometry, Chronobiologia, v. 6, p.305-323, 1979. 
PARK, Y.M.; MATSUMOTO, K.; SEO, Y.J.; KANG, M.J.; NAGASHIMA, H. Changes of sleep or waking habits by age and sex in Japanese. Perceptual and Motor Skills, v.94, p.1199-1213, 2002.

REIMÃO, R; SOUZA, J.C.; MEDEIROS, M.M.; ALMIRÃO, R.I. Sleep habits in native Brazilian Terena children in the state of Mato Grosso do Sul, Brazil. Arquivos de Neuro-psiquiatria, v.56, n.4, p.703-707, 1998.

REIMÃO, R; SOUZA, J.C.; GAUDIOSO, C.E. Sleep habits in native Brazilian Bororo children. Arquivos de Neuro-psiquiatria, v.57, n.1, p.14-17, 1999

REIMÃO, R; SOUZA, J.C.; GAUDIOSO, C.E.; GUERRA, H.C.; ALVES, A.C.; OLIVEIRA, J.C.; GNOBIE, N.C.; SILVÉRIO, D.C. Siestas among Brazilian native Terena adults. Arquivos de Neuro-psiquiatria, v.58, n.1, p.39-44, 2000.

REIMÃO, R; SOUZA, J.C.; GAUDIOSO, C.E.; GUERRA, H.C.; ALVES, A.C.; OLIVEIRA, J.C.; GNOBIE, N.C.; SILVÉRIO, D.C. Nocturnal sleep in native Brazilian Terena adults. Arquivos de Neuro-psiquiatria, v.58, n.2-A, p.233-238, 2000.

ROENNEBERG, T.; KUEHNLE, T.; PRAMSTALLER, P.P.; RICKEN, J.; HAVEL, M.; GUTH, A.; MERROW, M. A marker for the end of adolescence. Current Biology, v.14, n.24, R1038-1039, 2004.

ROTENBERG, L.; PORTELA, L.F.; MARCONDES, W.B.; MORENO C.; NASCIMENTO, C.P. Gender and night work: sleep, daily life and the experiences of night shift workers. Cadernos de Saúde Publica, v.17, n.3, p.639-649, 2001. 
SCHADEN, E. Aspectos fundamentais da Cultura Guarani. . São Paulo, Editora Pedagógica e Universitária: Editora da Universidade de são Paulo, 1974, 190p.

SHIN, C.; LEE, S.; AHN, Y.; JOO, S. Sleep habits, excessive daytime sleepiness and school performance in high school students. Psychiatry and Clinical Neurosciences, v.57, p. 451-453, 2003.

SORENSEN, E.; URSIN, R. Sleep habits among adolescents. Tidsskr Nor Laegeforen, v.121, p.331-333, 2001.

STRAUCH, I.; MEIER, B. Sleepiness in adolescents: a longitudinal approach. Sleep, v. 11, n.4, p.378-386, 1988.

TANNER, J.M. Growth at adolescence. Oxford, Blackweel, 1962.

THORLEIFSDOTTIR, B.; BJORNSSON, J.K.; BENEDIKTSDOTTIR, B; GISLASON, T.; KRISTBJARNARSON, H. Sleep and sleep habits from childhood to young adulthood over a 10-year period. Journal of Psychosomatic Research, v.53, n.1, p.529-537, 2002.

THORPY, M.J.; KORMAN, E.; SPIELMAN, A.J.; GLOVINSKY, P.B. Delayed sleep phase syndrome in adolescents. Journal of Adolescent Health Care, v.9, n.1, p.22-27, 1988.

TORRES, F.J.; MENNA-BARRETO, L.S.; ARNHOLD, I.J.P. Ciclo vigília/sono e transtornos da puberdade. $\mathbf{1 0}^{\circ}$ SIICUSP. Resumo disponível na Internet: http://www.usp.br/siicusp/cd 2002/index02.htm. [14 jun. 2005].

TORRES, F.J.; FERRARI, A.; MENNA-BARRETO, L.S.; ARNHOLD, I.J.P. Ciclo Vigília/Sono e Transtornos da Puberdade. In: CONGRESSO BRASILEIRO DE SONO, 9., Espírito Santo, 2003. Anais. Sociedade Brasileira de Sono, Hypnos, São Paulo, 2003, p.23, res.25. 
VAN SOMEREN, E.J.W. Sleep propensity is modulated by circadian and behavior-induced changes in cutaneous temperature. Journal of Thermal Biology, v.29, p. 437-444, 2004.

VELOSO, H.P.; RANGEL FILHO, A.L.; LIMA, J.C. Classificação da vegetação brasileira, adaptada a um sistema universal. RJ: IBGE, Departamento de Recursos Naturais e Estudos Ambientais. 124p., 1991.

WORTHMAN, C.M.; MELBY, M.K. Toward a comparative developmental ecology of human sleep. In: Carskadon, M.A. (ed) Adolescent sleep patterns: biological, social, and psychological influences. Cambrigde, University Press, 2002, p.69-117. 